\title{
IEA Annex 26: Advanced Supermarket Refrigeration/Heat Recovery Systems
}

\section{Final Report Volume 1 - Executive Summary}

\author{
Canada \\ Denmark \\ Sweden \\ United Kingdom \\ United States (Operating Agent)
}

Compiled by

Van D. Baxter

Oak Ridge National Laboratory

Oak Ridge, TN, USA

April, 2003 


\section{List of Contributors}

This volume of the IEA Annex 26 final report contains a detailed summary of the Annex activities including principal conclusions from each participant. The following persons provided the information for this report.

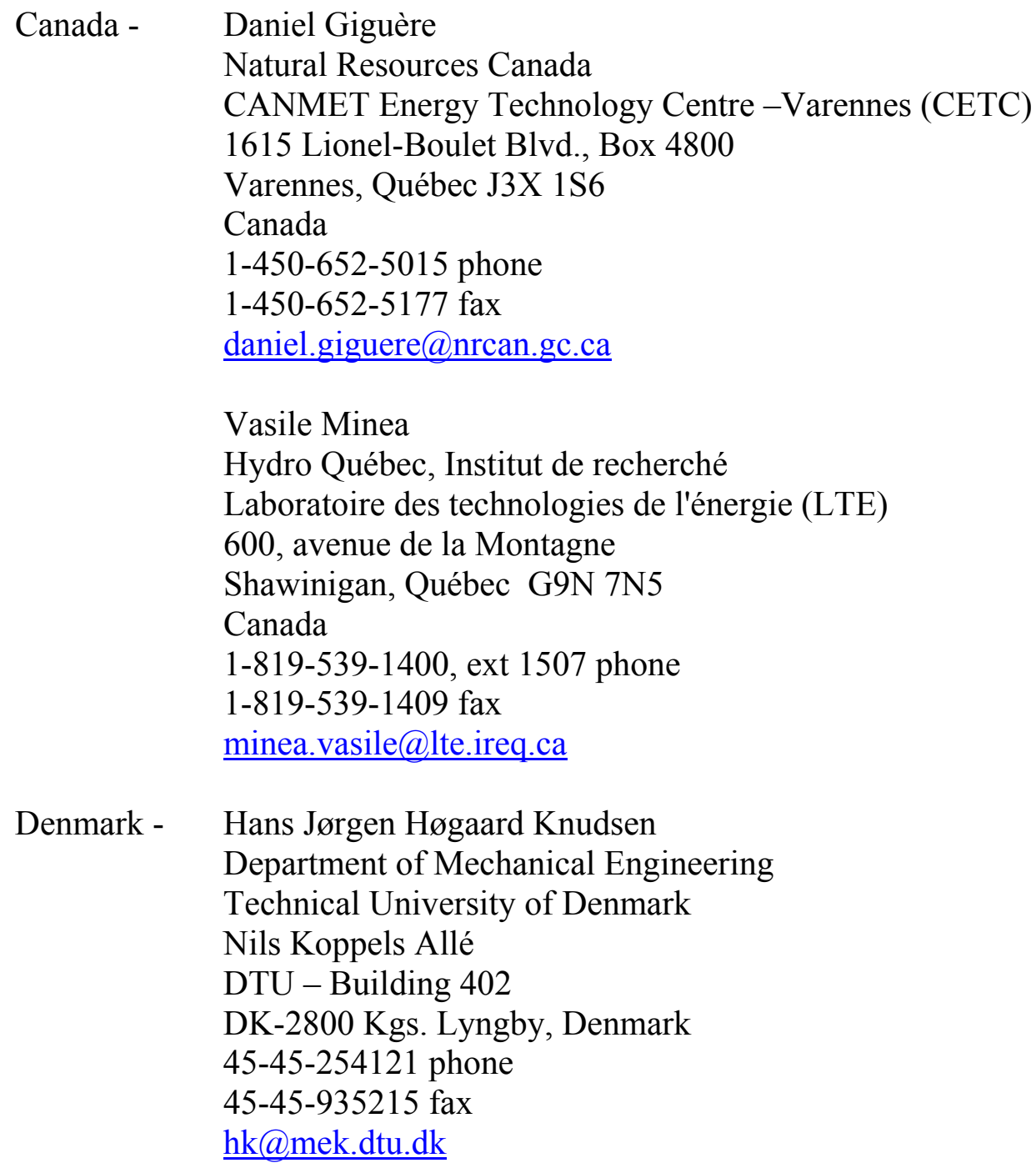

Denmark - $\quad$ Hans Jørgen Høgaard Knudsen

Department of Mechanical Engineering

Technical University of Denmark

Nils Koppels Allé

DTU - Building 402

DK-2800 Kgs. Lyngby, Denmark

45-45-254121 phone

45-45-935215 fax

hk@mek.dtu.dk

Sweden - $\quad$ Per Lundqvist \& Jaime Arias

The Royal Institute of Technology

Department of Energy Technology

Div. of Applied Thermodynamics and Refrigeration

S-100-44 Stockholm, Sweden

46-8-790-7452 phone (Lundqvist)

46-8-790-8642 phone (Arias)

46-8-20-3007 fax 
perlundq@egi.kth.se

jaime@thermo.kth.se

UK - $\quad$ Alison Crompton

Faber Maunsell

Marlborough House

Upper Marlborough Road

St Albans, Hertfordshire AL1 3UT

United Kingdom

44-20-8784-5586 phone

44-20-8784-5562 fax

alison.crompton@fabermaunsell.com

John Palmer

Faber Maunsell

Beaufort House

94/96 Newhall Street

Birmingham B3 1PB

United Kingdom

44-121-262-6750 phone

44-121-262-1999 fax

john.palmer@fabermaunsell.com

US - Van D. Baxter

Steven K. Fischer

Oak Ridge National Laboratory

Box 2008, Bldg 3147, MS-6070

Oak Ridge, TN 37831-6070

USA

1-865-574-2104 phone (Baxter)

1-865-574-2017 phone (Fischer)

1-865-574-9329 or 9338 fax

vdb@ornl.gov

fis@ornl.gov

David H. Walker

Foster-Miller, Inc.

350 Second Avenue

Waltham, MA 02451

1-781-684-4237 phone

1-781-890-3489 fax

dwalker@foster-miller.com 


\section{Table of Contents}



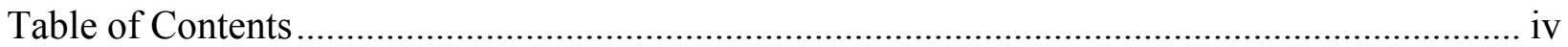

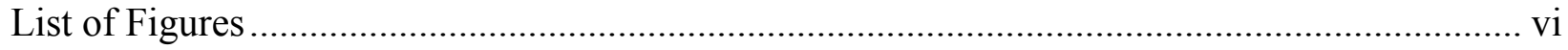

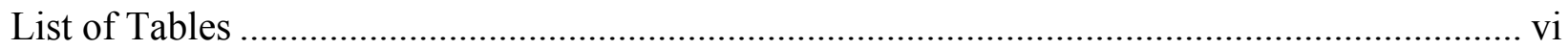

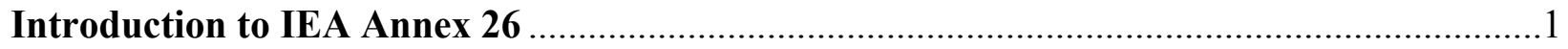

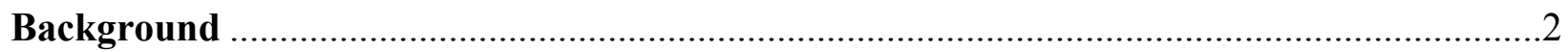

General summary of system technology approaches to reduce supermarket TEWI ............5

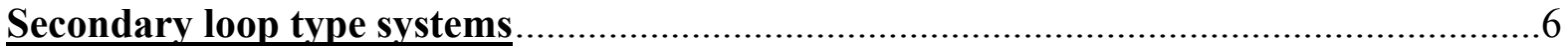

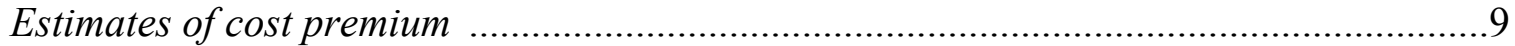

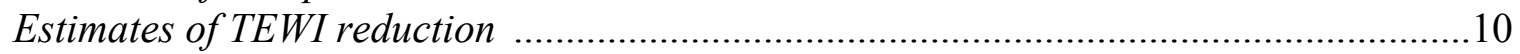

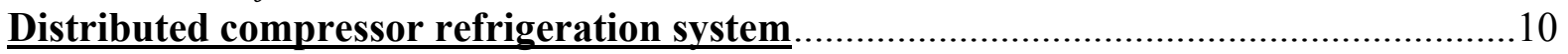

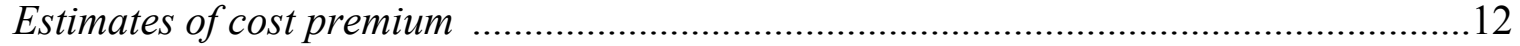

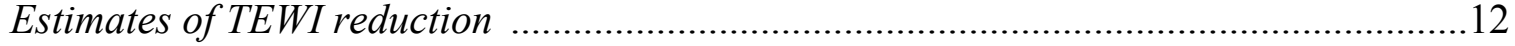



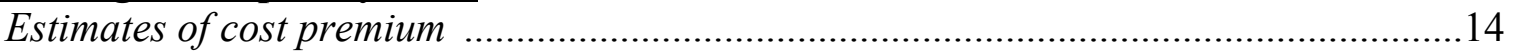

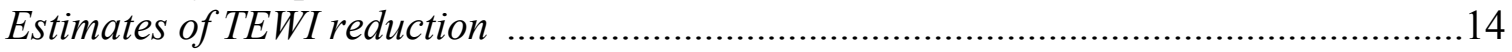

Advanced self-contained systems





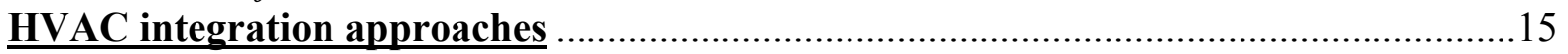

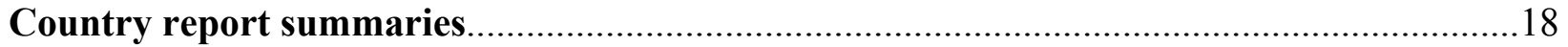

Canada - CANMET Energy Technology Centre -Varennes (CETC-Varennes) of Natural Resources Canada................................................................................ 18

Canada - Hydro-Quebec Research Institut, Laboratoire des technologies de l'énergie

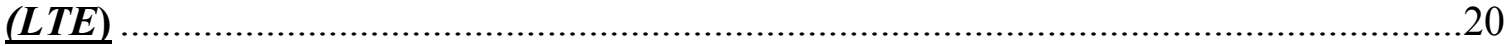

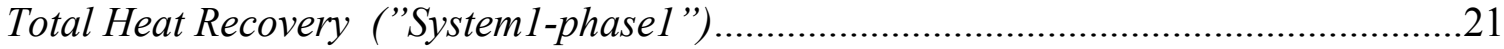

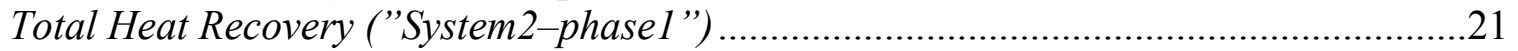

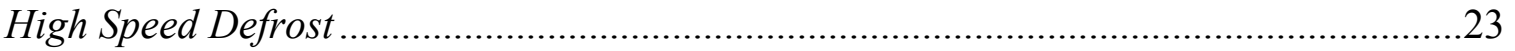

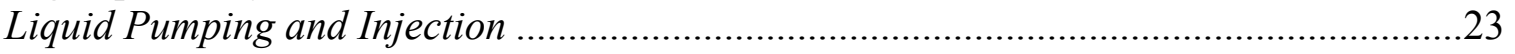

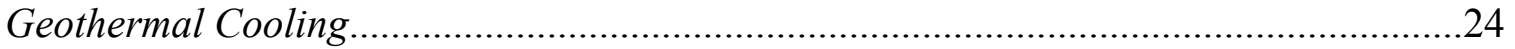

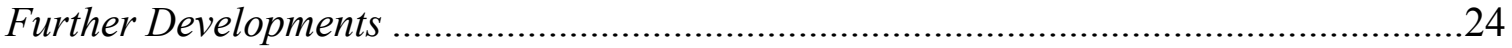







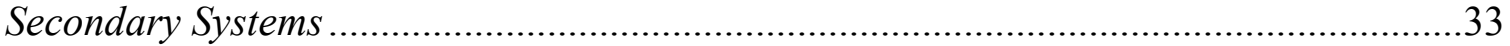

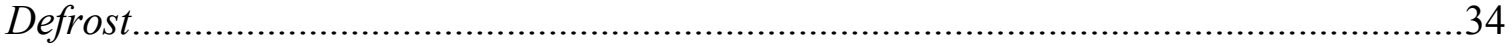




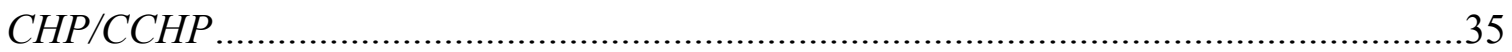

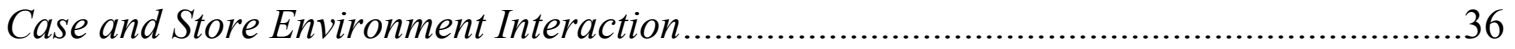

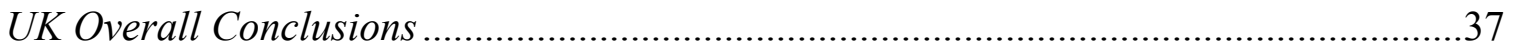

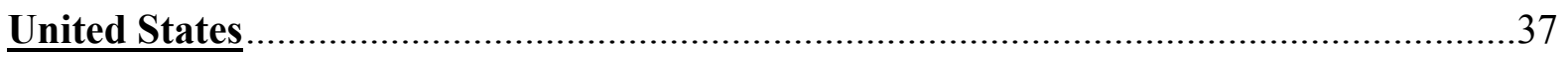

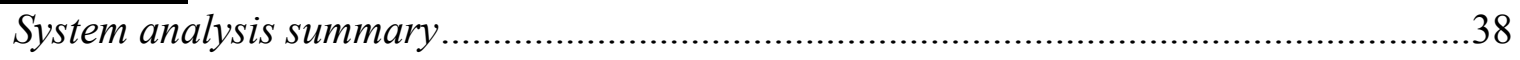



Field test summary ……………………………………....................................... 41

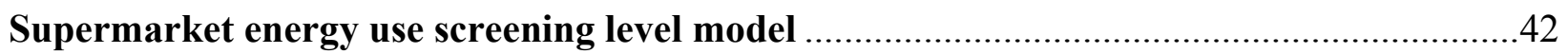

Overall Summary

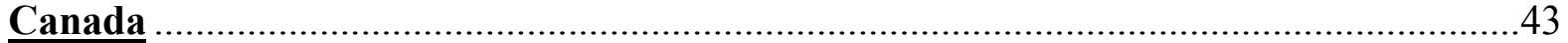

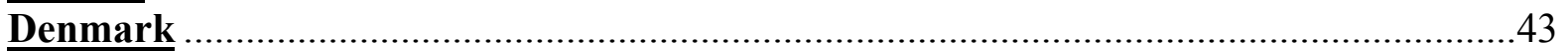

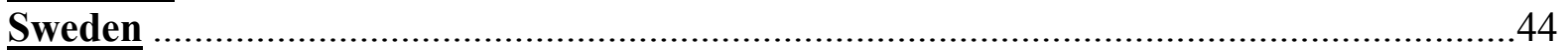



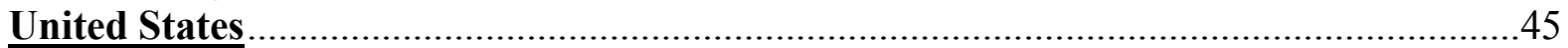

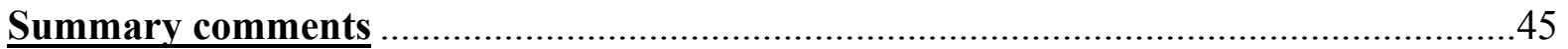

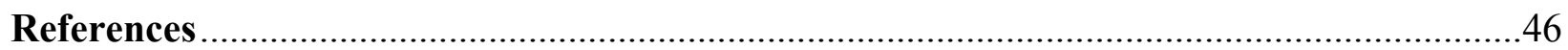

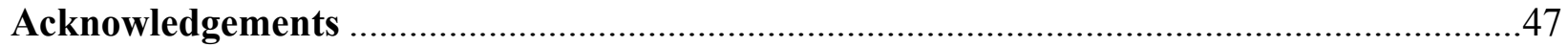

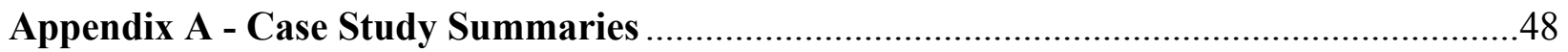

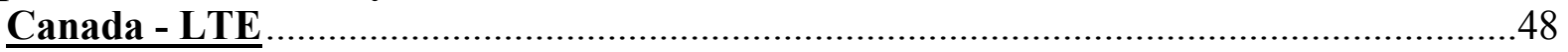








\section{List of Figures}

Fig. 1. Layout of a typical modern supermarket.

Fig. 2. Total equivalent warming impact (TEWI) for low temperature supermarket refrigeration in North America.

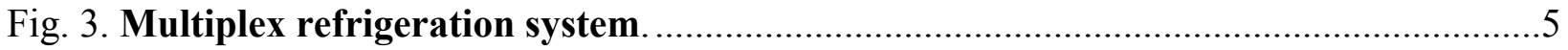

Fig. 4. Elements of the secondary loop refrigeration system........................................... 7

Fig. 5. Propane/carbon dioxide cascade refrigeration system............................................8

Fig. 6. Distributed compressor refrigeration system schematic. ........................................11

Fig. 7. Low-charge multiplex system compressor rack concept 1 . ................................. 13

Fig. 8. Low-charge multiplex system compressor rack concept 2 . ..................................13



Fig. 10. Plate heat exchangers (HX) for heat pump evaporators and refrigeration desuperheaters and subcooler.

Fig. 11. Results from CyberMart..................................................................................29

Fig. 12. Indoor temperature, outdoor temperature and indoor relative humidity in

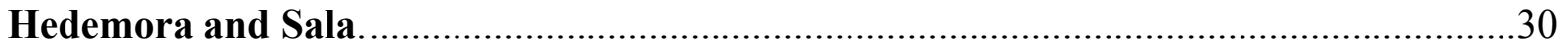

Fig. 13. Temperatures, relative humidity and compressor power in Sala...........................31

Fig. 14. Temperatures in a deep freeze cabinet and indoor and outdoor temperatures

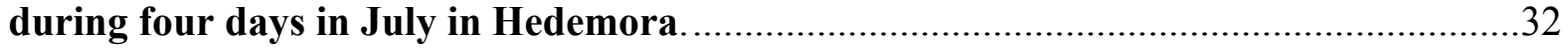

Fig. 15. Refrigeration energy usage in The United Kingdom by end use. ..........................33

Fig. 16. Example of freezer case type tested by UK team in environmental chamber to determine impact of store temperature, relative humidity and ventilation mode (conventional or displacement) on performance.

Fig. A1. Comparison of energy use of Fakta Beder store (with cascade refrigeration system) to that of eight other Fakta stores (with conventional R404A DX refrigeration systems); July 2000 through February 2002.

List of Tables

Table 1. Predicted Energy Consumption for Low-Charge Refrigeration Systems...............39

Table 2. Total Equivalent Warming Impact (TEWI) for Supermarket Refrigeration..........40 


\section{Annex 26 Final Report \\ Advanced Supermarket Refrigeration/Heat Recovery Systems Executive Summary}

\section{Introduction to IEA Annex 26}

With increased concern about the impact of refrigerant leakage on global warming, a number of new supermarket refrigeration system configurations requiring significantly less refrigerant charge are being considered. In order to help promote the development of advanced systems and expand the knowledge base for energy-efficient supermarket technology, the International Energy Agency (IEA) established IEA Annex 26 (Advanced Supermarket Refrigeration/Heat Recovery Systems) under the IEA Implementing Agreement on Heat Pumping Technologies. Annex 26 focuses on demonstrating and documenting the energy saving and environmental benefits of advanced systems design for food refrigeration and space heating and cooling for supermarkets. Advanced in this context means systems that use less energy, require less refrigerant and produce lower refrigerant emissions. Stated another way, the goal is to identify supermarket refrigeration and HVAC technology options that reduce the total equivalent warming impact (TEWI) of supermarkets by reducing both system energy use (increasing efficiency) and reducing total refrigerant charge.

The Annex has five participating countries: Canada, Denmark, Sweden, the United Kingdom, and the United States. The working program of the Annex has involved analytical and experimental investigation of several candidate system design approaches to determine their potential to reduce refrigerant usage and energy consumption. Advanced refrigeration system types investigated include the following:

distributed compressor systems - small parallel compressor racks are located in close proximity to the food display cases they serve thus significantly shortening the connecting refrigerant line lengths;

secondary loop systems - one or more central chillers are used to refrigerate a secondary coolant (e.g. brine, ice slurry, or $\mathrm{CO}_{2}$ ) that is pumped to the food display cases on the sales floor;

self-contained display cases - each food display case has its own refrigeration unit;

low-charge direct expansion - similar to conventional multiplex refrigeration systems but with improved controls to limit charge.

Means to integrate store HVAC systems for space heating/cooling with the refrigeration system have been investigated as well. One approach is to use heat pumps to recover refrigeration waste heat and raise it to a sufficient level to provide for store heating needs. Another involves use of combined heating and power (CHP) or combined cooling, heating, and power (CCHP) systems to integrate the refrigeration, HVAC, and power services in stores. Other methods including direct recovery of refrigeration reject heat for space and water heating have also been examined. 
A workshop on advanced supermarket refrigeration was held October 2-4, 2000 in Stockholm. Reports were made by Annex participants and other invited experts on the status of refrigeration research and development activities in the US and Europe. The workshop proceedings (in cd-rom format) are available from the IEA Heat Pump Centre (Lundqvist, ed, 2000).

This report provides an account of the results of the work programs of the Annex participants. This volume gives an executive summary of the results. Full details are given in the individual country reports in volume 2 .

\section{Background}

Supermarkets are one of the most energy-intensive types of commercial buildings. Significant energy is used to maintain chilled and frozen food in both product display cases and storage refrigerators. The refrigeration systems also produce a large amount of rejected heat that can be recovered and used by heat pumps or other equipment to provide space and water heating for store requirements. There is a wide range in size of supermarkets among the Annex 26 countries. In Europe stores range in size from about $500 \mathrm{~m}^{2}$ to $3000 \mathrm{~m}^{2}$ or somewhat larger. Stores are typically larger in Canada and the US ranging from a minimum of about $1000 \mathrm{~m}^{2}$ to $10000 \mathrm{~m}^{2}$. Plant capacities range from 30 $60 \mathrm{~kW}$ for small markets to over $400 \mathrm{~kW}$ for the largest stores. Similarly, annual energy use ranges from about $100,000 \mathrm{kWh} / \mathrm{y}$ for the smaller stores to $1.5 \mathrm{million} \mathrm{kWh} / \mathrm{y}$ or more for the largest.

Refrigeration is the largest component of supermarket energy use, accounting for half or more of the store total. Perishable products must be kept refrigerated during display and for storage. Compressors and condensers account for $60-70 \%$ of refrigeration energy consumption. The remainder is consumed by the display and storage cooler fans, display case lighting, evaporator defrosting, and for anti-sweat heaters used to prevent condensate from forming on doors and outside surfaces of display cases.

Figure 1 shows a representative layout for a supermarket showing refrigerated display cases and storage areas located generally around the store perimeter. The most commonly used refrigeration system for supermarkets today is the multiplex direct expansion (DX) system. All display cases and cold store rooms use direct expansion airrefrigerant coils that are connected to the system compressors in a remote machine room located in the back or on the roof of the store. This requires thousands of meters of pipe with case connections that have historically been designed for ease and rapidity of service rather than low leakage. This practice is changing for new supermarkets with more emphasis on reducing leakage. Heat rejection is usually done with air-cooled condensers because these are the least cost to install and maintain. Evaporative condensers can be used as well and will reduce condensing temperature and system energy consumption. However, they carry the burden of increased maintenance effort and cost. In either case, system controls are usually set to allow the condensing temperature to float with the outdoor dry bulb (or wet bulb) temperature, usually to a minimum level of around $21^{\circ} \mathrm{C}$ (about the lowest condensing temperature for reciprocating compressors which are the most common type used in supermarkets). 
The amount of refrigerant needed to charge multiplex DX systems is very large typically $4-5 \mathrm{~kg} / \mathrm{kW}$ of refrigeration capacity. The large amount of piping and pipe joints required can also result in large refrigerant losses - historically $30 \%$ or more of the total charge annually. New systems can achieve annual refrigerant leakage rates of around $15 \%$ or somewhat lower (Sand, et al, 1997). The large refrigerant charge and high loss rate for multiplex direct expansion refrigeration systems results in high values of TEWI (total equivalent warming impact) with direct refrigerant loss impact accounting for about half of the total as shown in Figure 2.

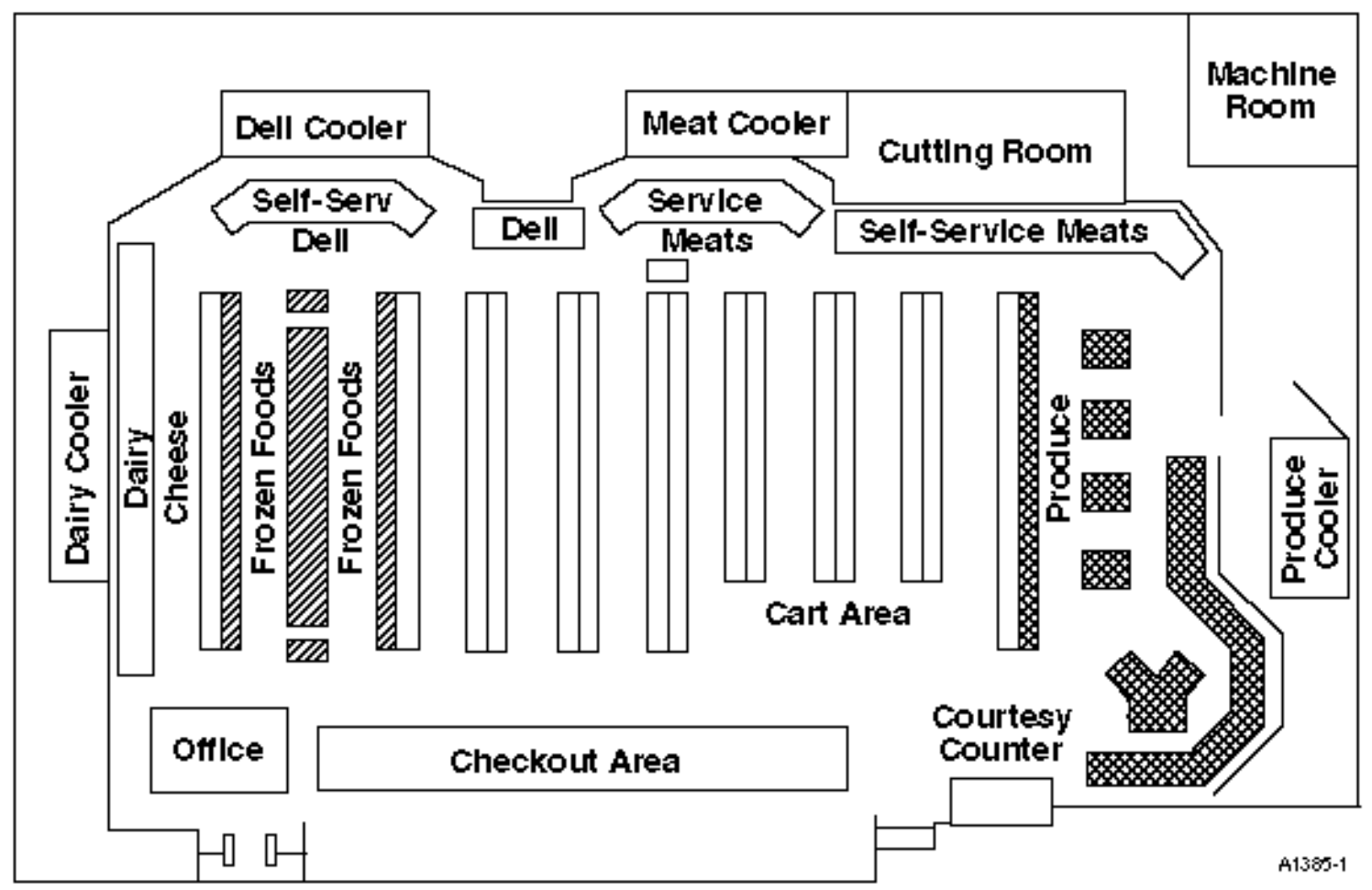

Figure 1 - Layout of a typical modern supermarket

Figure 3 shows the major elements of a multiplex refrigeration system. Multiple compressors operating at the same saturated suction temperature are mounted on a skid, or rack, and are piped with common suction and discharge refrigeration lines. Using multiple compressors in parallel provides a means of capacity control, since the compressors can be selected and cycled as needed to meet the refrigeration load. 


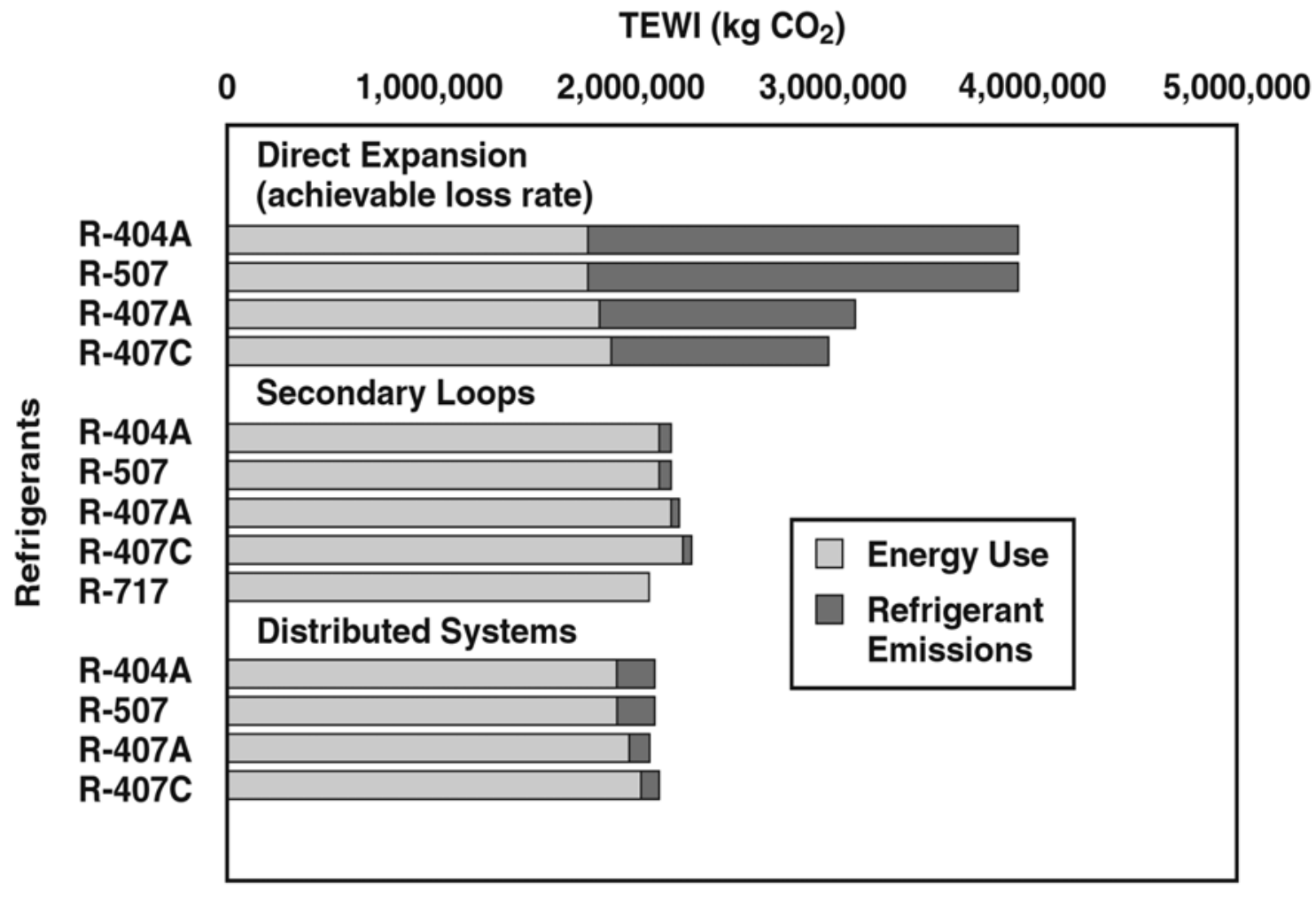

ORNL. 02-03970/abh

Figure 2 - Total equivalent warming impact (TEWI) for low temperature supermarket refrigeration in North America 


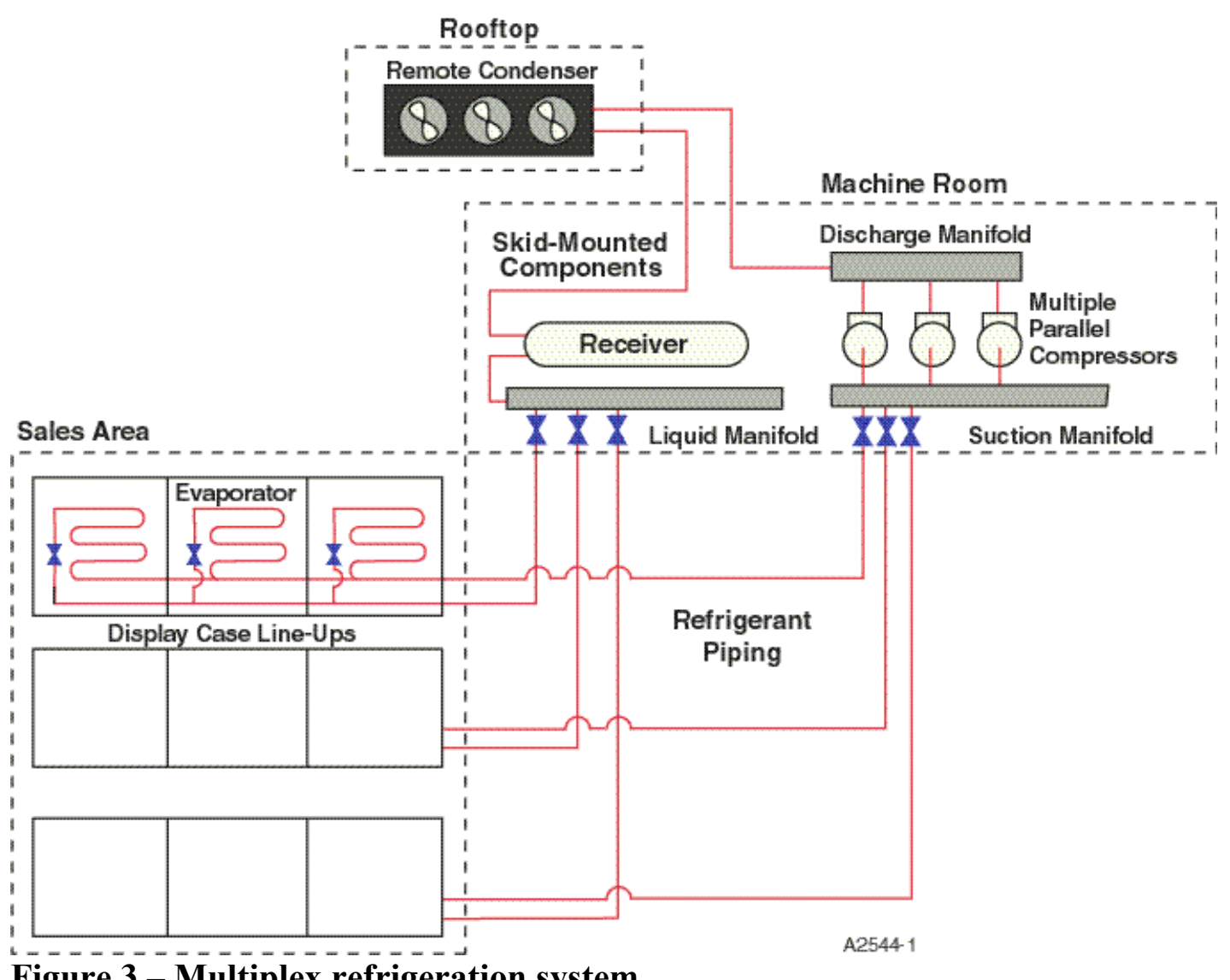

Figure 3 - Multiplex refrigeration system

\section{General summary of system technology approaches to reduce supermarket TEWI}

Part of the UK's contribution to the Annex was a detailed review of existing technologies and new technologies for supermarkets (see UK country report, Volume 2). The bottom line from this state of the art review of advanced supermarket refrigeration is that there are a number of areas in which significant energy savings may be realized and environmental impact reduced. From the overall design of the energy supply, from CHP and CCHP, through to the interaction of the store environment and the cabinets, savings can be made. These factors offer a wide range of opportunities to bring about reductions in the energy use and TEWI of supermarket refrigeration systems.

The advanced supermarket refrigeration systems described in this section are designed primarily to reduce the amount of refrigerant needed for operation and thereby the amount of annual refrigerant loss. This is generally accomplished by use of secondary refrigerants in a secondary loop type system, reduction of refrigerant connecting line length between compressors and display cases, improved refrigerant management and flow controls, or a combination of these approaches. Advantages and disadvantages of these systems with respect to energy efficiency and possible cost implications are briefly discussed in this section also. These issues are dealt with in more 
comprehensive fashion in the individual country reports. Four generic system types have been investigated as part of the Annex 26 work effort. They are secondary loop, distributed, low-charge multiplex, and advanced self-contained systems.

\section{Secondary loop type systems}

Secondary loop refrigeration systems can take many forms, but they generally employ one or more chillers to refrigerate a secondary fluid that is then pumped to the display cases and storage rooms. Figure 4 shows the elements of one secondary loop approach. In this case the chillers, similar in configuration to multiplex compressor racks, provide chilled secondary refrigerant for the cases. The discharge of the compressors is to a common manifold and the discharge gas is piped to a remote condenser, normally located on the roof above the machine room. The use of evaporative condensing can produce the lowest average condensing temperature with lower fan energy than seen with air-cooled condensers, thus minimizing overall energy consumption especially in warmer climate areas. Primary refrigerant charge requirement can be reduced to about $10-15 \%$ of that needed for conventional direct expansion system. A variation on the system shown in Figure 4 is to use a secondary fluid on the heat rejection (condenser) side of the chiller as well as on the refrigeration (evaporator) side. This approach can reduce primary refrigerant requirements to less than $5 \%$ of direct expansion but would introduce an additional secondary heat exchanger thermodynamic energy penalty to the system and increase energy usage.

Secondary loop systems have features that tend to improve the efficiency of the primary system. These include close coupling of the compressors to the chiller evaporators, and the ability to subcool the primary refrigerant with the secondary fluid (brine) and use the warmed brine to defrost the case heat exchangers. 




Figure 4 - Elements of the secondary loop refrigeration system

For large stores secondary loop systems generally use at least two separate secondary fluid loops and chillers - one each for the low temperature (frozen food) cases and storage rooms and medium temperature (chilled food) cases and rooms. Using only two fluid loops for refrigeration, however means that all display cases and storage coolers must operate with these two temperatures. The use of multiple secondary fluid loops with temperatures more closely matching the case air temperature requirements can improve energy efficiency because it raises the effective average evaporator temperature of the system. The US country report includes an analysis of such a system using four different fluid loops. It must be stated however, that each loop will require a separate chiller and controls and that will increase the system cost.

Another approach to secondary systems is the cascade-type system. Figure 5 schematically illustrates one example of a cascade system. The high temperature loop (using propane as the refrigerant in this illustration) removes heat from the low temperature loop (using $\mathrm{CO}_{2}$ ) condenser and also chills a brine (propylene glycol), which is circulated to the chilled food cases. The $\mathrm{CO}_{2}$ refrigerates the frozen food cases through direct expansion evaporators. Other combinations of refrigerants are possible for this system concept. 


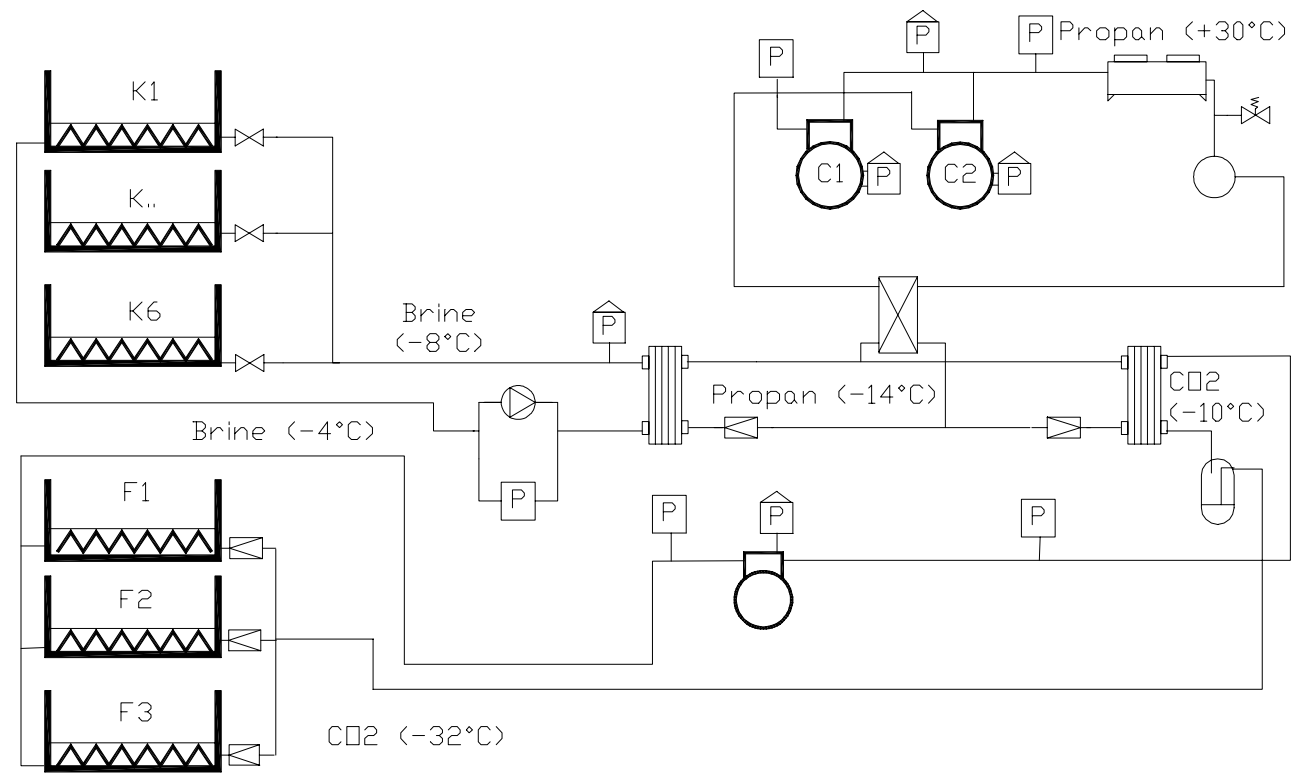

Figure 5 - Propane/carbon dioxide cascade refrigeration system (from Danish country report)

The following is a listing of several candidate fluids for use in secondary loop systems that have been investigated in prior studies (Melinder, 2000; Kazachki, et al, 1997; Hrnjak, 1996; Hrnjak, 2000; Horton, 2002; Sherwood, 1999). Under Annex 26 some detailed property measurements and comparisons were conducted by the UK team (see country report in Volume 2).

Ethylene glycol/water

Propylene glycol/water

Potassium Formate/water

Pekasol 50

Freezium

Hycool

Trichloroethylene

Inhibited alkali ethanate solution

Tyfoxit

Hydrofluoroether

HFE-L-13938

HFE-7100

Cyclohexene

D-Limonene

Polydimethilsiloxane (Silicon Oil)

Syltherm

Dowtherm

Synthetic Isoparaffinic Petroleum Hydrocarbons

Therminol 
No single one of these fluids can be considered ideal for all secondary refrigerant applications. Those most widely used in supermarket systems appear to be propylene glycol/water solutions for medium temperature loops and potassium formate/water solutions for low temperature loops. However, some analytical studies indicate thermal and pressure droop advantages for HFE-7100 over potassium formate solutions for low temperature applications -- below about $-20^{\circ} \mathrm{C}$ (Sherwood, 1999; Horton, 2002). Liquid $\mathrm{CO}_{2}$ is also seeing increasing use as a secondary fluid for both temperature levels particularly in Europe. Means must be considered to deal with internal tube pressures in $\mathrm{CO}_{2}$ systems in the event of power outages or other failures.

Estimates of cost premium. A number of studies have been conducted to estimate cost premiums with the added cost estimates ranging from none to about $40 \%$. A study by Sherwood (1999) compared installed costs for a secondary loop and a multiplex direct expansion system for a low-temperature system typical of North American supermarkets - about $80 \mathrm{~kW}$ total cooling capacity. The secondary system used $\mathrm{NH}_{3}$ in the primary loop and HFE-7100 as the brine while the DX used R-404A. Installation cost (material and labor) for the DX system was the actual figure taken from the refrigeration schedule for the store. Costs for the secondary loop system were estimated based on interviews with supermarket industry professionals. This study considered the total cost of the system (including cases, piping, refrigerant, brine, and labor in addition to the compressor rack or primary chiller) with the exception of the condenser subsystem. It was determined that installed costs for both approaches were equal - i.e., $0 \%$ cost premium for the secondary approach.

Vana (2000) noted in discussions at the Annex 26 workshop that installation cost premiums for secondary loop approaches (using R404A or R507 as primary refrigerant and propylene glycol or potassium formate brines for secondary loops) were about $15 \%$ for typical US markets. He also noted that maintenance costs for the secondary system should be less. Horton (2002) conducted an operating (energy and maintenance) cost comparison between secondary loop $\left(\mathrm{NH}_{3}\right.$ primary/HFE-7100 secondary) and multiplex DX (R22 medium temperature/R404A low temperature) systems and concluded that maintenance costs were $25 \%$ lower and operating costs $15 \%$ lower for the secondary approach. All of the operating savings were attributed to the high efficiency of the $\mathrm{NH}_{3}$ primary system - high enough to overcome the secondary pumping power and heat transfer penalties in this analysis.

A cost and payback analysis is included in the US country report for secondary loop (R507 primary/ propylene glycol and potassium formate secondary brines) and multiplex DX (R22/R404A) systems serving a supermarket with a $330 \mathrm{~kW}$ refrigeration load. The DX system was assumed to have standard air-cooled condensers while the secondary system was assumed to have evaporative condensers (to minimize energy use). The secondary system had an estimated installation cost premium of $\$ 147,000$ US that was based on interviews with engineering departments of two supermarket companies. Payback in this case ranged from 8 to 17 years depending on climate conditions. More details are given in the US report (in Volume 2).

The Danish country report (Volume 2) compares installation costs and operating efficiencies for a cascade system based on that shown in Figure 5 and R404A DX systems. A test system installed in a small store $(30 \mathrm{~kW}$ load) was estimated to cost 
about $20 \%$ more than a traditional DX system and to have about the same energy efficiency. With more experience for installers the premium is estimated to drop to under $15 \%$. For larger systems $(90 \mathrm{~kW})$ the premium is estimated to be $10 \%$ or less.

Estimates of TEWI reduction. TEWI reduction estimates from the investigations carried out under Annex 26 range from $<10 \%$ to about $60 \%$ compared to the multiplex DX/air-cooled condensing baseline. The wide range in TEWI estimates is attributable to assumptions made about the overall system design (compressor type, heat rejection approach, selection of secondary fluid, etc.) and operation. Secondary loop systems must be designed and operated carefully with an eye to minimizing the inherent secondary heat exchange and pumping power penalties in order to achieve the greatest TEWI benefit.

\section{Distributed compressor refrigeration system}

Figure 6 shows a diagram of the distributed compressor refrigeration system. The big difference between this system and conventional multiplex systems is that several small compressor racks are located in cabinets that are distributed throughout the store and close-coupled to the display case lineups or storage rooms they serve. With this approach the long lengths of piping needed to connect the cases with large remote compressor racks in a machine room are eliminated. The cabinets may be placed either at the end of a case lineup on the sales floor or behind the cases around the perimeter of the store.

With this arrangement, the saturated suction temperature (SST) employed for each compressor cabinet can closely match the evaporator temperature of the display cases and walk-in coolers to which it is connected. This is not always possible with conventional multiplex systems, since a single rack will often provide refrigeration to display cases with three or four different evaporator temperatures. Each compressor rack of a multiplex system must operate at a SST value that will satisfy the temperature requirements of all display cases connected to it. The better temperature matching seen with distributed refrigeration can benefit the energy consumption of the overall system.

The refrigerant charge requirement for the distributed system is much less than for multiplex systems. The reduction in charge is due to the shortening of the suction and liquid lines to the display cases. If a secondary fluid loop is used for heat rejection (as shown in Figure 6) then the refrigerant heat rejection piping to a remote condenser and it's associated charge is eliminated as well. With a secondary loop for heat rejection, the refrigerant charge required for a distributed system would be about $30-35 \%$ of that required for multiplex systems. If separate rooftop condensers are used for each cabinet, the total charge requirement will be about $50-60 \%$ that of multiplex systems. A secondary heat rejection loop will result in higher condensing temperatures and energy consumption than if direct roof top condensers are used. 



Figure 6 - Distributed compressor refrigeration system schematic

Each compressor cabinet in a distributed system is similar to a multiplex rack only smaller. All necessary electrical and piping connections are provided within the cabinet, such that the only field connections are the refrigerant liquid and suction lines, fluid inlet and outlet piping for heat rejection, and electric service wiring. Multiple compressors of several sizes are employed, which are piped in parallel so that multiplex operation can be used to match the refrigeration capacity to the load. Usually, three to five compressors are installed in each cabinet. The cabinets are equipped with discharge and suction manifolds for parallel piping of the compressors. The suction manifold can be divided so that multiple suction temperatures can be provided from a single cabinet.

Current distributed refrigeration systems generally employ scroll compressors, because of the very low noise and vibration levels encountered with this type of compressor. These characteristics are necessary if the compressor cabinets are located in 
or near the sales area. Current refrigeration scroll compressors are typically less efficient at evaporating and condensing temperatures of interest for supermarket refrigeration than the reciprocating types used in most conventional systems. However, they do have several features that can offset this efficiency disadvantage in system applications and potentially yield system efficiency improvements. For instance, scroll compressors have no valves, and, therefore, can be operated at significantly lower condensing temperatures than can reciprocating compressors. The lowest condensing temperature possible is at a suction-to-discharge pressure ratio of two (2), which means for supermarket systems that the lowest condensing temperature possible is on the order of $10-15{ }^{\circ} \mathrm{C}$.

The close coupling of the display cases to the distributed refrigeration cabinets has other ramifications to energy consumption. The shorter suction lines mean that the pressure drop between the case evaporator and the compressor suction manifold should be less than that seen with conventional multiplex systems, which means that the compressors' SST will be closer to the display case evaporator temperature. Typically, the SST of conventional multiplex racks will be $1-2.5^{\circ} \mathrm{C}$ less than the case evaporator temperature. SST values for the distributed system will be about $0.5-1{ }^{\circ} \mathrm{C}$ less than the case evaporator temperature. The shorter suction lines also mean that less heat gain to the return gas should be experienced. The cooler return gas has a higher density and results in higher compressor mass flow rates, which means that less compressor on time is needed to satisfy the refrigeration load. The return gas temperature rise expected for distributed refrigeration systems is normally on the order of 3 to $9{ }^{\circ} \mathrm{C}$, depending on the distance between the compressor cabinet and the display cases and the evaporator temperature of the display cases. A greater return gas temperature rise is seen in low temperature systems than is seen in medium temperature. In comparison, the return gas temperature rise typically seen with multiplex systems falls between 20 and $35^{\circ} \mathrm{C}$, due to the longer length of suction lines employed. The liquid temperature can also be adversely affected by line length if subcooling is employed. Heat gain to a subcooled liquid line will result in a rise in liquid refrigerant temperature before reaching the display cases.

Estimates of cost premium. The US country report includes cost and payback estimates for this system. Installed cost for a distributed (using a secondary fluid loop and evaporative cooling tower for condenser heat rejection) was estimated at $\$ 60,000$ (about 15\%) over a baseline multiplex DX system (R22/R404A with air-cooled condensers) for a supermarket with a $330 \mathrm{~kW}$ refrigeration load. Payback ranged fro about 3 to 7 years depending on location.

Estimates of TEWI reduction. Potential TEWI reductions from this work range from a high of about $60 \%$ (analytical estimate for well designed system) to $40 \%$ (from a field test). As in the secondary loop case, careful attention to design and operation is essential to achieving maximum benefits.

\section{Low charge multiplex systems.}

Several approaches have been taken by refrigeration system manufacturers to reduce the refrigerant charge required by traditional multiplex system compressor racks. These approaches reduce the overall system refrigerant charge but retain the long connecting lines between compressors and display cases. Figures 7 and 8 illustrate two such low charge multiplex rack options. 


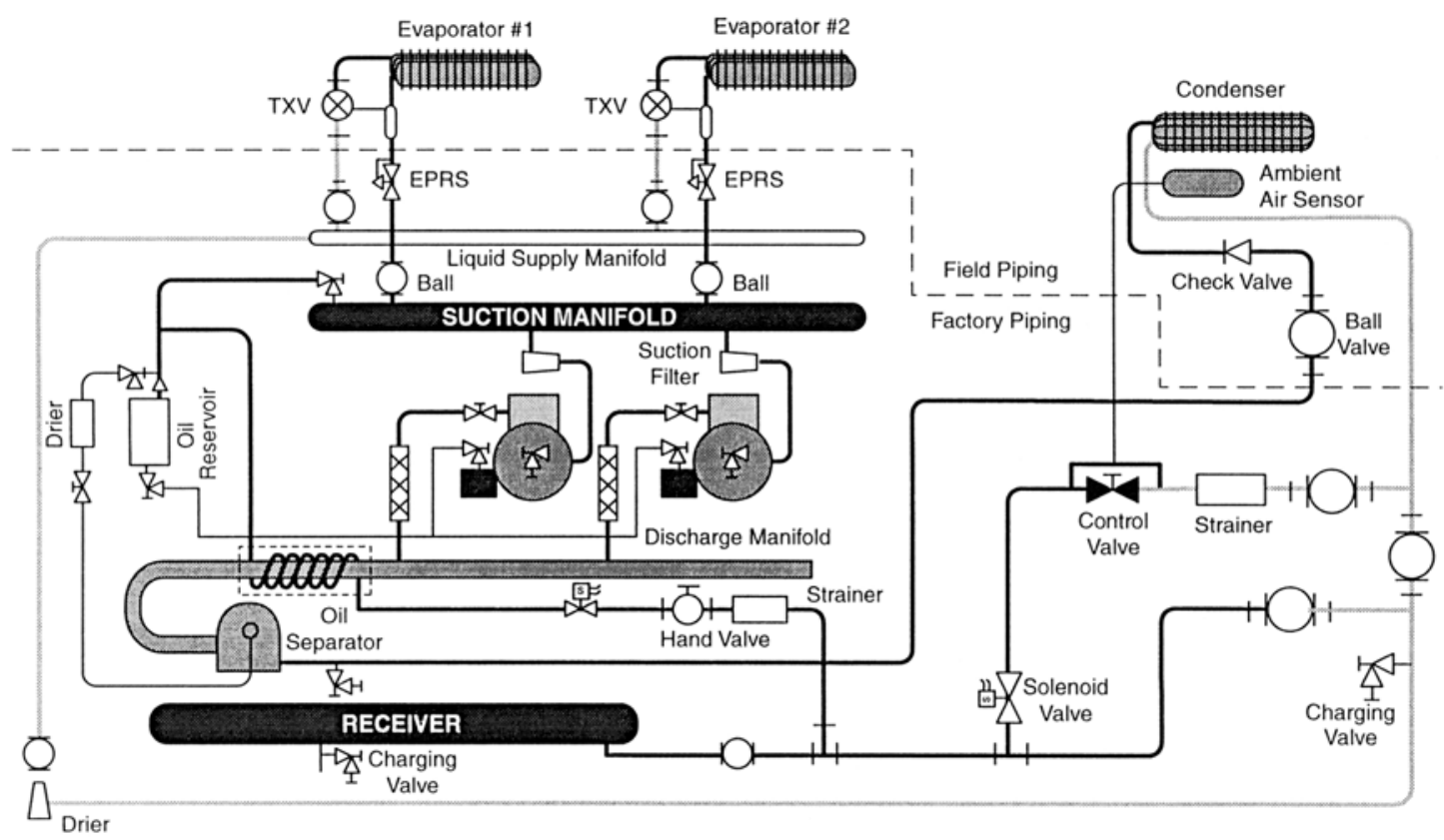

Figure 7 - Low-charge multiplex system compressor rack concept 1



Figure 8 - Low-charge multiplex system compressor rack concept 2 
The first system (Figure 7) limits refrigerant charge by minimizing the refrigerant inventory in the receiver during normal operation (the receiver's primary function in this design is to provide refrigerant storage during system servicing). Total charge required for this system is expected to be about $2 / 3$ that of a conventional multiplex system. This charge control approach also can yield some energy savings because it can allow the system compressors to operate at lower condensing temperatures than would normally be the case. The control valve and ambient temperature sensor are intended to maintain a constant temperature difference between the condenser outlet liquid and the ambient. Liquid refrigerant flow through the valve is vaporized by heat exchange with the discharge manifold. Any refrigerant not vaporized is stored in the receiver. Saturated discharge temperatures can be as low as about $5{ }^{\circ} \mathrm{C}$ for low temperature racks and about $15{ }^{\circ} \mathrm{C}$ for medium temperature racks. Normally reciprocating compressors are limited to minimum condensing temperatures of about $21^{\circ} \mathrm{C}$ and scroll compressors to a minimum of about $15^{\circ} \mathrm{C}$.

The second charge control approach (Figure 8) tries to reduce charge to the minimum needed for correct operation of the system evaporators. A mixture of vapor and liquid refrigerant is sent to each display case lineup and storage room. Operation of the evaporators is done using a combination of relay and balancing valves to control refrigerant flow and evaporation. Refrigerant mixture flow to each case lineup is controlled at the compressor rack. Total refrigerant charge required by this approach is expected to be as little as $30 \%$ of that needed by conventional multiplex systems and the energy efficiency is claimed to equal that of conventional systems. Heat reclaim can be done with a heat exchanger and fluid loop as shown in Figure 8.

Estimates of cost premium. System economic analysis in the US country report (Volume 2) assumed the installed cost for this system type to be the same as for baseline multiplex DX systems (if both use the same type condenser).

Estimates of TEWI reduction. TEWI could be reduced by from $20 \%$ to over $40 \%$ by these systems (compared to the baseline) if the charge reduction and energy saving targets can be achieved in real systems.

\section{Advanced self-contained systems.}

A self-contained refrigeration system consists of display cases or storage coolers each having their own condensing units. Self-contained systems are presently used in supermarkets for a limited number of cases, where the cases are in a location inaccessible to the central refrigeration piping. An example is a refrigerated beverage case placed at the cash registers for spot sales. Self-contained units are also employed as add-on cases or for temporary display of special sales items. Present self-contained display cases use small reciprocating compressors and air-cooled condensers. Heat is rejected directly into the sales area. Only a limited number of self-contained units of this type can be employed before noise and heat rejection levels interfere with store operation. Problems of this type caused store designers in the past to go to the remote machine room approach now used in most supermarkets.

The self-contained system approach could be attractive for reduction of refrigerant charge. It is estimated that the total charge for a supermarket could be 
reduced to about $5-10 \%$ that of conventional multiplex systems if self-contained systems were used for all refrigeration needs.

An advanced self-contained system could be formulated using water-cooled condensers and a fluid loop for heat rejection to eliminate concerns of heat rejection in the store sales area. The compressor noise issue will still be a factor, but can be addressed by the use of scroll compressors. Until recently, scroll compressors were available only in a vertical configuration, which was not suitable for placement in display cases. Now, horizontal scroll compressors have been introduced, which could be employed for this purpose. These horizontal scrolls are capable of continuous unloading for capacity control and maintenance of a suction pressure set point.

Estimates of cost premium. No referencable cost studies have been found for this system approach. The system can be assumed to be an extreme case of the distributed compressor approach, however, and therefore the cost premium over multiplex DX could be assumed to be similar as well.

Estimates of TEWI reduction. No definite estimate has been made for this system type. However, as above it could potentially achieve the same TEWI reductions as the distributed system if efficient enough small compressors and other system components can be found or developed to keep the system energy use on a par with or better than that of the baseline DX system.

\section{HVAC integration approaches}

The large amount of heat rejected by the refrigeration system in a typical supermarket offers an attractive resource for use in store space heating. Integration approaches examined during the course of this Annex have included straightforward heat reclaim, use of heat pumps integrated with the refrigeration system, and use of CHP or CCHP systems.

During a meeting of the Annex in Canada a supermarket with a heat reclaim system was visited. The store had two R22 multiplex refrigeration compressor racks (one each for medium temperature and low temperature loads) with two condensers in series. In winter, primary condensing is done in a plate heat exchanger with water on the other side. The water from the medium temperature rack heat exchanger is piped to coils in the HVAC air ducts and used for store heating. Heat from the low temperature rack is used for store water heating and for reheat for the store dehumidification system in summer. An auxiliary boiler is included in the HVAC system to cover times when heat from the refrigeration condenser cannot meet the store heating load. According to the installer, the propane boiler was not needed during the first winter $(01 / 02)$ of operation. The refrigeration system saturated discharge temperature is allowed to float to a minimum of about $27{ }^{\circ} \mathrm{C}$ under most conditions. In periods of high space heat demand, the refrigeration system condensing temperature is raised as necessary (to a maximum of 35 ${ }^{\circ} \mathrm{C}$ with some negative impact on refrigeration compressor energy use) to meet the store heating demand. In summer the refrigeration system uses a conventional rooftop aircooled condenser for heat rejection. Also according to the installer this system has about $3 \%$ higher cost than a conventional refrigeration/HVAC system (Bastrash, 2002).

The use of heat pumps represents an excellent way to utilize refrigeration reject heat for space heating. Two different heat pump integration approaches have been examined by individual Annex participants. One involves direct integration of the heat 
pump evaporator(s) and refrigeration system condenser(s) and the second utilizes watersource heat pumps (WSHP) where water-cooled condensers and water/glycol loops are used for refrigeration system heat rejection. The heat pumps can be installed in the glycol/water loop and use the rejected heat to provide space heating. Either method enables reclamation of a very large portion of the reject heat without requiring elevation of the condensing temperature of the refrigeration system as can happen with conventional heat reclaim approaches. Refrigeration system energy savings achieved by low head pressure operation can be realized along with the energy benefits seen through heat reclaim.

An example of the first type was also seen during the Annex meeting in Canada. The refrigeration system is a traditional R22 multiplex system with two racks (low temperature and medium temperature) and both used a common set of two condensers in series. Figures 9 and 10 illustrate this heat pump integration approach. In winter, the discharge gas from the refrigeration compressors goes first through three plate heat exchangers which serve to desuperheat and precondense the gas. Final condensing is accomplished in a conventional rooftop air-cooled condeser. The other side of the three heat exchangers serve as the evaporators for three rooftop heat pumps which supply space heating to the store. A fourth rooftop heat pump is similarly integrated with the liquid line exiting the air-cooled condenser via a fourth plate heat exchanger. This heat pump subcools the liquid refrigerant leaving the refrigeration system condenser and uses the recovered heat for store space heating. In summer, the refrigeration system uses the air-cooled condenser exclusively and the heat pumps use their own condensers to reject heat from space cooling loads. The refrigeration system also includes a liquid refrigerant pump to boost the pressure of the refrigerant before it is sent to the cases. The pump is included because with the heat pump integration the refrigeration system head pressure is allowed to float to about $15{ }^{\circ} \mathrm{C}$ minimum saturated discharge temperature. According to the installer the system cost for that store is about $8 \%$ more than what a conventional refrigeration and HVAC system would have cost (Kantchev, 2002). Some details of this system are included in Canada's country report where it is identified as the LMP system. 


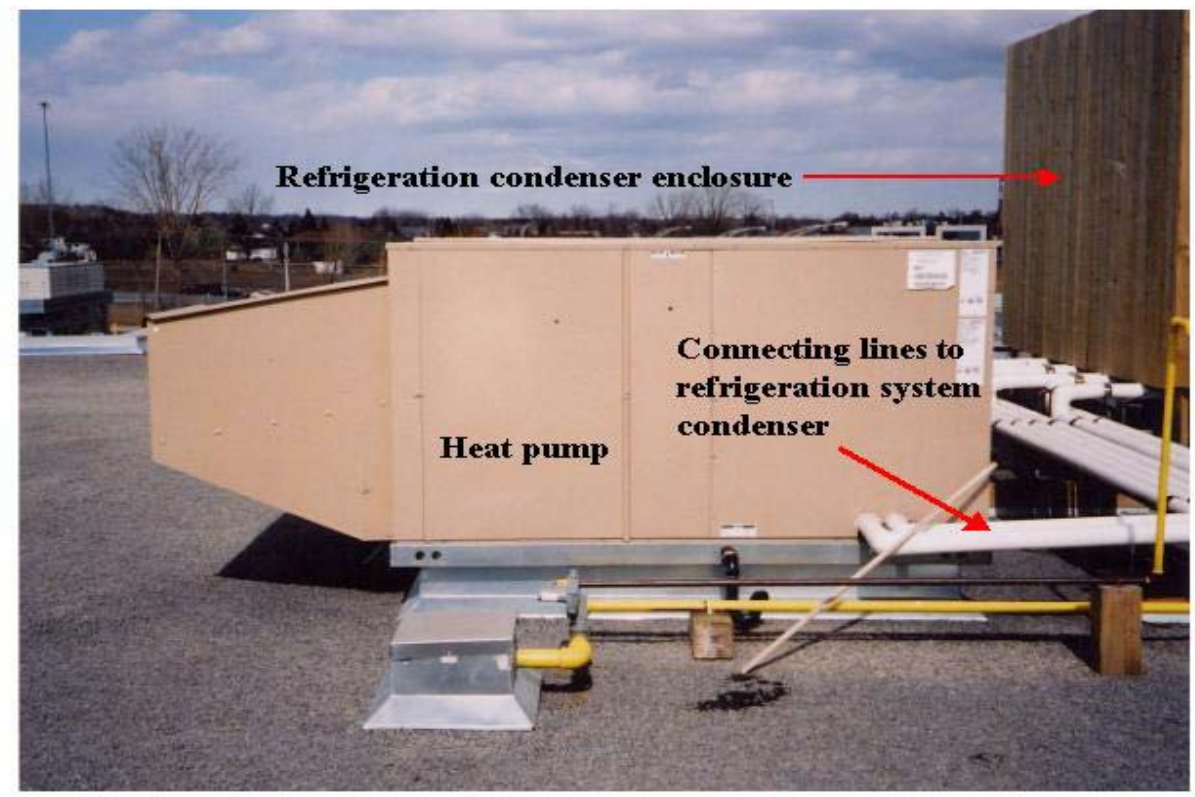

Figure 9 - Roof top heat pump unit

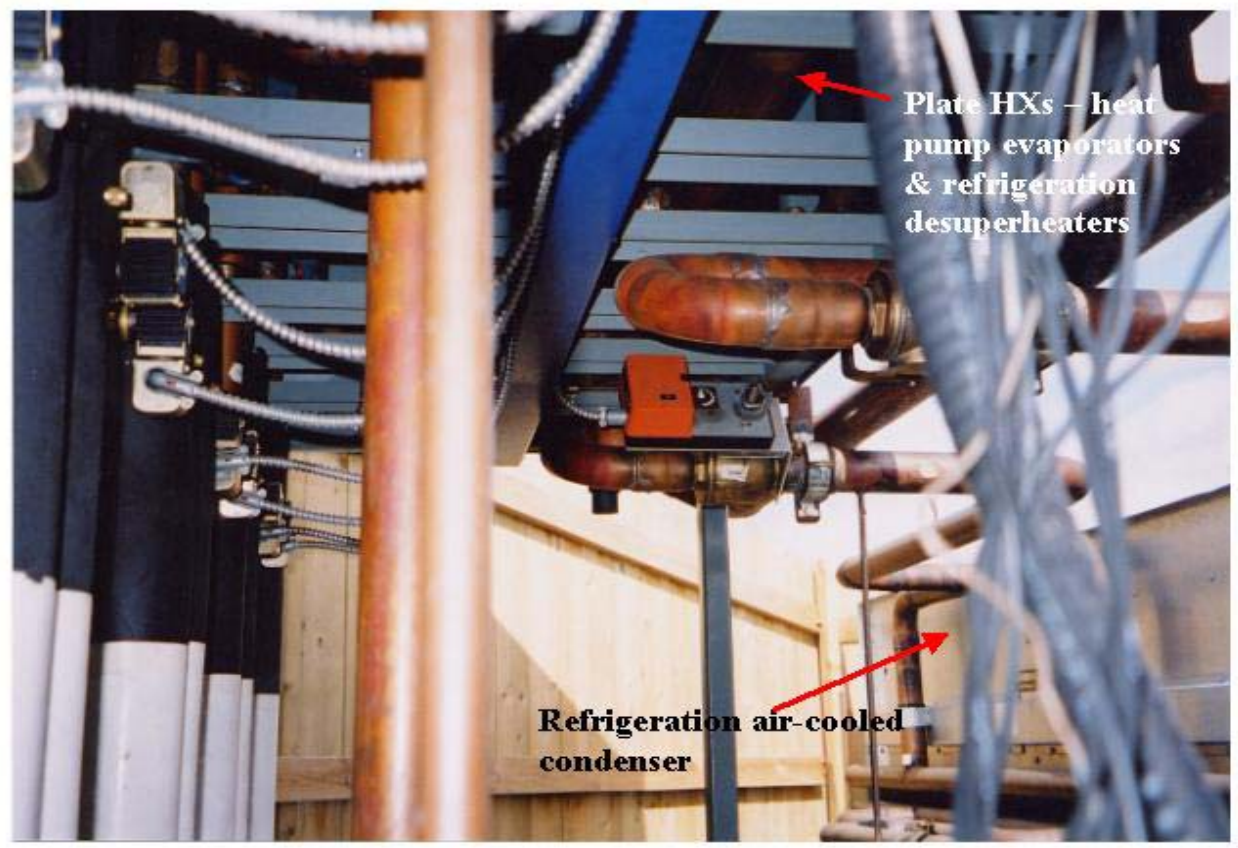

Figure 10 - Plate heat exchangers (HX) for heat pump evaporators and refrigeration desuperheaters and subcooler 
The use of WSHPs in conjunction with water-loop heat rejection for the refrigeration system was examined by the US (see US country report, Volume 2). An analysis was performed for a supermarket HVAC system where conventional rooftop airconditioner/gas heating units and water-source heat pumps were examined and compared. The combination of a water-cooled distributed compressor refrigeration system with water-source heat pumps was predicted to save about $10-20 \%$ in overall operating (refrigeration plus HVAC energy) costs depending on local climate and utility rates when compared to the baseline air-cooled multiplex DX refrigeration system with conventional rooftop HVAC units. The added installation cost for the WSHP approach was estimated to be about $\$ 25,000$ US (about $30 \%$ ) over the conventional rooftop unit system.

$\mathrm{CHP} / \mathrm{CCHP}$ system concepts were studied in detail by the UK team. They concluded that CCHP has an improved load match compared to CHP, when used with absorption chilling for building cooling. Integral cascade vapor compression systems within each display case integrated with the absorption system provide food refrigeration. Primary energy savings are around $15 \%$, and there is a TEWI reduction of more than $50 \%$ compared with conventional supermarket systems.

The impact that store ambient conditions can have on refrigeration system and case energy use was illustrated by part of the UK team effort. Environmental chamber tests of low and medium temperature case systems show that an increase in ambient temperature from 19 to $22{ }^{\circ} \mathrm{C}$ increases system energy use by $20 \%$. Increasing $\mathrm{RH}$ from 35 to $50 \%$ at an ambient of $22{ }^{\circ} \mathrm{C}$ increased the medium temperature case energy use by $15 \%$ but had no effect on the freezer case.

\section{Country report summaries}

Following are summarized key results from the work programs carried out by each country under Annex 26. Full details of these projects can be found in the individual country reports.

\section{Canada - CANMET Energy Technology Centre -Varennes (CETC-Varennes) of Natural Resources Canada}

The CETC-Varennes contribution to the Annex included a supermarket showcase with a fully integrated HVAC/Refrigeration system using secondary fluid on condenser and evaporator sides, the organization of an advisory committee, one workshop for the Canadian refrigeration industry and two research projects directly related to supermarket refrigeration.

There are approximately 31,000 retail food stores in Canada 7,150 of which are considered large supermarkets - with a floor cover area of over 1,000 $\mathrm{m}^{2}$. Supermarkets are among the most energy intensive buildings in the commercial sector with a total energy consumption of more than $800 \mathrm{kWh}$-equivalent $/ \mathrm{m}^{2} /$ year (and increasing with time). Refrigeration represents about $50 \%$ of the electrical energy consumption of a supermarket, costing on average $\$ 150,000$ CND per year for a typical large size supermarket $\left(2000 \mathrm{~m}^{2}\right)$. The typical refrigeration system contains approximately $750 \mathrm{~kg}$ of synthetic refrigerant equivalent to 2,000 tonnes of $\mathrm{CO}_{2}$ in terms of greenhouse gas 
effect. Refrigerant losses are on average, $25 \%$ per year of the total charge. The refrigeration sector is currently facing several major challenges such as: the legislated replacement of synthetic refrigerants that have negative environmental impacts; the increasing cost of refrigerants; the poor efficiency of equipment that are not adapted to Canadian climatic conditions; new regulations for refrigerated product storage and transportation; and a lack of innovation and adequate expertise in Canada to address these issues.

CTEC signed an agreement with a major Canadian supermarket chain to develop a supermarket technology showcase in a Montreal area in the end of 2003. The project's objective is to develop innovative integrated HVAC\&R technologies and practices suitable for Canadian climatic conditions, using compact and hermetic refrigeration systems using secondary fluid for the evaporator and condenser sides, and to demonstrate them in partnership with a major chain of supermarkets in Canada. These demonstrations will provide the opportunity to get a better understanding of their technical requirements such as design, installation, commissioning, and performance as well as their nontechnical barriers (knowledge transfer to energy consultants and technical operators, costs, procurements, etc.). The selected measures should result in reductions in operating and maintenance costs, refrigerant leakage and, indirectly, food spoilage. Secondary fluid systems will contain less refrigerant and fewer potential refrigerant leak locations, resulting in a substantial reduction in the emission of greenhouse gases. This project is part of a strategy to transfer technology and disseminate know-how.

CTEC organized meetings of an Industry Advisory Panel consisting of supermarket and refrigeration sector representatives. The objective of these committees is to provide advice for case studies, laboratory experiments or demonstration projects in accordance with the Canadian supermarket sector needs. The committee's invited membership includes companies representing retailers, compressor rack manufacturers, display case manufacturers, supermarket refrigeration control manufacturers, consulting engineers and government agencies. The Industry Advisory Panel participants understand and are pleased with the Annex 26 strategy to increase the energy efficiency/heat recovery of supermarket refrigeration systems, while reducing the overall refrigerant charge and potential leaks.

More than 85 people attended the first Canadian Workshop on Refrigeration Systems on March 11, 2003 in Montreal. The event was sponsored by CETC-Varennes and the Office of Energy Efficiency (OEE), in collaboration with Agence de l'efficacité énergétique (AEE), Hydro-Québec, Manitoba Hydro and BC Hydro. With a possible reduction of $1.4 \mathrm{Mt}$ equivalent $\mathrm{CO}_{2} /$ year by 2010 , refrigeration in supermarkets has a great potential of energy efficiency and greenhouse gas emission reductions. The refrigeration industry (equipment manufacturers, food retailers, design engineers, mechanical contractors, utilities) sees this as an opportunity. The event allowed the identification of proven and emerging refrigeration technologies and the validation of the supermarkets' interests. In addition, six discussion groups shared ideas on how to lift barriers for adoption of the energy efficient refrigeration technologies. The information collected will provide CETC-Varennes and OEE with new ways to facilitate the adoption of the technologies developed

A laboratory test bench was developed to test novel methods of providing refrigeration for the food marketing industry. In the first series of tests, CETC is expected 
to develop the knowledge to operate refrigeration systems at minimal head pressure and maintaining controllability of refrigeration system using an electronic expansion valve. Results from this work will validate or further improved the accuracy of refrigeration equipment models and will help to transfer the know-how to refrigeration experts. Some technical papers will be published soon.

During the year 2000, CTEC started a new strategic project scheduled to last four years. The main objective is to construct and perform experiments on a liquid $\mathrm{CO}_{2}$ secondary fluid loop test bench. The secondary objectives are development of basic know-how (technical documentation, simulation models, experimental data) and demonstration of the technologies feasibility to potential partners. CTEC got a CFD program (Computational Fluid Dynamic) to model complex problems related to refrigeration technologies. A major partner from the carbon dioxide industry has joined the research team to realise this project.

\section{Canada - Hydro-Quebec Research Institut, Laboratoire des technologies de l'énergie (LTE)}

The contribution of LTE covered the following areas:

- Development of two improved methods for total heat recovery in cold climates.

- Development of a high-speed defrost technique.

- Effective use of liquid pumping and injection.

- Further research on systems having low refrigerant charges and reduced supplementary costs and energy consumption.

In Canada, supermarkets are one of the most energy-intensive types of commercial buildings, and the major source of electric energy use and demand comes from refrigeration systems (around $50 \%$ ), of which compressors and condensers account for $60-70 \%$. Also, the majority of conventional supermarkets take partial advantage of the large amount of heat rejected, by using this heat for space or water heating. Generally, a conventional heat reclaim coil located in the central air handler allows recovery of approximately $35 \%$ to $45 \%$ of total heat rejection. However, this amount of heat is not sufficient to completely eliminate the use of fossil fuel combustion (natural gas, propane) during the coldest periods of the year. Moreover, at the present time, an issue facing the industry is the phase-out of ozone depleting refrigerants and the reduction of refrigerant charge and leakage, because a typical supermarket may experience refrigerant leakage of $10 \%$ to $30 \%$ per year.

The main objective of the LTE project was to experimentally document the benefits of two improved heat recovery systems developed in Canada, and to compare their performances with those of existing multiplex systems. Specific aims were to measure the energy usage for both low and medium-temperature zones and for total store, as the main system operating parameters and overall energy performances. An ultimate goal was the further development of options to reduce total equivalent warming impact (TEWI) of supermarkets by reducing the total refrigeration charge and leakage risks. LTE Laboratory worked with three retailers and two Canadian manufacturers on development and field testing of two commercial prototypes. The "System1-phase 1" (known as RSD) comprises a method to maximize the heat recovery capability for space and water 
heating, and a new, high-speed defrost concept. The "System2-phase 1" (known as LMP) proposes a new heat recovery and air-conditioning/dehumidifying method involving intermediate heat exchangers and multifunctional refrigerant-to-air heat pumps. These systems represented the first phase of their respective development processes. They have already been further improved, particularly in order to reduce total refrigerant charge and leak hazards. Three new supermarkets were extensively instrumented in order to compare a number of operating parameters, high-efficiency features such as heat recovery, defrosting, sub-cooling and liquid pumping, and to quantify energy performances (compressors and store energy consumption and demand, etc.). Two of the stores monitored, having approximately the same size and energy usage, (basically, electric refrigeration and natural gas cooking) were equipped with above-mentioned improved refrigeration systems, and a third one was used as a new baseline supermarket. In these stores, food is stored prior to transfer to the store in walk-in storage areas, and a variety of display cases are located at the periphery. A continuous monitoring of these systems was performed over a 12-month period $(2000-2001)$.

Total Heat Recovery ("System1-phase1"). This heat recovery method consists of bi-directional valves to supply discharge superheated vapour to condensers (in winter), or to a groundwater cooling device (in summer), depending on the outdoor temperature, or to heat reclaim coils for air or domestic hot water heating, when required. A parallel installed modulating valve equipped with an outside temperature sensor adjusts the discharge pressure depending on the outside temperature, and automatically re-directs a predetermined quantity of superheated vapour to the heat reclaim coils by means of a simple, economical and efficient method. If the system controller requires heating during the winter cold months, the modulating valve will direct some or all of the refrigerant to the heat recovery coils in order to cover up to $100 \%$ of the space heating demand. The last heat reclaim coil and remote condensers are separately connected to a main receiver where the liquids flow at approximately the same pressure, independently of one another. Prior to being fed to the evaporators, the liquid is further sub-cooled by an internal heat exchanger equipped with special thermostatic expansion valves.

Total Heat Recovery ("System2-phase1"). In conventional supermarket refrigeration systems, the condensing pressure and temperature are subject to ambient air temperature. During the cold periods of the year, even if there is a possibility of reducing condensing pressure, a high level is artificially maintained in order to provide sufficient pressure differential for proper operation of the expansion valves, and for heat reclaim. The "System2-phasel" heat recovery concept provides an original method to maximize the extraction of the condensing heat by using heat pumps. Refrigeration system superheated vapour is first directed to four intermediate plate heat exchangers that also serve as evaporators for heat recovery heat pumps where a minimum suction pressure, corresponding at about $10{ }^{\circ} \mathrm{C}$ refrigeration condensing temperature, is maintained. When store space heating is required, the plate heat exchangers and their respective refrigerantto-refrigerant heat pumps are activated. Sensible (superheat) and, if necessary, latent heat are removed from the hot discharge gas of the refrigeration system, which is then fed to the remote air condensers. The heat extraction from the superheated vapour is effected without excessively increasing the discharge pressure, thus allowing a reduction of the refrigeration compressor energy consumption as compared to conventional heat reclaim methods. In air conditioning mode, the plate heat exchangers aren't used, and heat 
removed from the store is rejected outdoors through each heat pump's own condenser.

The heat recovery system is completely independent of the refrigeration system, and it is possible to extract total condensing heat without affecting its normal operating conditions. Each heat pump includes a heat exchanger for space heating, and the same coil is used for air re-heating in dehumidification mode. The heat pump's condenser and air conditioning coil are not operational in heating mode, and special inlet pressure valves maintain a minimum suction pressure. Refrigeration system liquid returns from the remote condensers to a liquid delivery unit (including a refrigerant pump) where static pressure is increased before supplying the display cases, and a small quantity can be injected into the common discharge line during the summer. Low condensing pressures during the cold periods of the year are compensated for by the pressure increase provided by the liquid delivery system.

Inside the heat pump dedicated to sub-cooling/heat reclaim, the evaporator removes heat from the condensed liquid of the main refrigeration system before it is sent to the display cases and storage coolers/freezers. When this heat pump operates in heat recovery mode, its own intermediate plate heat exchanger plays the role of an evaporator, and the discharge line goes to an air-heating coil for store space heating. It should be noted that this heat pump-heat reclaim concept is easily adaptable to any existing refrigeration system using a liquid delivery system.

\section{Results}

- With lower compressor energy consumption, the 12-month field monitoring proved that fossil fuel consumption for space heating in supermarkets has been completely eliminated in both cases.

- "System1-phasel" raised the head pressures/condensing temperatures during the heating demand periods as high as they were in the baseline system with conventional heat reclaim devices, and also modified refrigerant flow and controls to eliminate current limitation of heat reclaim capability and giving priority to the heat reclaim mode. A modulating valve operating on the ambient temperature optimizes this process by varying head pressures as a function of the actual heating demand and the outdoor temperature variation.

- The "System2-phase 1" was capable of reducing discharge pressures to an almost constant level (about $29 \%$ lower than the other system), without compromising its own heat reclaim method. The discharge pressures were lowered to about 125 psig during the winter, but the thermodynamic level of the heat reclaim was increased by using heat pumps as a cascade stage. Savings in compressor energy consumption were however obtained, mainly by using four refrigerant-to-air heat pumps having average coefficients of performance of around 3.0.

- The total annual specific energy consumption $\left(\mathrm{kWh} / \mathrm{y} / \mathrm{m}^{2}\right)$ of the refrigeration compressors represented $32.5 \%$ ("System 1-phasel") and 34 \% ("System2phasel", including the four heat pumps), of to each store's total electrical energy usage, compared to the current average in Canada, of $39 \%$. These performances were obtained even if the "System1 - phasel" was slightly penalized by the use of less efficient screw compressors, excessive fouling and lack of proper maintenance of groundwater heat exchangers. "System2phasel" was also penalized by the heat pump's supplementary energy 
consumption, even when compensated for by lower head pressure operation in winter. Simultaneously, the total annual specific electrical energy consumption (vs. sales area) of improved supermarkets was reduced by $6 \%$, and the corresponding energy costs, including power demand cost, by $12.9 \%$ and $17.9 \%$ respectively, compared to the baseline monitored supermarket.

High Speed Defrost. "System 1-phase1" system includes a high speed defrost concept capable of performing defrost cycles in a short period of time. In fact, the major disadvantages of conventional defrosting methods are their fairly lengthy cycles, because of a low-pressure differential across the evaporators, adverse effects on foodstuffs and compressors (energy cost increases, overheating, reduced technical life). As in conventional systems, when a refrigeration zone goes into a defrost cycle; superheated vapour is fed to the outlet of the evaporator coil. The return line of the defrost circuit is provided with a second valve which is open during the defrost cycle. This valve connects the return line to a special auxiliary receiver, which has a sufficient volume to take the full refrigerant charge and protect the compressors during and after each defrost cycle. The auxiliary receiver is connected to the low suction pressure header by means of a solenoid valve. By using an auxiliary receiver, a pressure differential can be created across the evaporator coils within a range of about 200 to $700 \mathrm{kPa}$, thus achieving quick defrost. In order to keep the main receiver supplied with sufficient quantities of liquid, it is necessary to periodically flush the auxiliary receiver during the refrigeration cycle. When the refrigerant temperature is below a predetermined value, normally $-1{ }^{\circ} \mathrm{C}$, the refrigerant liquid is directed to the main receiver. A pressure differential of about $200 \mathrm{kPa}$ is created in order to have sufficient pressure to flush out most of the liquid accumulated in the auxiliary receiver. If the liquid is above $-1{ }^{\circ} \mathrm{C}$, it is sent to the remote condensers and then back into the main receiver. The auxiliary receiver is also provided with a level detector. When the liquid level reaches a predetermined value, the flushing circuit will operate during the next refrigeration cycle. A second level detector feeds an alarm that produces both a visual and an acoustic signal.

Results

- The new high-speed defrost method proposed by "System 1-phase1" reduced defrost cycle time by about $85 \%$ compared with a conventional hot gas defrost method. Immediate beneficial effects were a better quality and about $50 \%$ less perishable food losses. The actual maximum deformation of a representative case evaporator during a fast defrost cycle represents about 56 $\%$ of the elastic limit of existing materials, but the long-term effects are not known, nor are they known for existing conventional systems.

- Because of the high speed defrost, it was estimated that is possible to reduce the number of the refrigeration lines and consequently, the total refrigerant quantity by up to $15 \%$.

Liquid Pumping and Injection. A simple, reliable liquid delivery technology developed in Canada can improve refrigeration efficiency, reduce compression ratios and work, and allow refrigeration systems to better operate with floating condensing pressures, depending on outdoor temperatures. This technology generally produces energy savings of up to $35 \%$, but creates difficulties in the area of heat recovery, especially when total condensing heat reclaim is required, because the air to be heated is warmer than the refrigerant to be cooled. Accordingly, when heat reclaim is required, the 
condensing pressure has to be artificially raised in order to achieve proper heat transfer, thus losing the benefits of the liquid delivery system. However, by combining liquid pumping with the new "System 2 - phase1" heat recovery method, it was expected that head pressures would not be artificially raised when heating is required. Refrigerant pumping pressurizes the liquid refrigerant enough to compensate for any pressure losses between the receiver and the expansion valve, and thus eliminates the formation of vapour. The liquid pump is a sealed unit, with no moving seals to wear out or leak. The "System 2 - phase 1" new heat recovery concept allows the use of the same equipment (heat pumps) for air conditioning and sub-cooling purposes, and also improves the efficiency of the liquid pumping technology. It is well known that the compressor's energy consumption and efficiency are a function of the ratio between the condensing and evaporating pressures. By lowering the condensing temperature to $16^{\circ} \mathrm{C}$ or even 10 ${ }^{\circ} \mathrm{C}$, the compressor energy consumption and power diminish, and its refrigeration capacity increases. Moreover, because the pressure of the pump is usually higher than the compressor discharge, the injection of a small percentage of the liquid (6-10\%) back into the discharge line was possible. Thus, for ambient temperatures above $24{ }^{\circ} \mathrm{C}$, the temperature of the discharge vapour was reduced, and the efficiency of the condenser increased. The liquid injection means lower velocity through the condenser, lower pressure drop, reduction of the discharge temperature, an increase in the area of the condenser used for condensing, and increased system capacity.

\section{Result}

- Liquid pumping technology used by "System 2 - phasel" helped this new heat recovery technique by increasing the liquid pressure by about $180 \mathrm{kPa}$ during the cold periods when the head pressure decreased to $860 \mathrm{kPa}$.

Geothermal Cooling. During the hottest periods of the year, condensing heat from the "System 1-phase1" refrigeration system was rejected to the ground instead to the ambient air in order to reduce energy consumption and thus optimize the overall efficiency of the system. This concept allowed the reduction of the compressor's head pressures and condensing temperatures, because the cooling fluid will be groundwater at an average temperature of about $8^{\circ} \mathrm{C}\left(46.4^{\circ} \mathrm{F}\right)$ instead the ambient air at more than $30^{\circ} \mathrm{C}$ $\left(86^{\circ} \mathrm{F}\right)$. This objective was achieved by using supply and discharge groundwater wells. Two refrigerant-to-water heat exchangers for both low and medium temperature racks were employed. The main disadvantage of this energy efficiency method is the risk of clogging of the groundwater heat exchangers, which involves additional costs for periodical maintenance. However, the energy savings may generally justify the initial investment and supplementary maintenance.

Further Developments. The major weakness of the proposed systems lies in the large of refrigerant required, and the associated environmental disadvantages (1,400 to 2,300 $\mathrm{kg}$ for total sales area of 3,000 to $5,600 \mathrm{~m}^{2}$ ). Even if the "Systeml - phasel" has demonstrated that the developed high speed defrost method enables a reduction in refrigerant charge of up to $15 \%$, it isn't considered sufficient. Therefore, the main objective of future systems improvement is to reduce total refrigerant quantity and leakage risks, and also to replace the HCFC-22 by alternative fluids, in order to develop new environmentally low-TEWI systems.

(i) The "System1 - phase2" improved system, available since 2001, was developed by retaining both prior innovations (integral heat recovery and high speed defrost). It aims to 
replace the actual HCFC-22 fluid with a good replacement having no, or lower environmental impact (e.g., R-404a). The central refrigeration system was divided into several smaller, ultra-compact units that can be installed on the roof (distributed compressor approach). The previous conventional central refrigeration room was thus completely eliminated, and the space created could be used for commercial activities. This arrangement reduces total refrigeration piping length and number of fittings, thermal insulation and electric piping by $60 \%$, and total refrigerant charge by $30-40 \%$, because of the proximity of display cases and of heat reclaim coils, reduced diameters and length. Thus, the additional costs are lowered by $40 \%$ compared to the previous system. These cabinets are insulated and equipped with their own heating and cooling devices $\left(21^{\circ} \mathrm{C}\right.$ in winter and $32^{\circ} \mathrm{C}$ in summer). Additional ventilation or make-up air and evacuation devices aren't needed. "System1 - phase3" improved system aims also to retain the main previously analysed innovations, and also to reduce the refrigerant charge by $60 \%$ or more compared with the first method. This concept retains the same small cabinets, but each high temperature side (condensers and heat reclaim) uses closed loops with circulation pumps and anti-freeze secondary fluid, storage tanks and controls. These condensing circuits can transfer heat directly to each heated space, or can use water-to-air heat pumps. Reduction of additional costs is estimated at $50 \%$ compared to the first improved system.

(ii)"System 2 - phase2" aims to maintain heat recovery by heat pumps, but to improve the liquid delivery system (horizontal receiver installed outdoors with improved level control), accelerate the defrost cycles by increasing the refrigerant flow rate, and reduce the additional cost by about $10 \%$ compared to the previous concept. On the other hand, "System 2 -phase3" aims to develop a simplified heat recovery method without heat pumps, a zoned defrost concept, and to reduce the refrigerant charge by up to $30 \%$ and the additional cost by $80 \%$ compared to the first improved system.

Summary information on the phase 1 test systems is included in Appendix A. Full details on the tested and improved systems may be found in the Canada country report.

\section{Denmark}

There is a great deal of concern in Denmark about the use of HFCs due to concerns about their impact on the environment in the long term, especially the contribution to global warming. In the opening speech to the IIR conference on "Applications for Natural Refrigerants", Aarhus, Denmark (1996) the Danish Minister for Environment and Energy, Svend Auken, in his conclusion said: "It is therefore my sincere hope that in ten years' time, not a single fridge, freezer or cooling plant is being built in Denmark that requires HFCs or other greenhouse gases." Recently an announcement (in Danish; Bekendtgørelse, BEK nr. 552 of July 2., 2002) has been issued which forbid the use of certain industrial warming potential gasses, which includes the HFC's. From January 1, 2006 the use of HFC's is no longer allowed in new products. Exemptions are the use in refrigeration plants, heat pumps, air conditioning plants and dehumidifiers with refrigerant charge between $0.15 \mathrm{~kg}$ and $10 \mathrm{~kg}$ and compact heat recovery plant factory assembled with charge less than $50 \mathrm{~kg}$. According to this rule conventional multiplex refrigeration systems cannot be used in supermarkets after January 2006. 
Besides the phase out in 2006 for new plants HFCs are charged a $\mathrm{CO}_{2}$ tax. In Denmark emission of carbon dioxide $\left(\mathrm{CO}_{2}\right)$ has been taxed since May 15, 1992. Starting January 1, 2001 following the Kyoto protocol Denmark extended the $\mathrm{CO}_{2}$ tax to include industrial greenhouse gasses ( $\mathrm{HFCs}$, PFCs and $\mathrm{SF}_{6}$ ) based on the global warming potential (GWP) of each gas. The tax is US\$ 0.0127 (DKK 0.10) pr. $\mathrm{kg} \mathrm{CO}$ with $\mathrm{CO}_{2}$ by definition having the GWP of 1 with a maximum tax of US\$ 50.95 (DKK 400) pr. kg (Danish law \#49 of December 21, 2000).

In view of what is stated above it is obvious why the Danes are searching for natural refrigerant substitutes for HFCs. Several supermarket case studies have been done in Denmark with a primary focus on increasing energy efficiency and applying natural refrigerants (like hydrocarbons, ammonia, and $\mathrm{CO}_{2}$ ). In one small Danish supermarket the old refrigeration plant was replaced with a cascade plant. Propane was used as the high temperature refrigerant $\left(-14 /+30^{\circ} \mathrm{C}\right)$ while $\mathrm{CO}_{2}$ was used at the low temperature level $\left(-32 /-11^{\circ} \mathrm{C}\right)$. Direct expansion of $\mathrm{CO}_{2}$ is used in the freezer cases while a brine circuit with propylene glycol is used in the coolers. Total energy consumption decreased by $10 \%$ with the new plant, however it must be noted that the old plant was worn out. Based on the results from this initial demonstration a second propane/ $\mathrm{CO}_{2}$ cascade plant was built in a medium-size supermarket and just started operation in late 2001. The test supermarket is part of a chain of about 250 similar shops so it has been possible to compare the propane/carbon dioxide plant with newer traditional plants with the same cooling capacity. Energy use of the demonstration store has been compared to that of eight similar stores in the same chain and found to be about the same as that of the most efficient of the newest conventional stores. It is estimated that the additional cost for a propane/ $\mathrm{CO}_{2}$ cascade plant for a medium sized Danish supermarket $(30 \mathrm{~kW}$ freezing load and $60 \mathrm{~kW}$ cooling load) will amount to approximately $10 \%$ or less of the total installation. Details of this second demonstration are included in Appendix A.

A third demonstration plant has recently been started in a new supermarket in which carbon dioxide is used in both the low temperature and medium temperature cases. This approach eliminates the secondary propylene glycol circuit with its thermodynamic efficiency penalty. The plant has $190 \mathrm{~kW}$ cooling capacity and $60 \mathrm{~kW}$ freezing capacity, and the condenser heat is utilized to supply the shop with all of its space heating and sanitary hot water needs. The refrigeration plant is a cascade plant with R404A in the high temperature stage and $\mathrm{CO}_{2}$ in the low temperature stage. $\mathrm{R} 404 \mathrm{~A}$ is used in this plant because the equipment is installed in the basement of the store where it is difficult to get permission to install flammable or toxic refrigerants. Both the freezer cases and fresh food cases are cooled by direct evaporation of $\mathrm{CO}_{2}$. Liquid $\mathrm{CO}_{2}$ is pumped directly to the fresh food cases while $\mathrm{CO}_{2}$ is direct expanded into the freezer cases. The amount of $\mathrm{R} 404 \mathrm{~A}$ in this demonstration is only about $10 \%$ of that needed by conventional direct expansion systems for stores of this size. Taking into account the Danish tax on R404A this reduction reduces the investment in refrigerant by about US\$37,000. (DKK 290,000). The total investment in the refrigeration plant is approximately $10 \%$ higher than a conventional HFC-plant taking into account the reduced refrigerant cost. This demonstration has been underway since February 2002. A comparison with similar shops in the area with conventional refrigeration systems shows significantly lower energy consumption. In November 2002 a second plant built in according with this concept has been set in operation. 
In the future a project with title, "Energy efficient design and control of the secondary side of an indirect refrigeration system with natural refrigerant" will be performed.

\section{Sweden}

Swedish activities for Annex 26 have been aimed at improving supermarket energy efficiency in several different ways. These have included development of a detailed computer model and analyses of full stores to examine different secondary loop system designs and heat recovery approaches including impact of climate effects particularly relative humidity. Several full-scale demonstration projects have been undertaken examining different secondary loop systems and display cases with advanced features such as automatic night covers.

Increased sales in supermarkets, stricter environmental legislation for $\mathrm{CFC}$ and HCFC refrigerants and a major consideration of the use of energy and the effect on the environment have influenced the supermarket sector during the last year in Sweden. Sales in supermarkets have increased $4.6 \%$ during year 2001 in comparison with the year 2000 [30]. The consumption of deep-frozen products in supermarkets during 2001 was 231788 metric tons while during 2000 it was 216427 metric tons, which is an increase of 7\%. The increase in sales in supermarkets places a demand on more cabinets, cold rooms and refrigeration systems that increase the energy consumption from food stores.

Supermarkets are using large amounts of energy; approximately 3\% of the electric energy consumed in Sweden is used in supermarkets $(1,8 \mathrm{TWh} /$ year $)$. A breakdown of the energy usage shows that, typically, $47 \%$ is used for medium and low temp refrigeration, $27 \%$ for illumination, $13 \%$ for fans and climate control, $3 \%$ for kitchen, $5 \%$ for outdoor usage and 5\% for other uses.

Refrigeration systems, display cases, indoor climate control and illumination are the areas with the greatest potential for improvement. Since the energy systems of a supermarket are relatively complex, improvements in one subsystem affects other systems, thus making an analysis of potential improvements non-additive. Typical efficiency improvements may involve refrigeration systems, heat recovery, more efficient illumination, more efficient display cases with night lids, more efficient control, floating condensation etc.

Several new system solutions such as completely, partially and cascade secondary loop (or indirect) systems have been developed and introduced in recent years in Sweden to lower the refrigerant charge and, at the same time, minimize potential refrigerant leakage.

Growing interest in secondary loop systems has led to the development of some new secondary refrigerants based on potassium formate and potassium acetate alone or mixed. Another very promising development is $\mathrm{CO}_{2}$ as a secondary refrigerant. This technology is implemented in more than 30 supermarkets throughout Sweden. $\mathrm{CO}_{2}$ systems require much lower tube diameters and the pressure drop is negligible when compared to conventional systems. A third promising development in this field is ice slurries. These systems offer additional advantages with enhanced thermal capacity and a "built-in" thermal storage in the system without increased pressure drop if ice-slurry with the right consistence is produced. 
Secondary systems and the minimization of refrigerant charge may lead to an unwanted trade off in overall energy efficiency. Theoretical calculations confirm this due to the obvious extra temperature differences introduced in the system. An evaluation using a concept like TEWI (Total Equivalent Warming Impact) may be used to estimate the overall environmental impact.

In 1998 the Department of Energy Technology of the Royal Institute of Technology of Sweden started a project in co-operation with different companies and the Swedish National Energy Administration. Modelling and field measurements of supermarket energy systems have been undertaken in the research project "The energy efficient supermarket" for more than four years. The results have been part of the Swedish contribution to the IEA Annex 26.

The overall aim of the project "The energy efficient supermarket" is to develop a sound simulation model where different system solutions can be compared in detail with focus on energy usage, environmental impact (TEWI) and LCC (Life Cycle Cost).

The program, "CyberMart" is built in modules dealing with subsystems such as in- and outdoor climate, display cases, cooling and freezing rooms, refrigeration machinery, the building envelope etc. CyberMart is a day-to-day simulation program that allows the user to see the variation of different variables such as compressor power, refrigeration capacity and temperatures in the supermarket during one year.

The model is currently under validation with four different supermarkets in Sweden in cooperation with COOP and ICA, two major Swedish supermarket chains. The model development activities are now treating issues such as illumination, indoor climate and heat recovery, comfort cooling etc. Interesting issues to study are the potentials in heat recovery in the winter, moisture control/dehumidification and floating condensation. Additional Field measurements intended to validate data are currently being set up. A window for calculation of energy consumption is shown in Figure11. The diagram shows the results from the simulation of the compressor power of the intermediate and low temperature systems during one year. 


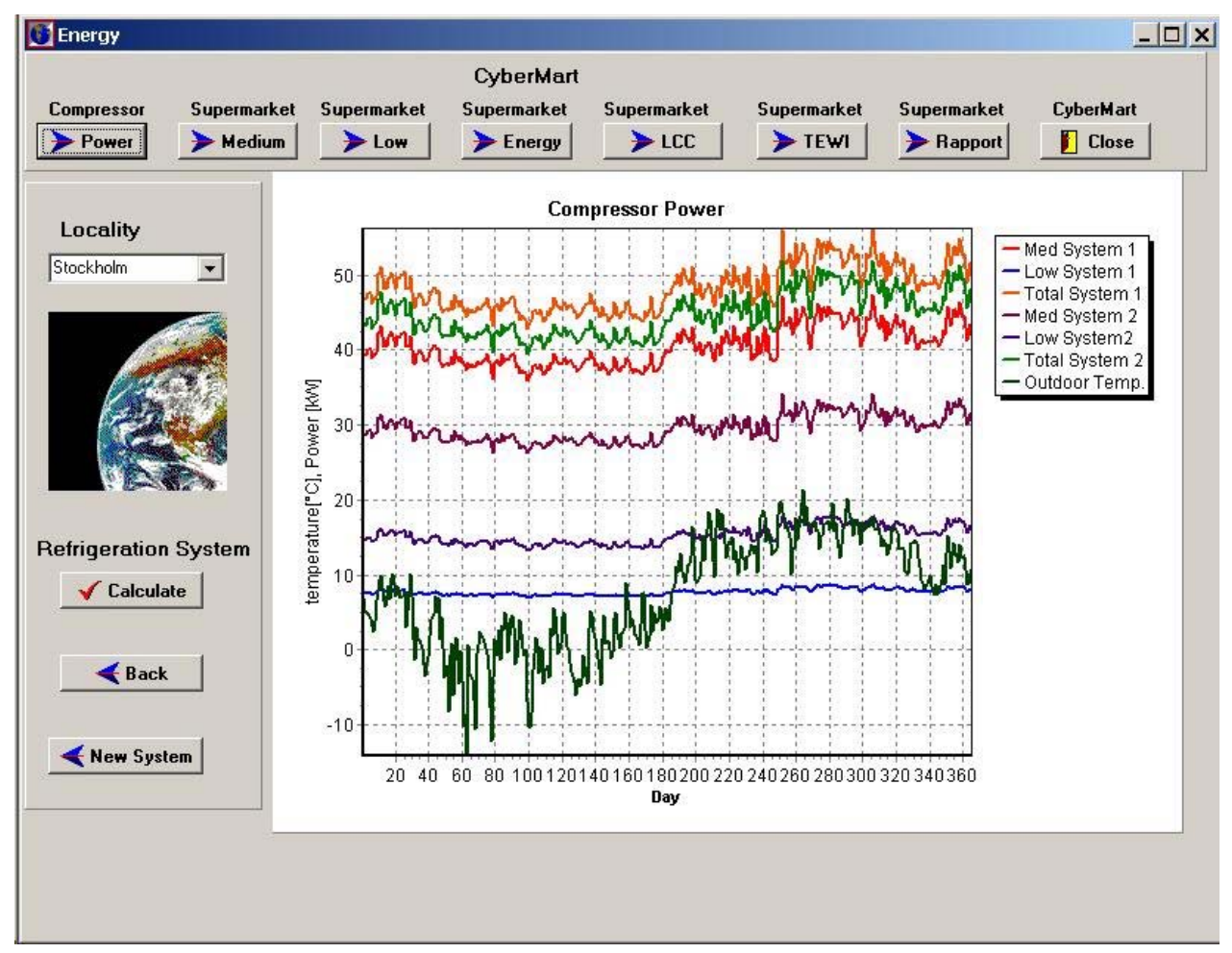

Figure 11 - Results from CyberMart

The influence of the outdoor temperature on the indoor relative humidity of air is an important factor to take in consideration when dimensioning refrigeration and heat recovery systems in supermarkets. Lower outdoor temperature and moisture affect the compressor power and the dry cooler fluid approach temperature. 
Sala - Hedemora

Aug 2000 - Feb 2001

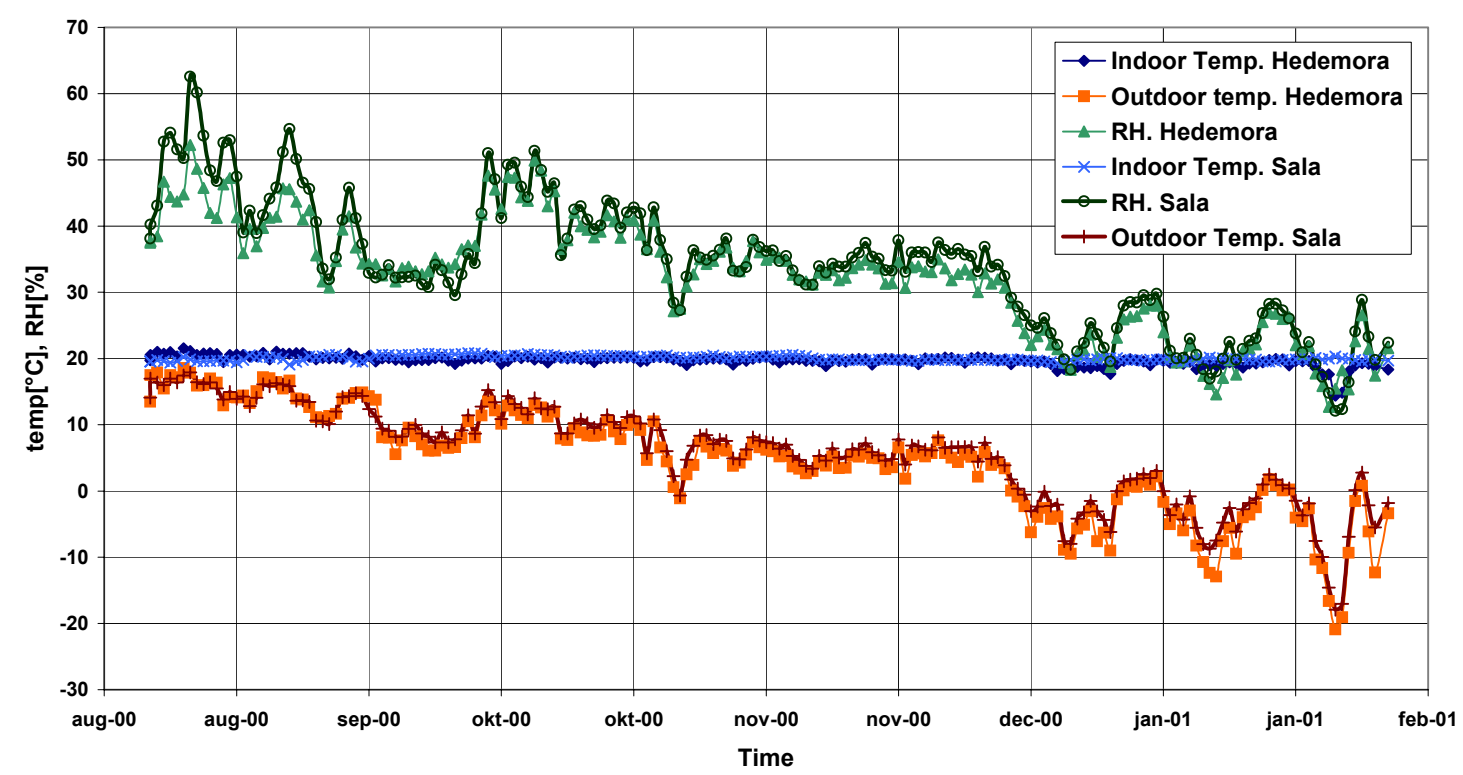

Figure 12 - Indoor temperature, outdoor temperature and indoor relative humidity in Hedemora and Sala

Measurement of indoor temperatures, outdoor temperatures and indoor relative humidity from two supermarkets in the cities of Hedemora and Sala are shown in Figure 12. The distance between the cities is about $60 \mathrm{~km}$. The results confirm the dependence of relative humidity on outdoor temperature. The indoor relative humidity in both supermarkets follows the variation of outdoor temperature during the period of study. 


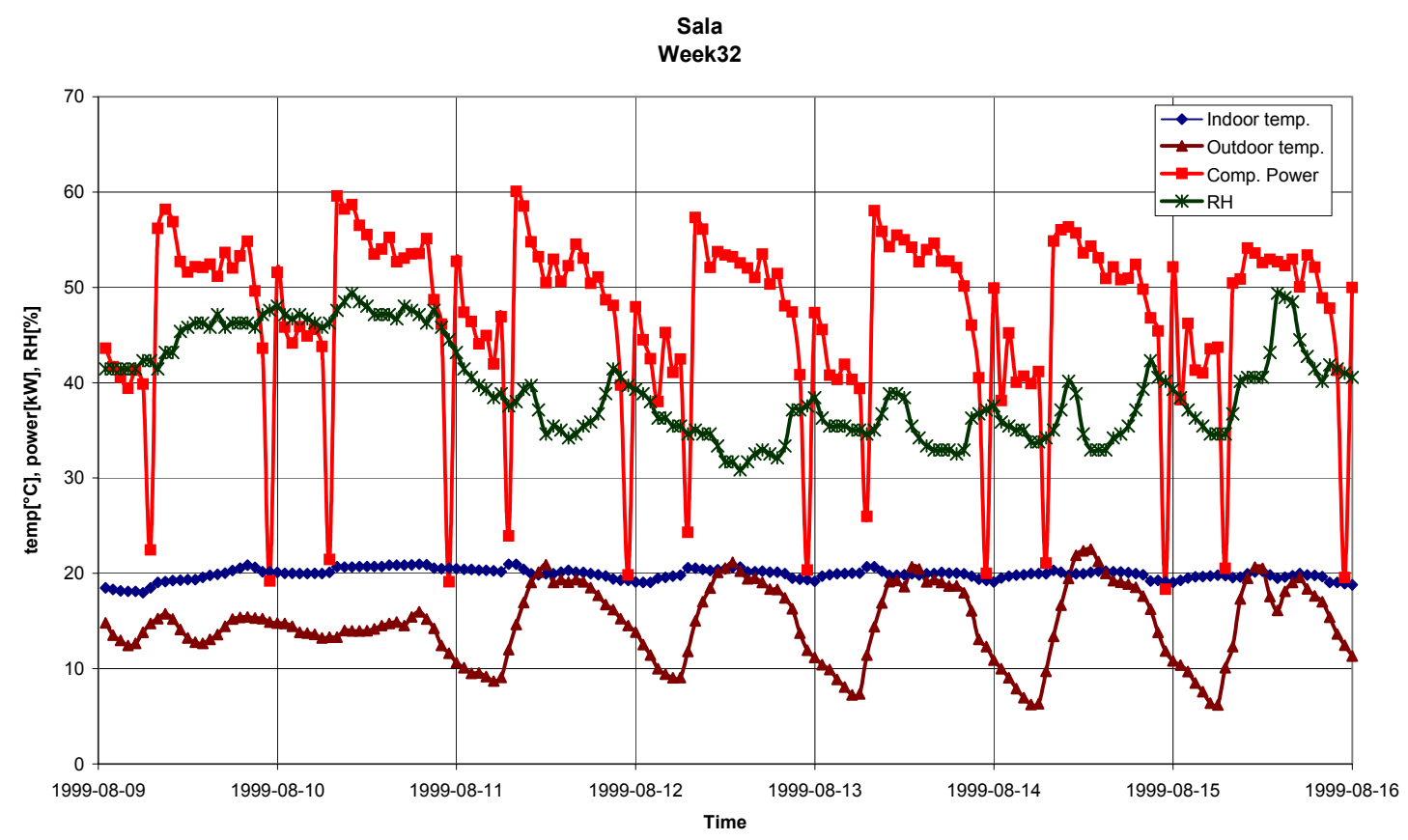

Figure 13 - Temperatures, relative humidity and compressor power in Sala

The variations of temperatures, moisture and compressor power during week 32 in August 1999 in the supermarket in the city of Sala are shown in Figure 13. In the figure it is possible to see the influence of night covering of the display cases and defrosting on the compressor power. The cabinets are defrosted with electrical defrost. The compressor power is reduced between 10 and $20 \%$ by the night covering of the cabinets. The covering occurs automatically when the supermarket closes at 21.00 and ends at 8.00 in the morning. The positive effect on energy saving of night covering is dependent on the quality of the curtains. Night covering is an efficient method to reduce infiltration and radiation loss in cabinets.

The influence of high indoor temperatures on compressor power has been studied in the supermarket in the city of Hedemora. The high investment cost of the air conditioning system and a short period of higher outdoor temperatures during the summer have affected the decision of install AC in many supermarkets in Sweden. 
Hedemora

3 - 6 July 2001

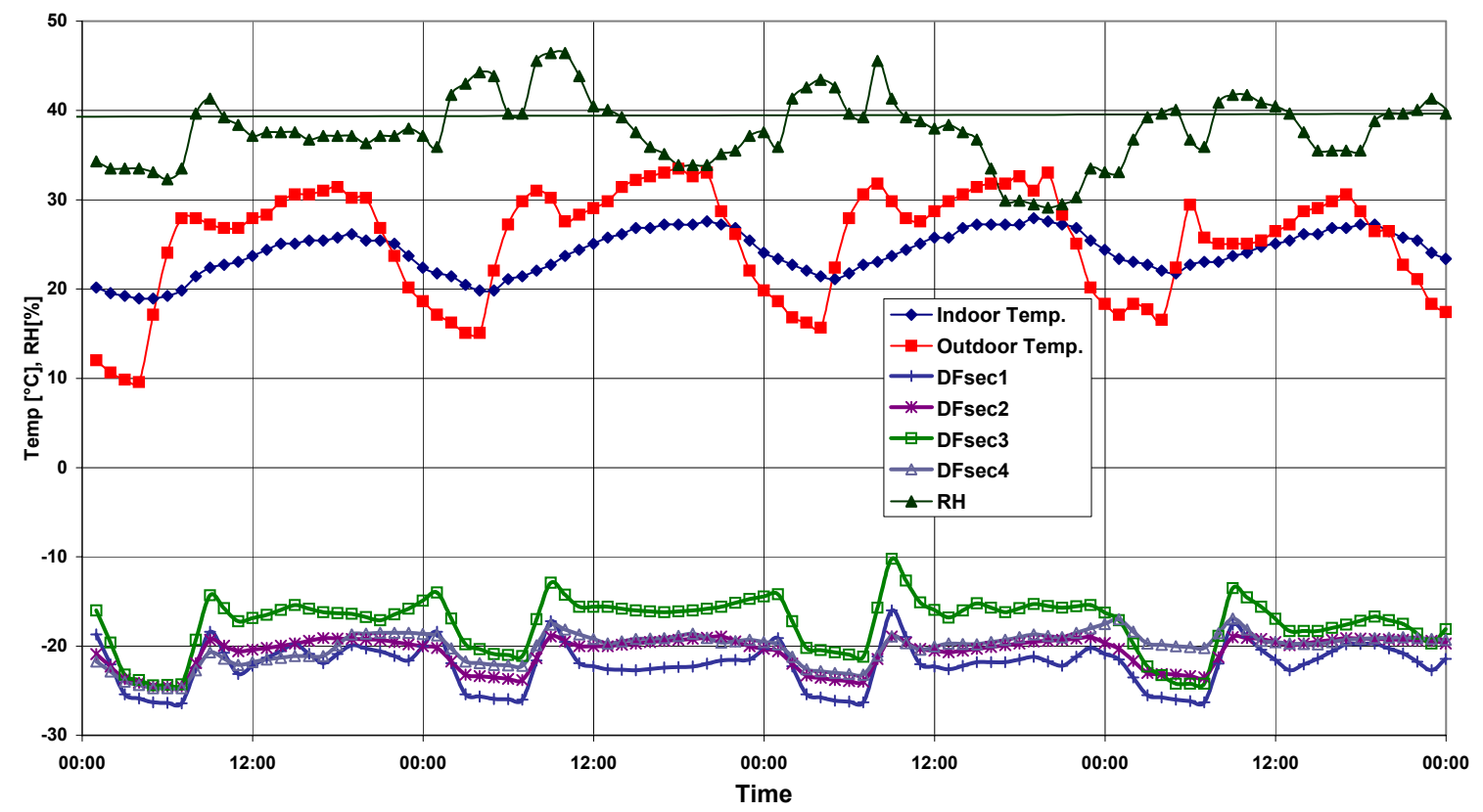

Figure 14 - Temperatures in a deep freeze cabinet and indoor and outdoor temperatures during four days in July in Hedemora

Figure 14 presents indoor temperatures, outdoor temperatures and air return temperatures in four sections of a deep-freeze cabinet during four days in July 2001. The outdoor temperatures are above $30^{\circ} \mathrm{C}$ during a long part of the day and this affects the indoor temperatures. The values of indoor temperatures during the day are above $25^{\circ} \mathrm{C}$, which is the dimensioning indoor temperature of the display cases. The maximum indoor temperature is $28^{\circ} \mathrm{C}$, which occurs on the $5^{\text {th }}$ of July at around 17:00 o'clock. The air return temperatures in three sections are above $-20^{\circ} \mathrm{C}$ and one of them has air return temperatures higher than $-15^{\circ} \mathrm{C}$ during the day. If the temperature of the products is assumed $1^{\circ} \mathrm{C}$ higher than the air return temperature, which is a reasonable supposition, then the temperature of the product should be about $-14^{\circ} \mathrm{C}$ at an air return temperature of $-15^{\circ} \mathrm{C}$. According to the National Food Administration, which regulates and supervises the food area in Sweden, the maximum temperature of freeze products is $-18^{\circ} \mathrm{C}$. The date for the minimum durability, or use-by date, of frozen food is calculated at a temperature of $-18^{\circ} \mathrm{C}$. Higher product temperature implicates a risk of the multiplication of bacteria in the frozen food that might cause illness to the consumers. The results from Figure 12 confirm the necessity of air conditioning during the warmer days in the summer in Sweden.

The economy and overall energy efficiency of supermarkets, in cold climates, benefit from heat recovery. In theory, the necessary heat can always be supplied from the condensers. Practical experiences show that in real systems only $40 \%-70 \%$ of the necessary heat is recovered. There are many reasons for this but the most important are on/off regulation, low cooling load during cold days, poorly designed heat recovery systems and non-communication control systems for refrigeration and HVAC. 


\section{United Kingdom}

Storing and displaying refrigerated goods accounts for a considerable amount of energy use in the UK. Figure 15 shows the breakdown of the end use of refrigeration energy. Of the total of $24,000 \mathrm{GWh}$, refrigerated retail display cabinets overall consume some 7,740 GWh per year in the UK. This provides a great incentive to improve the energy efficiency of refrigerated supermarket display units. In addition to this there is also the requirement to reduce the emission of environmentally damaging refrigerants that contribute to the total equivalent warming impact.

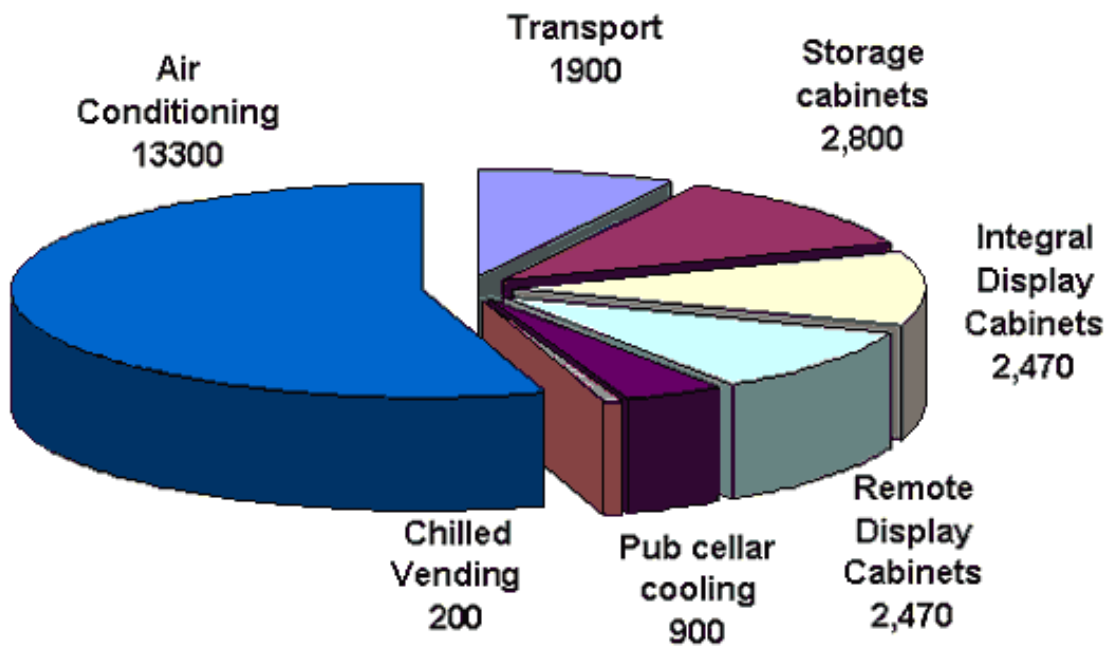

Figure 15 - Refrigeration energy usage in The United Kingdom by end use

Reported here are a summary of the Phase 2 studies and the overall analysis of the current position regarding the available technologies. Full details of the Phase I technology review and Phase 2 detailed studies are included in the UK country report. The second phase of the UK contribution covered four research areas:

- $\quad$ secondary refrigerant systems

- $\quad$ alternative defrost approaches

- $\quad$ interactions between the store environment and the cabinet case

- combined heat and power and combined heating, cooling and power applications in supermarkets.

This summary records the main points that were concluded from each of the four studies carried out. Each area of research was carried out by an organisation specialising in refrigeration technology. The areas where further research may be useful have also been identified.

Secondary Systems. Secondary refrigerant systems offer the potential of reduced total equivalent warming impact (TEWI) as a consequence of reduced refrigerant leakage of high ozone depleting potential (ODP) refrigerants. However, it is recognised that there 
may be additional energy requirements to operate this type of system because of greater temperature gradients and increased pumping power.

Field monitoring data from a typical supermarket was used to validate a refrigeration simulation model, and a detailed investigation of the thermal and fluid properties of secondary refrigerant fluids was made. This enabled simulations to be carried out to assess the feasibility of a wide range of secondary systems and refrigerants in a typical supermarket. A key finding of the simulation was that the energy use of the secondary systems simulated would typically be greater than for other systems and as a consequence they would deliver higher operational $\mathrm{CO}_{2}$ emissions. In terms of overall TEWI, the secondary system using R290 (propane) would reduce the TEWI by $8 \%$ over a 15 -year life compared to an R22 direct system with 15\% refrigerant leakage. The benefit of a reduced TEWI of a secondary system is lessened as the leakage rate of the equivalent direct system decreases.

The project has shown that there is sufficient knowledge of secondary fluid properties to be able to design an effective system. However, careful optimisation will be needed for a secondary system to become more attractive both financially and in terms of TEWI, so further research is recommended into the optimisation of secondary systems.

Further research needs. Secondary systems using pumpable ice have been tried in the UK but further work is needed to establish if it is a viable option. Research is also needed to address the issues of store layout and pipework arrangements with the specific aim of reducing the capital cost of the secondary system.

The use of $\mathrm{CO}_{2}$ as the secondary refrigerant needs to be researched in the UK context. The current situation is not clear with respect to the health and safety issues and the performance of the systems in operation. Cascade systems have been used in the USA and may have some energy benefits and the possibility of using these in the UK should be investigated.

If changes in legislation force the adoption of lower Global Warming Potential (GWP) refrigerants then retailers may wish to investigate secondary systems further. The options for improvement include: system design (store layout to reduce pipework capital costs); pumpable ice; $\mathrm{CO}_{2}$; and cascade systems. Reference should be made to experience in North America and Scandinavia where some of these approaches have been adopted.

Defrost. The energy used for defrosting evaporator coils in supermarkets can amount to $30 \%$ of the operating energy. Alternative means of reducing the defrost energy have been researched by laboratory studies of different defrosting techniques and control strategies. Studies were carried out in both high and low temperature applications and the following defrost techniques were considered:

$$
\begin{array}{ll}
\text { - } & \text { off-cycle } \\
\text { - } & \text { hot/cool gas } \\
\text { electric. }
\end{array}
$$

However, not all techniques can be used in all circumstances, for example, offcycle is not appropriate in low temperature applications, leaving a choice of gas or electric defrost.

The findings showed that, for high temperature applications, the cheapest and least energy consuming means of defrost is 'off-cycle'. This method of defrost is widely 
used in the industry. For low temperature applications, the use of gas defrosting is more energy efficient than electric defrost but the considerable extra capital costs lead to long payback periods, up to 28 years. Consequently, electric defrost is most commonly used for low temperature applications in the UK.

The length and frequency of the defrost cycle has a significant effect on the energy use of a refrigerated cabinet. The normal procedure of a fixed number of cycles per day is wasteful of energy because the time period between defrosts may be either too long - thereby reducing the frosted evaporator efficiency before defrost - or too short which provides unnecessary defrost events. In addition, the length of defrost can be excessive and this wastes further energy, and risks adverse effects on the product quality and life. Optimised defrost cycles could reduce energy use by between 25 and 50\%, where electric defrost is employed. Work is under way to develop controls to achieve this.

The optimum defrosting cycle will depend on the cabinet type and store conditions and a means of control that relates to these parameters would lead to significant energy savings.

Further research needs. A number of issues for further research were revealed by these studies. Liquid defrosting for low temperature applications should be further researched as it is potentially a more effective and energy efficient technique.

Methods of determining the need for defrosting should be investigated and these should take into account the avoidance of simultaneous defrosting of a number of units leading to high electrical loads. Evaporator design has an influence on the formation of ice and should also be researched in order to avoid or reduce the incidence of frosting.

CHP/CCHP. Combined heat and power and combined cooling, heat and power are potentially efficient methods of providing the energy for supermarkets. A simulation model has been developed that allows the energy and heat flows in a supermarket to be modelled and will predict energy and cost savings arising from a range of measures taken to improve efficiency of supply or use of energy. The model was tested against a store using CHP and then used to evaluate a range of options.

The studies showed that currently available equipment can be used satisfactorily but needs to be carefully optimised for the specific store in which it is being installed. The cost effectiveness of CHP/CCHP is sensitive to the fuel costs and in particular the ratio of the gas and electricity costs. Additionally the number of hours for which the plant operates in a year is a key determinant of the cost effectiveness.

Further research needs. Determining the heat and power load profiles of a wider range of stores would assist in developing a clearer view of the potential for CHP in supermarkets.

The design of the refrigeration system with the use of CHP and CCHP needs to be investigated as novel approaches may provide a better match of heat and power usage. For example, gas engine prime movers for vapour compression machines can be attractive and the potential for their use should be examined.

The simulation model that has been developed in the context of this research could be made available for retailers and other interested parties to carry out feasibility studies on future stores. 
Case and Store Environment Interaction. This project was based on the premise that the internal environment of the store, in which the refrigerated display cabinet is located, can have a significant bearing on the energy use and performance. The temperature and humidity of the air and its movement around the cabinet are all likely to influence the energy use. A store environment was measured and the conditions were recreated in the laboratory. Tests were then carried out with these different internal environmental parameters to investigate their impact on energy use. Two different cases were tested in the laboratory - an integral (self-contained open front chiller unit and an open well (coffin-type) freezer with a row of half-height glass door shelves above the open well (see Figure 16).

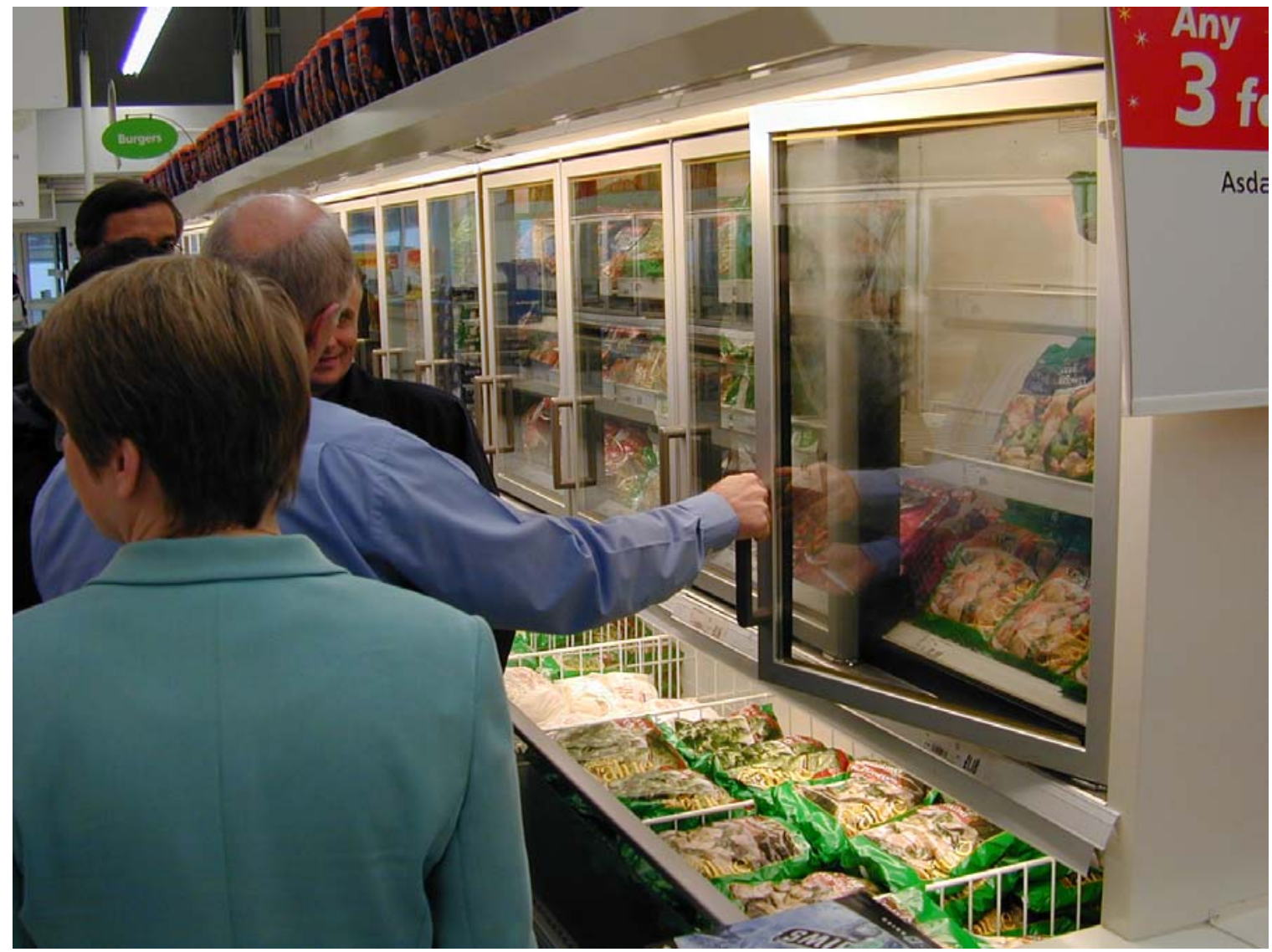

Figure 16 - Example of freezer case type tested by UK team in environmental chamber to determine impact of store temperature, relative humidity and ventilation mode (conventional or displacement) on performance

The results showed that for the freezer tested varying the store's temperature, relative humidity and ventilation mode and rate had little impact on the energy consumption of the unit. It may be surmised that although the rate of frost formation on the evaporator was dependent on the ambient relative humidity, whilst the defrost initiation and duration were preset, no significant impact on the energy use for defrost was observed. 
For the chilled cabinet the energy consumption was more dependent on the store conditions. A change of store temperature from 19 to $22^{\circ} \mathrm{C}$ increased the energy use by up to $20 \%$. At the higher temperature of $22^{\circ} \mathrm{C}$ the relative humidity of the store environment increased the energy consumption by $15 \%$, when raised from $35 \%$ rh to $50 \%$ rh. Increased ventilation around the chiller could also lead to some increase in energy use.

Overall, relative humidity is not as much of a significant factor in energy use as was initially expected from the literature review. This is probably because the rh values in the UK are typically much lower than in the USA, where the other research had been carried out.

An additional finding was that reduction of the voltage supply to the cabinet had a large effect on the electricity use. Reducing the voltage from 240 to 220 volts resulted in a saving in energy of approximately $10 \%$ without any loss in performance. This effect has also been observed in stores, and current practice is to reduce voltage supply to the whole store in order to make savings.

Further research needs. The use of high velocity air supply in aisles in order to mix the stagnant cool air needs to be investigated particularly to ascertain the impact on customer comfort. This needs to be studied in the context of customers' expectations of comfort levels in stores and particularly adjacent to refrigerated display areas.

Research is required into controlling anti-sweat heaters by methods other than time control. The control of the anti-sweat heaters is an area in which there is a potentially large energy saving to be made.

The design and manufacture of cabinets is a major issue that warrants further examination. The tendency is to provide standard solutions that are not being developed in line with the aims of improving energy efficiency. To overcome this needs the active participation of manufacturers in the realistic testing and measurement of in-store operation in future trials.

UK Overall Conclusions. These projects have confirmed that many of the practices the retailers currently have in place are the most cost effective e.g. the use of DX systems at low leakage rates, and electric and off-cycle defrosting. However, some of the more expensive and/or innovative technologies could further reduce the TEWI of supermarket refrigeration.

A number of issues remain to be addressed in order to achieve these potential savings in all applications. There also appears to be great scope for considering the whole system - from power supply to refrigerated goods display in a store environment - as a single system to be optimised; rather than a collection of individual components each acting in isolation. Of particular note are:

- Defrost methods and control strategies - which has great retrofit potential

- Secondary system optimisation

- $\quad$ Store environmental conditions for comfort and cabinet energy use

- Variable speed compressors.

\section{United States}

The US contribution to the Annex included an analysis of several low-charge refrigeration system options, a field test of a distributed compressor refrigeration system, 
and development of a spreadsheet-based refrigeration system model. Summaries of the analyses and the field test results are given below. The spreadsheet model is described briefly below and more fully in the US country report. Full details of the analyses and field test projects are given in the US country report. Appendix A provides some summary information on the field tests as well.

There are over 100,000 retail food markets in the United States. Of these almost 33,000 are supermarkets - stores with over $\$ 2$ million in sales annually and generally having much more than $1000 \mathrm{~m}^{2}$ of sales floor area. Total annual electricity consumption for refrigeration alone in all US supermarkets combined is about 35-40 billion $\mathrm{kWh}$.

System analysis summary. A $3720 \mathrm{~m}^{2}$ supermarket based on the layout in Figure 1 was simulated and energy consumption estimates were made for a baseline air-cooled multiplex refrigeration system which uses R22 for the medium temperature compressor rack and R404A for the low temperature compressor rack and four advanced, low charge systems (Walker and Baxter, 2003). The advanced systems investigated included distributed compressor (R404A), secondary loop (R507, primary refrigerant), low-charge multiplex (same refrigerants as baseline), and advanced self-contained (R404A). The secondary loop system modeled included four separate temperature loops operating at temperatures of $-30,-18,-7$, and $-1{ }^{\circ} \mathrm{C}$ with a potassium formate brine in the lowest temperature loop and propylene glycol brine in the higher temperature loops. The lowcharge multiplex system modeled was based on the system described in Figure 7.

Total refrigeration load was $328 \mathrm{~kW}$ ( $82 \mathrm{~kW}$ for frozen foods and $246 \mathrm{~kW}$ for fresh foods). The baseline system charge was $1360 \mathrm{~kg}$ or $4.15 \mathrm{~kg} / \mathrm{kW}$ load. Both the distributed compressor system (with secondary loop for heat rejection and evaporative cooling tower) and the secondary loop system (with evaporative condensing) achieved similar results with annual energy savings of $11.3 \%$ and $10.4 \%$, respectively, compared to the baseline for a Washington, DC location. The low-charge multiplex refrigeration system (with an evaporative condenser) showed annual energy savings of $11.6 \%$ compared to the baseline system. No energy savings were estimated for the advanced, self-contained system. Refrigerant charge reductions were $67 \%$ for the distributed compressor system, $85 \%$ for the secondary loop system, and 33\% for the low-charge multiplex system. Energy savings results are summarized in Table 1. 


\begin{tabular}{|l|l|c|c|c|}
\hline Table 1 - Predicted Energy Consumption for Low-Charge Refrigeration Systems \\
\hline System & Heat Rejection & $\begin{array}{c}\text { Annual } \\
\text { Energy } \\
(\mathrm{kWh})\end{array}$ & $\begin{array}{c}\text { Energy Savings } \\
(\mathrm{kWh})\end{array}$ & $\begin{array}{c}\text { \% Savings vs } \\
\text { baseline }\end{array}$ \\
\hline $\begin{array}{l}\text { Multiplex } \\
\text { (baseline) }\end{array}$ & $\begin{array}{l}\text { Air-Cooled } \\
\text { Condenser }\end{array}$ & 976,800 & - & - \\
\hline Multiplex & Evap. Condenser & 896,400 & 80,400 & 11.6 \\
\hline $\begin{array}{l}\text { Low-Charge } \\
\text { Multiplex }\end{array}$ & Evap. Condenser & 863,600 & 113,100 & 11.3 \\
\hline Distributed & $\begin{array}{l}\text { Water-Cooled } \\
\text { Condenser, Evap } \\
\text { Rejection }\end{array}$ & 866,100 & 110,700 & 10.4 \\
\hline Secondary Loop & Evap. Condenser & 875,200 & 101,600 & - \\
\hline $\begin{array}{l}\text { Advanced Self- } \\
\text { Contained }\end{array}$ & $\begin{array}{l}\text { Water-Cooled } \\
\text { Condenser, Evap } \\
\text { Rejection }\end{array}$ & $1,048,300$ & - & 1.8 \\
\hline Secondary Loop & $\begin{array}{l}\text { Water-Cooled } \\
\text { Condenser, Evap } \\
\text { Rejection }\end{array}$ & 959,700 & 17,100 & \\
\hline
\end{tabular}

Use of evaporative heat rejection (evaporative condenser or cooling tower) was the principal driver for energy savings for all of the advanced systems compared to the baseline case. The energy consumption of the multiplex baseline system would be about $8.2 \%$ lower if equipped with an evaporative condenser instead of the air-cooled condenser.

An environmental assessment of these refrigeration systems was also made through a TEWI analysis for a 15-year life. The lowest TEWIs were achieved by the distributed compressor system and the secondary loop systems with estimated $\mathrm{CO}_{2}$ emission reductions compared to the baseline multiplex system (multiplex with aircooled condensing) of 13- 14 million $\mathrm{kg}$, or about $57-60 \%$. The low-charge multiplex system had estimated TEWI reductions of about $43 \%$ compared to the baseline system for a $15 \%$ annual refrigerant loss rate. Replacing the air-cooled condenser with an evaporative condenser on the baseline system resulted in an estimated TEWI reduction of about 3\% due to the energy savings from operation at lower condensing temperatures. TEWI results are summarized in Table 2. 


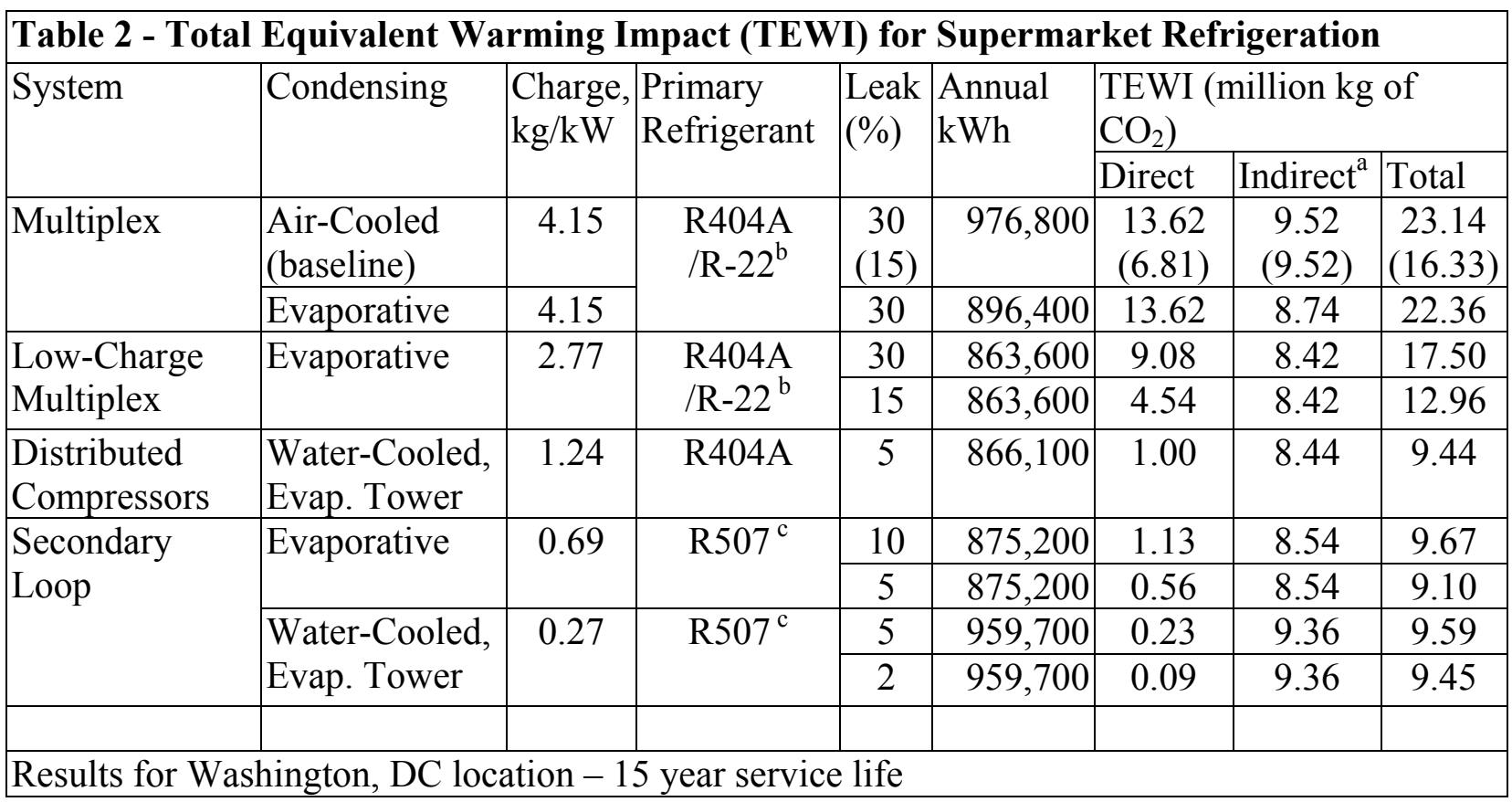

${ }^{\mathrm{a}}$ Conversion factor $=0.65 \mathrm{~kg} \mathrm{CO} / \mathrm{kWh}$

${ }^{\mathrm{b}} 1 / 3$ R404A (low temp), GWP = 3260; 2/3 R22 (medium temp), GWP $=1700$

${ }^{c} \mathrm{R} 507, \mathrm{GWP}=3300$

One observation from this study is that further efforts to reduce total global warming impacts for the distributed and secondary loop systems would benefit more from reduction in energy usage (through efficiency increases or load reductions) than from further reduction in direct impact (from refrigerant losses). This based on the fact that the direct (refrigerant loss) portion of the estimated TEWI for these systems only comprises about $10 \%$ of the total.

Payback estimates. A simple payback analysis was conducted based on the results from the analysis project. Estimated installed cost premiums for the distributed compressor, secondary loop, and low-charge multiplex refrigeration systems were $\$ 60,000$ (about 15\%), $\$ 147,000$ (about $35 \%$ ), and $\$ 0$, respectively compared to the baseline air-cooled multiplex DX system. These estimates were based on actual construction budgets supplied by the engineering departments of two supermarket chains. It should be noted that the actual installed cost of any refrigeration system will vary greatly, depending upon many factors, such as: purchasing arrangements between the supermarket and refrigeration equipment vendors; whether or not display cases are purchased in conjunction with the refrigeration system; special system features or configuration requested by the supermarket; and unique installation requirements of each site.

The cost premium for the water-source heat pumps used for heat recovery in refrigeration systems that use a secondary fluid heat rejection loop was estimated to be $\$ 25,000$ (about 30\%) over a conventional system consisting of roof top airconditioners/gas heaters. The cost premium includes water piping for the heat pumps and 
over-sizing of the refrigeration heat rejection system to allow heat pump heat rejection during space cooling.

Simple paybacks for refrigeration operation only were estimated for each of the low-charge systems at four different locations in the US. Operating cost savings for the refrigeration systems include the savings obtained for reduced energy use and refrigerant leakage. Water costs are included for all systems employing evaporative heat rejection. The payback period for the low-charge multiplex system is immediate, since no installed cost premium exists. Paybacks for the distributed compressor system ranged from 3.4 to 7.0 years, while the payback for the secondary loop system ranged from 8.3 to 16.8 years. In addition simple payback was estimated for a distributed refrigeration system in combination with water-source heat pumps for store HVAC compared to a baseline multiplex refrigeration system with air-cooled condensers and rooftop air-condensers with gas heat for HVAC. These pay back periods ranged from 4.2 years to 7.8 years depending upon local outdoor climate conditions. The combined payback for refrigeration and HVAC savings was less than that for refrigeration savings alone for cold climate locations because of increased space heating savings. Combined paybacks were lower for refrigeration system alone in the warmer climate locations because space heating is not as significant at these locations.

Field test summary. A field test was conducted to compare the performance of a conventional multiplex system and a distributed compressor refrigeration system. Two supermarkets in the vicinity of Worcester, Massachusetts were the sites utilized for the field test. One store was equipped with a multiplex refrigeration system that had three compressor racks and air-cooled condensers. At the second store, a low-refrigerantcharge distributed refrigeration system was installed that consisted of 10 compressor cabinets. Heat rejection for the compressor cabinets was accomplished through watercooled condensers piped to a fluid loop that used dry fluid coolers. The second store also had water-source heat pumps for space heating and cooling that were piped into the fluid loops. Both sites were instrumented to determine energy consumption, refrigeration and heating, ventilating and air conditioning (HVAC) loads, and numerous system state points to characterize operation.

Energy consumption of the two refrigeration systems was compared for winter and summer time periods from May 2001 through February 2002. The data show that overall energy consumption for the tested multiplex system was about $8 \%$ lower than that of the distributed compressor system tested in winter and 14\% lower in summer - in contrast to the analytical projections. For summer operation the multiplex system efficiencies (COPs) were 34.7 and $18.5 \%$ higher than those of the distributed system for low and medium temperature refrigeration, respectively. For winter operation the multiplex system COPs were higher than those of the distributed system by 12.1 and $22.2 \%$ for low and medium temperature refrigeration, respectively. These results are disappointing because the distributed compressor system did not perform as well as the analytical results suggested it could. This does not mean the advanced system is fatally flawed, but there are several reasons for its poor performance relative to the baseline system tested. First, the tested distributed system used dry cooling towers for heat rejection rather than wet towers as assumed in the analysis. Second, the technique used to provide subcooling for the scroll compressors in the low temperature cabinets of the distributed system simply did not work. Finally, the baseline multiplex system tested was more efficient 
than the one modeled in the analytical case study. This had the effect of degrading the relative performance of the advanced vs. baseline system in the field test as compared to the analysis.

A one-year TEWI analysis of each test system was conducted. The charge sizes were estimated at $1360 \mathrm{~kg}$ of refrigerant for the multiplex system and $454 \mathrm{~kg}$ for the distributed system. Actual refrigerant leakage rates for the systems were not known so rates of $20 \%$ and $5 \%$ were used in the analysis for the multiplex and distributed systems, respectively. The analysis showed that the distributed system had about a $40 \%$ lower TEWI than the multiplex system over the combined summer and winter test periods despite its higher energy consumption.

Field test results for the water-source heat pumps show that the amount of heat recovered from the refrigeration system was about $25.9 \%$ of the total heat rejection. This amount is considerably less than the capability of the heat pumps, which can recover as much as $59.8 \%$ of the rejected heat from the refrigeration system. The ambient conditions during this time period were very mild so that the amount of space heat needed for the store was much less than normally seen. Despite limited operation, the water-source heat pumps were able to displace approximately $37,346 \mathrm{~m}^{3}$ of natural gas usage at the test store for the winter period evaluated. The value of this displacement is dependent upon the utility rates for electricity and gas. For this particular site, the estimated energy cost savings seen over this winter period were $\$ 3,171$.

\section{Supermarket energy use screening level model}

The model discussed herein was developed by the US as part of its role as the Annex operating agent.

The model consists of a set of Excel ${ }^{\circledR}$ spreadsheets and was developed to provide tools to assist supermarket planners and engineers to compare the relative energy and refrigerant requirements for alternative designs of their refrigeration systems. The spreadsheets have been completed for multiplexed direct expansion and secondary loop refrigeration systems; an additional spreadsheet may be developed in the future for distributed refrigeration systems.

A users' manual for the model is included Volume 2 as part of the US country report. Users must specify or select information about the display cases and walk-in coolers/freezers, secondary loop piping and fluids, and type of condenser. All calculations of fluid viscosity, friction factors, pressure drops, compressor power, and secondary fluid loop pumping power are built into the model. Model validation exercises have been performed using data from the baseline multiplex DX system tested in Massachusetts. Results of the validation are included in the users manual in the US country report.

\section{Overall Summary}

The five participating countries in Annex 26 have carried out a significant amount of research on supermarket refrigeration and heat recovery systems - an estimated $\$ 5$ 
million US total effort. A few major conclusions and observations are noted (by country along with some summary comments) in this section from the analyses and testing programs conducted. Before proceeding, however, it must be noted that these conclusions are subject to the assumptions used in the analyses and the particular locations and installations of the field test systems. These specific results should not be considered to be generalizable to all store sizes and locations. However, they do provide a good relative indication of the energy savings and TEWI reduction potential of the lowcharge refrigeration systems.

\section{Canada}

Hydro Quebec's laboratory (LTE) is field-testing two advanced systems and a baseline multiplex DX system. One advanced approach uses a multiplex DX system with heat reclaim for space and water heating and ground water to supplement heat rejection. The other has heat pumps integrated to provide space heating for the store and subcooling for the refrigeration system. In winter, the discharge gas from the refrigeration compressors goes first through three plate heat exchangers that serve to desuperheat and precondense the gas. The three heat exchangers also serve as evaporators for rooftop heat pumps that supply space heating to the store. Using heat pumps for heat recovery places no minimum limit on refrigeration system condensing pressure, as is the case for traditional heat recovery approaches. A fourth rooftop heat pump is integrated with the liquid line exiting the air-cooled condenser via a fourth plate heat exchanger. This heat pump subcools the refrigerant leaving the condenser and uses the recovered heat for store space heating. Initial baseline tests in 1999-2000 showed that both advanced approaches achieved about $6 \%$ lower specific energy consumption $\left(\mathrm{kWh} / \mathrm{m}^{2} / \mathrm{yr}\right)$ compared to the baseline store.

In addition CETC-Varennes is partnering with Loblaws (Canadian supermarket chain) to install a refrigeration showcase in a new $9000 \mathrm{~m}^{2}$ store in 2003 . Refrigeration for all cases will be provided by a secondary loop system (the frozen food cases will have self-contained refrigeration systems with horizontal scroll compressors and will reject heat to the main secondary loop system). Refrigeration heat recovery will be used for store heating.

\section{$\underline{\text { Denmark }}$}

A propane/carbon dioxide demonstration plant has been built in a medium-size supermarket. Propane is used as the high temperature refrigerant $\left(-14 /+30^{\circ} \mathrm{C}\right)$ while carbon dioxide is used at the low temperature level $\left(-32 /-11^{\circ} \mathrm{C}\right)$. Carbon dioxide is used directly to perform the cooling in the freezers while a brine circuit with propylene glycol is used in the coolers. Energy consumption in the test store is similar to that of other new stores in the same chain of markets with conventional systems. The additional cost for a propane/carbon dioxide cascade plant for this size store is estimated at approximately $15 \%$ of the total installation. A second test store $(190 \mathrm{~kW}$ chilled food load, $60 \mathrm{~kW}$ frozen food load) with a cascade system using R404A as the high temperature refrigerant and R744 (carbon dioxide) for the lower stage has been monitored also. The $\mathrm{CO}_{2}$ is used to cool both frozen food and chilled food cases, thus the amount of R404A required is only about $120 \mathrm{~kg}$ or about $10 \%$ of what a conventional DX system would require resulting in initial refrigerant cost savings of about $\$ 37,000 \mathrm{US}$ due to high Danish taxes 
on HFCs. The total system cost was about $10 \%$ more than a conventional DX but showed 15-20\% lower energy use than similar stores with R404A DX systems. The store used recovered heat from the refrigeration system for heating and required no back up during the test period.

\section{$\underline{\text { Sweden }}$}

Sweden's work for the Annex is part of their national program Eff-Sys under a project "Energy Efficient Solutions for Supermarkets in Theory and Practice." They have developed a computer model (Cybermart) for system predesign and have carried out field measurements in four supermarkets to validate the model. Sweden's analyses indicate that well designed advanced secondary loop systems do not compromise energy efficiency compared to conventional DX systems. The analyses also show that two-loop secondary systems with subcooling of the low temperature loop are more efficient than cascade systems. Major conclusions from the field test results include the following.

- Standard secondary loop systems with subcooling of the low temperature loop primary refrigerant by the medium temperature brine have efficiency advantages over cascade systems.

- Night covering of display cases reduces energy consumption by $10-20 \%$

- Practical experience with heat recovery to date show that only about $40-70 \%$ of stores' heating needs are supplied by refrigeration heat recovery, primarily due to very low refrigeration loads during winter and unoptimized control systems.

- Air-conditioning is needed in Swedish stores even if the cooling season is very short to avoid food quality problems. When the store ambient exceeds $25{ }^{\circ} \mathrm{C}$ food in display cases will exceed code minimum temperatures and shelf life is halved.

\section{United Kingdom}

Four research activities have been completed. The first is an evaluation of combined heat and power, and combined cooling, heating, and power schemes for supermarkets. CCHP has an improved load match compared to CHP, when used with absorption chilling. Cascade vapor compression systems integrated with the absorption system provide case refrigeration. Primary energy savings are around $15 \%$, and there is a TEWI reduction of more than $50 \%$. A second study involved comparison of various secondary systems with standard DX systems. Results from that study indicated that secondary loop systems use about 30\% more energy mostly due to secondary pumping power. TEWI for secondary systems was estimated to be $8 \%$ lower than a DX baseline system, assuming the reference case had a $15 \%$ annual refrigerant leakage rate and a 15 year service life. Capital costs were estimated to be about $20 \%$ higher for the secondary approach. The third study was an investigation of the effect of various store conditions on case performance. Environmental chamber tests of low and medium temperature case systems show that an increase in ambient temperature from 19 to $22{ }^{\circ} \mathrm{C}$ increases system energy use by $20 \%$. Increasing RH from 35 to $50 \%$ at an ambient of $22{ }^{\circ} \mathrm{C}$ increased the medium temperature case energy use by $15 \%$ but had no effect on the freezer case. Large savings were observed when the voltage was dropped from $240 \mathrm{~V}$ to $220 \mathrm{~V}$, with no negative impact on product temperature. Finally analytical and experimental investigations of defrost methods and alternative control strategies were carried out. Studies looking at the frequency and duration of defrost cycles showed that the current 
cycles are suited to relatively warm internal temperatures and high relative humidities $\left(22^{\circ} \mathrm{C}\right.$ and $\left.60 \% \mathrm{RH}\right)$, and for different internal conditions, a lower frequency would be sufficient. For electric defrost, optimized cycles and controls could reduce energy use by $25-50 \%$, and better termination controls on completion of defrosting would reduce energy use still further.

\section{United States}

A $3720 \mathrm{~m}^{2}$ supermarket was simulated and TEWI and energy consumption estimates were made for a baseline air-cooled multiplex refrigeration system and advanced systems. Total refrigeration load was $328 \mathrm{~kW}$ with a refrigerant charge of 4.15 $\mathrm{kg} / \mathrm{kW}$ load. The distributed compressor, low-charge multiplex, and secondary loop systems (with four independent secondary loops) all achieved estimated annual energy savings of about $11 \%$. Use of evaporative heat rejection was the principal driver for these energy savings - baseline system energy consumption was $8.2 \%$ lower with an evaporative condenser. The lowest TEWIs were achieved by the distributed system and the secondary loop systems with $\mathrm{CO}_{2}$ emission reductions of about $13-14$ million $\mathrm{kg}$, or $57-60 \%$. The low-charge multiplex system had estimated TEWI reductions of about $24 \%$ or $43 \%$ depending upon the refrigerant loss assumption. An analysis of an integrated water source heat pump and distributed compressor refrigeration system showed about $13 \%$ operating cost savings compared to a baseline air-cooled multiplex refrigeration system with conventional rooftop HVAC units.

\section{Summary comments}

Analyses carried out under the Annex 26 project and individual country programs have shown that both energy savings (over 10\%) and TEWI reductions (up to 60\%) are possible with low-charge refrigeration systems as compared to the most prevalent type baseline -- a multiplex DX system with air-cooled condensers. Savings are possible with distributed compressor systems, secondary loop systems, and low-charge multiplex systems. The secondary loop system option was the most thoroughly investigated advanced low-charge alternative in this Annex (all participants studied this option to some extent). Energy consumption comparisons with the baseline ranged from up to $30 \%$ greater energy use to about $10 \%$ savings. Use of evaporative heat rejection approaches (condensers or cooling towers) to reduce condensing temperatures is a key to obtaining maximum energy savings for all of the systems studied. Evaporative condensers (or cooling towers) will impose greater maintenance efforts and costs, however. Proper design and implementation of advanced low-charge systems is essential if energy savings are to be realized.

In general further efforts to reduce total global warming impacts (TEWI) of the advanced low-charge systems examined here would benefit more from reduction in energy usage (through efficiency increases or load reductions) than from further reduction in direct impact (from refrigerant losses).

Recovery of refrigeration system rejected heat was shown to be able to provide from about $40 \%$ to all of space and water heat needs for the test stores examined in this Annex. The amount of waste heat that is effectively applied to the space and water heat requirements at a given site will depend upon the size of the coincident refrigeration load and the refrigeration/HVAC control system's ability to effectively manage the heat 
recovery process. The integration of heat pumps with refrigeration systems was shown to be an excellent means for recovering refrigeration waste heat and reducing overall store energy use. Heat-pump-based heat recovery does not require the refrigeration system condensing temperature to be maintained artificially high to facilitate heat recovery.

Available cost studies show installed cost premiums for secondary loop systems range from $0 \%$ to about $35 \%$ while distributed compressor systems show about a $15 \%$ premium. The low-charge multiplex approach is estimated to cost no more than current multiplex systems. It should be noted that the actual installed cost of any supermarket refrigeration system will be highly dependent upon many factors, not the least of which are the complex relationships between supermarket companies and equipment suppliers. These factors include negotiated purchasing arrangements, inclusion of display cases with system purchase, special system features, and unique installation requirements (site specific). If/when any of the advanced systems studied begin to obtain increased market share, the price differential with the current baseline can be expected to decrease somewhat due to the pressures of these market forces.

\section{References}

Danish law \#49, December 21, 2000. Act amending the Act on taxes on certain chloroflouro-carbons and halons (CFC tax). (Tax on the industrial greenhouse gasses HFCs, PFCs and $\mathrm{SF}_{6}$ ).

Bashtrash, S., 2002. Personal communication to Annex 26 participants during supermarket system tour near Montreal, April.

Horton, W. T., 2002. Modeling of secondary loop refrigeration systems in supermarket applications, HL 2002-3, Report \# 52571-1, Purdue University, W. Lafayette, IN, April.

Hrnjak, P., 1996. "Secondary Coolants for Low Temperature Supermarket Refrigeration", presentation given at EPRI Supermarket Refrigeration Design Review Panel Meeting, ComEd Commercial Center, Oak Brook, IL. May 3.

Hrnjak, P., 2000. "Heat transfer issues in laminar flow of single-phase secondary refrigerants through the pipes," Proceedings of the IEA Annex 26 Workshop, Stockholm, Sweden, October. P. Lundqvist, ed.

Kantchev, J., 2002. . Personal communication to Annex 26 participants during supermarket system tour near Montreal, April.

Kazachki, G., E. Bayoglu, and C. Gage, 1997. "Comparative Evaluation of Heat-Transfer Fluids for Secondary Loop Systems", presentation given at the International Conference on Ozone -Protection Technologies, Baltimore, MD, November 13. 
Lundqvist P., ed 2000. Proceedings of the IEA Annex 26 Workshop: Advanced Supermarket Refrigeration/Heat Recovery Systems, IEA Heat Pump Centre, Sittard, The Netherlands. (Cd-rom format only), ISBN\# 90-73741-39-4.

Melinder, A., 2000. "Update on Secondary Refrigerants for Indirect Systems", Proceedings of the IEA Annex 26 Workshop, Stockholm, Sweden, October. P. Lundqvist, ed.

Sand J. R., Fischer S. K., and Baxter V. D., 1997. Energy and global warming impacts of HFC refrigerants and emerging technologies, Alternative Fluorocarbons Environmental Acceptability Study and U. S. Department of Energy, Washington, DC, USA.

Sherwood, G. J., 1999. Design and analysis of secondary refrigeration systems, MS Thesis, University of Minnesota, March.

Vana, J., 2000, "Comparison of secondary and multiplex DX equipment," Proceedings of the IEA Annex 26 Workshop, Stockholm, Sweden, October. P. Lundqvist, ed.

Walker D. H. and Baxter V. D., 2003. "Analysis of advanced, low-charge refrigeration systems for supermarkets," ASHRAE Trans. V. 109, pt. 1.

\section{Acknowledgements}

The Annex Operating Agent gratefully acknowledges the support and contributions of the lead investigators from each Annex 26 participant: V. Minea and D. Giguère of Canada; Prof. H. J. H. Knudsen of Denmark, Prof. P. Lundqvist of Sweden, and A. Crompton and J. Palmer of the United Kingdom. Thanks are also expressed to US contributors S. Fischer and D. Walker. The US Department of Energy, Office of Building Technology, State and Community Programs sponsored U. S. activities for IEA Annex 26 under contract DE-AC05-00OR22725 with UT-Battelle, LLC. 


\section{Appendix A - Case Study Summaries}

This appendix is included to give the reader some summary details for a few of the stores that were the objects of case studies under Annex 26. For full details on the studies one should consult the individual country reports in Volume 2.

\section{Canada - LTE}

Test store 1 ("System1-phase1") -- METRO - Messier, Montreal

Test store 2 ("System2-phase1") -- IGA - Crevier, Montreal

Conventional store ("CON") -- METRO - Bordeleau, Montreal

- "System1-phase1" - multiplex system with reciprocating compressors for low temperature loads and screw compressors for medium temperature loads. New total heat reclaim technique for space and hot water heating. High speed hot gas defrost method.

- "System2-phase1" - improved multiplexed system with reciprocating compressors. Cascade heat pumps coupled with the refrigeration system to recover rejected heat for store heating in winter. Dedicated heat pump for mechanical sub-cooling. Refrigerant liquid pumping.

- "CON" - multiplex, conventional heat reclaim and defrost.

\section{Store and system design details}

Store Areas and Refrigeration Capacities as function of Saturated Suction Temperatures

\begin{tabular}{|c|c|c|c|c|c|c|c|c|c|c|c|}
\hline \multirow[t]{3}{*}{ System } & \multirow{2}{*}{$\begin{array}{c}\text { Total } \\
\text { Area } \\
-\end{array}$} & \multirow{2}{*}{$\begin{array}{c}\text { Sale } \\
\text { Area } \\
- \\
\end{array}$} & \multicolumn{4}{|c|}{ Low/Dual Temperatures } & \multicolumn{5}{|c|}{ Medium Temperatures } \\
\hline & & & $-37^{\circ} \mathrm{C}$ & $-32^{\circ} \mathrm{C}$ & $-29^{\circ} \mathrm{C}$ & $-26^{\circ} \mathrm{C}$ & $-12^{\circ} \mathrm{C}$ & $-9{ }^{\circ} \mathrm{C}$ & $-7^{\circ} \mathrm{C}$ & $-1{ }^{\circ} \mathrm{C}$ & $7^{\circ} \mathrm{C}$ \\
\hline & $\mathrm{ft}^{2}$ & $\mathrm{ft}^{2}$ & $\mathrm{~kW}$ & $\mathrm{~kW}$ & $\mathrm{~kW}$ & $\mathrm{~kW}$ & $\mathrm{~kW}$ & $\mathrm{~kW}$ & $\mathrm{~kW}$ & $\mathrm{~kW}$ & $\mathrm{~kW}$ \\
\hline System1 & 38,000 & 28,302 & 7.15 & 28.34 & 8.54 & 13.63 & - & 82.77 & 134.4 & 11.58 & 35.43 \\
\hline System2 & 40,900 & 30,838 & 4.61 & 9.02 & 56.33 & - & 3.61 & 118.0 & 155.3 & 9.50 & - \\
\hline CON & 18,000 & 12,200 & - & 35.57 & - & - & - & 45.70 & 78.61 & - & - \\
\hline
\end{tabular}

- $\quad$ store operating hours (hours open per day): 14 hours/day.

- $\quad$ total traffic or sales volume: average traffic - 10000 per week

- $\quad$ estimated total primary refrigerant charge (estimate): R-22, $1500-1800 \mathrm{~kg}$

- $\quad$ estimate of annual loss of primary refrigerant: $15 \%$ of charge 
"System 1-phase1": Display Cases and Walk-in Boxes - Low Temperature Rack (SST - Saturated Suction Temperature; CST - Condensing Saturated Temperature)

\begin{tabular}{l|l|l|l|l|l}
\hline No & Dimensions & Description & Capacity & SST & CST \\
\hline- & $\mathbf{f t}$ & - & Btu/h & ${ }^{\circ} \mathbf{F}$ & ${ }^{\circ} \mathbf{F}$ \\
\hline 1 & $8^{\prime}$ & Frozen Tomb & 10860 & -25 & 105 \\
\hline 2 & $12^{\prime}$ & Frozen Tomb & 13380 & -25 & 105 \\
\hline 3 & 15 doors & Ice Cream & 25500 & -25 & 105 \\
\hline 4 & 12 doors & Grocery & 18000 & -15 & 105 \\
\hline 5 & 14 doors & Meat & 21000 & -15 & 105 \\
\hline $6 \mathrm{~A}$ & 5 doors & Fish & 7500 & -15 & 105 \\
\hline $6 \mathrm{~B}$ & 3 doors & Bakery & 4500 & -20 & 105 \\
\hline $7 \mathrm{~A}$ & $26^{\prime} \times 15^{\prime} \times 8^{\prime}$ & Grocery & 12500 & -25 & 105 \\
\hline $7 \mathrm{~B}$ & $26^{\prime} \times 15^{\prime} \times 8^{\prime}$ & Grocery & 12500 & -25 & 105 \\
\hline 8 & $20^{\prime} \times 13^{\prime} \times 8^{\prime}$ & Meat & 15900 & -20 & 105 \\
\hline 9 & $11^{\prime} \times 8^{\prime} \times 8^{\prime}$ & Bakery & 8750 & -20 & 105 \\
\hline 10 & $12^{\prime}$ & Frozen Tomb & 3960 & -25 & 105 \\
\hline 11 & & Spare 10 $\%$ & 18000 & -25 & 105 \\
\hline $13 \mathrm{~A}$ & $8^{\prime}+2$ (bouts) & Ice Cream & 12200 & -35 & 105 \\
\hline $13 \mathrm{~B}$ & $8^{\prime}+2$ (bouts) & Ice Cream & 12200 & -35 & 105 \\
\hline
\end{tabular}


"System 1-phase 1": Display Cases and Walk-in Boxes - Medium Temperature (SST - Saturated Suction Temperature; CST - Condensing Saturated Temperature)

\begin{tabular}{|c|c|c|c|c|c|}
\hline No. & Dimensions & Description & Capacity & SST & CST \\
\hline- & ft & - & Btu/h & ${ }^{\circ} \mathbf{F}$ & ${ }^{\circ} \mathbf{F}$ \\
\hline 20 & 28 & Fresh Meat & 44800 & 15 & 110 \\
\hline 21 & 36 & Fresh Meat & 57600 & 15 & 110 \\
\hline $22 \mathrm{~A}$ & 14 & Delicatessen & 15400 & 15 & 110 \\
\hline $22 \mathrm{~B}$ & 14 & Delicatessen & 15400 & 15 & 110 \\
\hline $23 \mathrm{~A}$ & 14 & Cheese & 10850 & 15 & 110 \\
\hline $23 \mathrm{~B}$ & 14 & Cheese & 10850 & 15 & 110 \\
\hline $24 \mathrm{~A}$ & 8 & Pizza & 9600 & 15 & 110 \\
\hline $24 \mathrm{~B}$ & 8 & Spare & 10600 & 15 & 110 \\
\hline $24 \mathrm{C}$ & 8 & Spare & 2400 & 20 & 110 \\
\hline $24 \mathrm{D}$ & 8 & Spare & 2400 & 20 & 110 \\
\hline 25 & 36 & \begin{tabular}{|l} 
Delicatessen \\
\end{tabular} & 52800 & 15 & 110 \\
\hline $26 \mathrm{~A}$ & 8 & Fich & 9600 & 15 & 110 \\
\hline $26 \mathrm{~B}$ & 8 & Bakery & 9600 & 15 & 110 \\
\hline 27 & 12 & Start-up & 9300 & 15 & 110 \\
\hline 28 & Spare $10 \%$ & - & 26000 & 15 & 110 \\
\hline 29 & $\mathrm{~A} / \mathrm{C}$ & AC offices & 79800 & 45 & 110 \\
\hline $30 A$ & $30^{\prime} \times 20^{\prime} \times 10^{\prime}$ & Meat & 17550 & 20 & 110 \\
\hline $30 B$ & $30^{\prime} \times 20^{\prime} \times 10^{\prime}$ & Meat & 17550 & 20 & 110 \\
\hline $31 \mathrm{~A}$ & 10'x9'x8' & Fish & 8200 & 20 & 110 \\
\hline $31 B$ & $10^{\prime} x 9^{\prime} x 8^{\prime}$ & Delicatessen & 8200 & 20 & 110 \\
\hline $31 C$ & $12^{\prime} x 8^{\prime} \times 8^{\prime}$ & Bakery & 8000 & 20 & 110 \\
\hline $32 \mathrm{~A}$ & 8 & Meat & 3040 & 20 & 110 \\
\hline $32 \mathrm{~B}$ & 24 & Delicatessen Service & 9120 & 20 & 110 \\
\hline $33 A$ & 26'x18'x8' & Milk & 11300 & 20 & 110 \\
\hline $33 B$ & $26^{\prime} \times 18^{\prime} \times 8^{\prime}$ & Milk & 11300 & 20 & 110 \\
\hline $34 \mathrm{~A}$ & 36 & Milk & 47700 & 20 & 110 \\
\hline $34 \mathrm{~B}$ & 12 & Wine & 15900 & 20 & 110 \\
\hline 35 & 38 & Milk & 50360 & 20 & 110 \\
\hline 36 & 40 & Milk & 53000 & 20 & 110 \\
\hline 37 & 44 & Beer & 63800 & 20 & 110 \\
\hline $38 \mathrm{~A}$ & 8 & Fruits & 3800 & 20 & 110 \\
\hline $38 \mathrm{~B}$ & 20 & Fruits & 26500 & 20 & 110 \\
\hline 39 & 48 & Fruits & 37440 & 20 & 110 \\
\hline 40 & $24^{\prime} \times 15^{\prime} \times 8^{\prime}$ & Fruits & 20150 & 20 & 110 \\
\hline $41 \mathrm{~A}$ & 608 & Preparing & 19760 & 30 & 110 \\
\hline $41 B$ & 608 & Preparing & 19760 & 30 & 110 \\
\hline 42 & Spare $10 \%$ & - & 41000 & 20 & 110 \\
\hline 43 & - & Sub-cooling & 41084 & 40 & 110 \\
\hline TOTAL & - & - & 901514 & - & - \\
\hline
\end{tabular}


"System 1-phase1: Characteristics of the Low Temperature Compressors

\begin{tabular}{l|l|l|l|l|l|l|l}
\hline Compressor & SST & Model & Power & Capacity & THR & RLA & kW \\
\hline- & ${ }^{\circ} \mathbf{F}$ & - & hp & Btu/h & Btu/h & A & - \\
\hline Copeland & -25 & 3DA3-0600-TFE & 6 & 28661 & 44545 & 10,5 & 4,6 \\
\hline Copeland & -25 & 4DA3-1000-TSE & 10 & 48307 & 75860 & 17,5 & 8 \\
\hline Copeland & -25 & 4DL3-1500-TSE & 15 & 64685 & 101098 & 20,9 & 10,7 \\
\hline Copeland & -25 & 3DS3-1000-TFE & 10 & 46399 & 71891 & 16,8 & 7,4 \\
\hline Copeland & -35 & 3DF3-0900-TFE & 9 & 29470 & 49160 & 16,5 & 5,7 \\
\hline TOTAL & - & - & 50 & 217522 & 342554 & 82,2 & 36,4 \\
\hline
\end{tabular}

"System 1-phase1: Characteristics of the Medium Temperature Compressors

\begin{tabular}{l|l|l|l|l|l|l|l}
\hline Compressor & TSS & Model & Power & Capacity & THR & RLA & kW \\
\hline- & o & - & hp & Btu/h & Btu/h & A & - \\
\hline Carlyle & 15 & 06TAH078C2EA & 40 & 323173 & 408548 & 51,4 & 37,2 \\
\hline Carlyle & 15 & 06TAH078C2EA & 40 & 323173 & 408548 & 51,4 & 37,2 \\
\hline Carlyle & 15 & 06TAH078C2EA & 40 & 323173 & 408548 & 51,4 & 37,2 \\
\hline TOTAL & - & - & 120 & 969519 & 1225644 & 154,2 & 111,6 \\
\hline
\end{tabular}

"System 1-phase 1: Characteristics of the Air-Cooled Condensers

\begin{tabular}{l|l|l}
\hline & Low Temperature & Medium Temperature \\
\hline Model & CLD057 & FDFCT-180-R \\
\hline Capacity & $424800 \mathrm{Btu} / \mathrm{h}$ & $1800000 \mathrm{Btu} / \mathrm{h}$ \\
\hline AC Circuit; Control & $8,4 \mathrm{~A} ; 575 \mathrm{~V} / 3 \mathrm{ph} ; 120 \mathrm{~V} / 30 \mathrm{~A}$ & $575 \mathrm{~V} / 3 \mathrm{ph} ; 120 \mathrm{~V} / 30 \mathrm{~A}$ \\
\hline
\end{tabular}


"System 1-phase 1": Example of Monitored Parameters

\begin{tabular}{l|l}
\hline Type of Parameter & Observation \\
\hline Store Total Power $(\mathrm{kW})$ & - \\
\hline Compressor's Power $(\mathrm{kW})$ & Both DT and MT Compressor \\
\hline Total Electrical Power $(\mathrm{kW})$ & LT and MT Compressor \\
\hline Suction Pressures (psig) & Both DT and MT Refrigeration Line \\
\hline Discharge Pressures (psig) & Both DT and MT Refrigeration Line \\
\hline Suction Temperatures $\left({ }^{\circ} \mathrm{C}\right)$ & Both DT and MT Refrigeration Line \\
\hline Discharge Temperatures $\left({ }^{\circ} \mathrm{C}\right)$ & Both DT and MT Refrigeration Line \\
\hline Liquid Temperatures $\left({ }^{\circ} \mathrm{C}\right)$ & Both DT and MT Refrigeration Line \\
\hline Liquid Pressures (psig) & Both DT and MT Refrigeration Line \\
\hline Cold Water Temperatures $\left({ }^{\circ} \mathrm{C}\right)$ & Entering/Leaving Storage Tank \\
\hline Groundwater Temperature $\left({ }^{\circ} \mathrm{C}\right)$ & Entering/Leaving Plate Heat Exchanger \\
\hline Control Valves Status $($ on $/$ off $)$ & Defrost, Heat Recovery, Flushing, etc. \\
\hline
\end{tabular}

"System 1-phase 1": Example of Calculated Thermodynamic and Energy Parameters

\begin{tabular}{l|l}
\hline Type of Parameter & Observation \\
\hline Mass Enthalpies $(\mathrm{kJ} / \mathrm{kg})$ & Both DT and MT Line (Suction, Discharge, Liquid) \\
\hline Total Refrigerant Flow-rate $(\mathrm{kg} / \mathrm{s})$ & Both DT and MT Refrigeration Line \\
\hline Title of Two-phase Refrigerant $(\%)$ & Both DT and MT Refrigeration Line \\
\hline Refrigeration Power $(\mathrm{kW})$ & Both DT and MT Refrigeration Line \\
\hline Condensing Power $(\mathrm{kW})$ & Both DT and MT Refrigeration Line \\
\hline Refrigeration Load $(\mathrm{kWh})$ & Both DT and MT Refrigeration Line \\
\hline Energy Rejected from Condensers $(\mathrm{kWh})$ & Both DT and MT Refrigeration Line \\
\hline Refrigeration Efficiency & Both DT and MT Refrigeration Line \\
\hline Saturated Suction $(\mathrm{SST})$ and Discharge $(\mathrm{SDT}) \mathrm{Temperatures}\left({ }^{\circ} \mathrm{C}\right)$ & Both DT and MT Refrigeration Line \\
\hline Compressor Consumed Energy $(\mathrm{kWh})$ & Both DT and MT Refrigeration Line \\
\hline Energy Consumption $(\mathrm{kWh)}$ & Both DT and MT Refrigeration Line \\
\hline Operating Time: Heat Reclaim, Defrost; Condenser; Geothermal & Space and Water Heating Systems \\
\hline Defrost Cycle Status and Operating Time $(\mathrm{sec} / \mathrm{hr} ;$ hrs/day) & Fresh Meat Case and Cold Room; Ice Cream \\
\hline
\end{tabular}


"System2 - phase1": Characteristics of Dual (Low \& Medium) Temperature Compressors (THR Total Heat Rejection; EER - Energy Efficiency Ratio)

\begin{tabular}{|c|c|c|c|c|c|c|}
\hline Compressor & TSS & Model & $\begin{array}{l}\text { Condensing } \\
\text { temperature }\end{array}$ & $\begin{array}{l}\text { SUCTION } \\
\text { Capacity }\end{array}$ & THR & EER \\
\hline- & ${ }^{\circ} \mathbf{F}$ & - & ${ }^{\circ} \mathbf{F}$ & Btu/h & Btu/h & - \\
\hline COP/Discuss (22) L/T & -35 & 2DA3-060E-TFE-200 & 100 & 16000 & 27270 & 5,07 \\
\hline COP/Discuss (22) L/T & -25 & 3DB3-075E-TFE-200 & 100 & 37000 & 55490 & 6,76 \\
\hline COP/Discuss (22) L/T & -20 & 2DL3-040E-TFE-200 & 100 & 25000 & 36380 & 7,07 \\
\hline COP/Discuss (22) L/T & -20 & 3DS3-100E-TFE-200 & 100 & 56000 & 82320 & 7,1 \\
\hline COP/Discuss (22) L/T & -20 & 3DS3-100E-TFE-200 & 100 & 56000 & 82320 & 7,1 \\
\hline COP/Discuss (22) L/T & -20 & 4DA3-100E-TSE-200 & 100 & 59000 & 88510 & 6,93 \\
\hline COP/Discuss (22) M/T & 15 & 3DB3-100E-TFE-200 & 100 & 107000 & 136100 & 12,71 \\
\hline COP/Discuss (22) M/T & 15 & 3DS3-150E-TFE-200 & 100 & 142000 & 181100 & 12,32 \\
\hline COP/Discus (22) M/T & 15 & 4DA3-2000-TSE-200 & 100 & 150000 & 190800 & 12,54 \\
\hline \multirow[t]{4}{*}{ Total } & -35 & - & - & 16000 & - & - \\
\hline & -25 & - & - & 37000 & - & - \\
\hline & -20 & - & - & 195000 & - & - \\
\hline & 15 & - & - & 399000 & - & - \\
\hline Total Unit & - & - & - & - & 880200 & - \\
\hline
\end{tabular}

"System2 - phase1": Characteristics of Medium Temperature Compressors (THR -

Total Heat Rejection; EER - Energy Efficiency Ratio)

\begin{tabular}{l|l|l|l|l|l|l}
\hline Compressor & TSS & Model & $\begin{array}{l}\text { Condensing } \\
\text { Temperature }\end{array}$ & $\begin{array}{l}\text { SUCTION } \\
\text { Capacity }\end{array}$ & THR & EER \\
\hline- & ${ }^{\circ} \mathbf{F}$ & - & ${ }^{\circ} \mathbf{F}$ & $\mathbf{B t u} / \mathbf{h}$ & $\mathbf{B t u} / \mathbf{h}$ & - \\
\hline COP/Discuss (22) M/T & 20 & 2DA3-075E-TFE-200 & 100 & 83000 & 103600 & 13,78 \\
\hline COP/Discuss (22) M/T & 20 & 3DB3-100E-TFE-200 & 100 & 120000 & 149300 & 13,82 \\
\hline COP/Discuss (22) M/T & 20 & 3DL3-150E-TFE-200 & 100 & 159000 & 199200 & 13,34 \\
\hline COP/Discuss (22) M/T & 20 & 4 DH3-2500-TSE-200 & 100 & 222000 & 276800 & 13,69 \\
\hline Total & 20 & - & - & 584000 & - & - \\
\hline & - & - & - & - & 729000 & - \\
\hline
\end{tabular}


"System2 - phase1": Display Cases and Walk-in Boxes -Low Temperature

\begin{tabular}{l|l|l|l}
\hline No. & Description & Capacity & SST \\
\hline- & - & Btu/h & ${ }^{\mathbf{F}}$ \\
\hline 13 & Ice Cream & 15720 & -35 \\
\hline 11 & Pastry and Frozen Meat & 5280 & -25 \\
\hline 4 & Ice Cream 5 doors & 25500 & -25 \\
\hline 10 & Bakery and Frozen Crustaceous & 16680 & -20 \\
\hline 8 & Frozen Meat and Fish & 21720 & -20 \\
\hline 3 & Frozen Products & 10860 & -20 \\
\hline 5 & Frozen Products & 23160 & -20 \\
\hline 6 & Frozen Meat & 17640 & -20 \\
\hline 7 & Frozen Bakery & 20760 & -20 \\
\hline 9 & Frozen Meat and Fish & 27000 & -20 \\
\hline 2 & Frozen Products & 24000 & -20 \\
\hline 1 & Frozen Products & 22500 & -20 \\
\hline 12 & Spare & 7894 & -20 \\
\hline
\end{tabular}


"System2 - phase 1": Display Cases and Walk-in Boxes - Medium Temperature (SST : Saturated Suction Temperature)

\begin{tabular}{|c|c|c|c|}
\hline No. & Description & Capacity & SST \\
\hline- & - & Btu/h & ${ }^{\circ} \mathbf{F}$ \\
\hline 41 & Combined Service. "BAS" & 12320 & 10 \\
\hline 41 & Shelves of Prepared Meals & 7200 & 15 \\
\hline 41 & Flowers & 6240 & 20 \\
\hline 52 & Prepared Meals & 5080 & 15 \\
\hline 52 & Delicatessen and mets préparés & 12420 & 20 \\
\hline 31 & Fresh Meat & 30280 & 15 \\
\hline 30 & Fresh Meat & 44800 & 15 \\
\hline 32 & Fresh Meat, Fish and Crustaceous & 33960 & 15 \\
\hline 33 & Delicatessen & 52800 & 15 \\
\hline 34 & Delicatessen & 38400 & 15 \\
\hline 38 & Prepared Meals & 43200 & 15 \\
\hline 37 & Pizza & 31200 & 15 \\
\hline 38 & Prepared Meals & 11670 & 20 \\
\hline 35 & Wine & 26500 & 20 \\
\hline 35 & Delicatessen & 26500 & 15 \\
\hline 40 & Vinaigrettes & 37100 & 20 \\
\hline 46 & Fruits and Vegetables & 43680 & 20 \\
\hline 36 & Fruits and Vegetables & 18720 & 20 \\
\hline 42 & Fruits and Vegetables & 44160 & 20 \\
\hline 50 & Milk Products & 50340 & 20 \\
\hline 49 & Milk Products & 31800 & 20 \\
\hline 48 & Milk Products & 47700 & 20 \\
\hline 53 & Milk Products & 71520 & 20 \\
\hline 51 & Beer & 68900 & 20 \\
\hline 44 & Milk & 22650 & 20 \\
\hline 43 & Fresh Meat and Fish & 39090 & 20 \\
\hline 45 & Bakery; Fruits and Vegetables & 36990 & 20 \\
\hline 47 & Preparation Area & 32400 & 30 \\
\hline
\end{tabular}


"System 2 - phase1": Example of Monitored Parameters

\begin{tabular}{l|l}
\hline Type of Parameter & Observation \\
\hline Store Total Power $(\mathrm{kW})$ & - \\
\hline Compressor Power $(\mathrm{kW})$ & Each Low and Dual Compressor \\
\hline Rack Power $(\mathrm{kW})$ & LT and MT Compressor \\
\hline Heat Recovery and Sub-Cooling Heat Pump Power $(\mathrm{kW})$ & Each Unit \\
\hline Suction Pressures (psig) & Very Low, Low and Medium \\
\hline Common Discharge Pressures and Defrost Discharge $(\mathrm{psig})$ & Each Rack \\
\hline Suction Temperatures $\left({ }^{\circ} \mathrm{C}\right)$ & Very Low, Low and Medium \\
\hline Common Discharge Temperatures $\left({ }^{\circ} \mathrm{C}\right)$ & DT/MT \\
\hline Defrost Discharge Temperatures $\left({ }^{\circ} \mathrm{C}\right)$ & DT/MT \\
\hline Liquid Defrost Return Temperatures $\left({ }^{\circ} \mathrm{C}\right)$ & DT/MT \\
\hline Liquid Temperatures $\left({ }^{\circ} \mathrm{C}\right)$ & DT/MT \\
\hline Liquid Pressures $(\mathrm{psig})$ & DT/MT \\
\hline Liquid Pump Pressures (psig) & Entering/Leaving each LP \\
\hline Control Valves Status (on/off) & Defrost, Heat Recovery, Flushing, etc. \\
\hline Hot Gas Temperature at Plate Heat Exchangers Outlet $\left({ }^{\circ} \mathrm{C}\right)$ & Each Unit \\
\hline Natural Gas Valve Status (on/off) & Each Unit \\
\hline
\end{tabular}

"System2 - phase1": Example of Calculated Parameters

\begin{tabular}{l|l}
\hline Type of Parameter & Observation \\
\hline Mass Enthalpies $(\mathrm{kJ} / \mathrm{kg})$ & LT/DT (Suction, Discharge and Liquid0 \\
\hline Compression Mass Enthalpy Variation $(\mathrm{kJ} / \mathrm{kg})$ & LT/DT \\
\hline Saturated Suction and Discharge Temperatures $\left({ }^{\circ} \mathrm{C}\right)$ & Low and Dual Temperature \\
\hline Compressor Energy Consumption $(\mathrm{kWh})$ & Each Low and Dual Compressor \\
\hline Total Energy Consumption $(\mathrm{kWh})$ & Each Low and Dual Compressors \\
\hline Heat Pumps Operating Time $(\mathrm{sec} / \mathrm{hr} ; \mathrm{hrs} / \mathrm{day})$ & Space and Water Heating Systems \\
\hline Defrost Status and Duration $(\mathrm{sec} / \mathrm{hr} ; \mathrm{hrs} /$ day) & Fresh Meat Case and Cold Room; Ice Cream \\
\hline
\end{tabular}


"System CON" : Display Cases and Walk-in Boxes - Low Temperature

\begin{tabular}{l|l|l|l|l}
\hline Circuit & Description & Capacity & \multicolumn{2}{|l}{ Operation Temperatures } \\
\hline- & - & & Evaporation & Condensing \\
\hline & & Btu/h & ${ }^{\circ} \mathbf{F}$ & ${ }^{\circ} \mathbf{F}$ \\
\hline 1 & $\begin{array}{l}\text { Different } \\
\text { Products }\end{array}$ & 25500 & -25 & 105 \\
\hline 2 & Ice Cream & 22100 & -25 & 105 \\
\hline 3 & Different Product & 11500 & -25 & 105 \\
\hline 4 & Fish & 25680 & -25 & 105 \\
\hline 5 & Meat & 2640 & -25 & 105 \\
\hline 7 & Meat & 19260 & -25 & 105 \\
\hline 8 & Meat & 9000 & -25 & 105 \\
\hline 9 & Pastry & 5700 & -25 & 105 \\
\hline Total & - & 121380 & - & - \\
\hline
\end{tabular}


"System CON": Display Cases (15 ${ }^{\circ} \mathrm{F}$ - Medium Temperature)

\begin{tabular}{l|l|l|l|l}
\hline Circuit & Description & Capacity & \multicolumn{2}{|l}{ Operation Temperatures } \\
\hline- & - & & Evaporation & Condensing \\
\hline & & Btu/h & ${ }^{\circ} \mathbf{F}$ & ${ }^{\circ} \mathbf{F}$ \\
\hline 19 & Fresh Meat & 57600 & 15 & 110 \\
\hline 11 & Delicatessen & 16140 & 15 & 110 \\
\hline 12 & Fish & 9600 & 15 & 110 \\
\hline 13 & Mets cuisinés & 24000 & 15 & 110 \\
\hline 14 & Delicatessen & 14400 & 15 & 110 \\
\hline 15 & Cheese & 10800 & 15 & 110 \\
\hline 20 & Meat & 23400 & 15 & 110 \\
\hline Total & - & 155940 & - & - \\
\hline
\end{tabular}

“System CON" : Display Cases (20 ${ }^{\circ} \mathrm{F}$ - Medium Temperature)

\begin{tabular}{l|l|l|l|l}
\hline Circuit & Description & Capacity & \multicolumn{2}{|l}{ Operation Temperatures } \\
\hline- & - & & Evaporation & Condensing \\
\hline & & Btu/h & ${ }^{\circ} \mathbf{F}$ & ${ }^{\circ} \mathbf{F}$ \\
\hline 17 & Pastry & 9600 & 20 & 110 \\
\hline 18 & Farm Delicatessen & 10500 & 20 & 110 \\
\hline 18 & Milk & 63600 & 20 & 110 \\
\hline 20 & Beer & 21200 & 20 & 110 \\
\hline 21 & Jus/Vegetables & 37100 & 20 & 110 \\
\hline 21 & Refrigerated Table & 5600 & 20 & 110 \\
\hline 22 & Fruits/Vegetables & 40300 & 20 & 110 \\
\hline 23 & Milk & 11500 & 20 & 110 \\
\hline 24 & Delicatessen & 4500 & 20 & 110 \\
\hline 25 & Fruits/Vegetables & 10000 & 20 & 110 \\
\hline 26 & Beer & 19000 & 20 & 110 \\
\hline 27 & Meat & 24505 & 20 & 110 \\
\hline 28 & Fruits/Vegetables & 10800 & 20 & 110 \\
\hline Total & - & 268205 & & \\
\hline
\end{tabular}


“System-CON”: Monitored Parameters

\begin{tabular}{l|l}
\hline Type of Parameter & Observation \\
\hline Compressor Power $(\mathrm{kW})$ & LT and MT Compressors \\
\hline Electrical Oven Power - Cooking $(\mathrm{kW})$ & Ovens \#1, 2 and 3 \\
\hline Suction Temperature $\left({ }^{\circ} \mathrm{C}\right)$ & Low and Medium Temperature Racks \\
\hline Common Discharge Temperature $\left({ }^{\circ} \mathrm{C}\right)$ & Each Rack \\
\hline Hot Gas Temperature - Heat Reclaim $\left({ }^{\circ} \mathrm{C}\right)$ & Entering and Leaving HR Coil \\
\hline Defrost Valves Status $($ on $/$ off $)$ & Freezing Products; Fresh Meat \\
\hline
\end{tabular}

Based on the measured parameters, several thermodynamic, energy and performance calculations were performed ( ) .

"System-CON": Thermodynamic, Energy and Performance Calculated Parameters

\begin{tabular}{l|l}
\hline Type of Parameter & Observation \\
\hline Energy Consumption of Compressor $(\mathrm{kW})$ & Low and Medium Temperature Compressors \\
\hline Total Refrigeration Consumed Energy $(\mathrm{kWh})$ & Low and Medium Temperature Compressors \\
\hline Cooking Energy Consumption $(\mathrm{kWh})$ & Each Electrical Oven \\
\hline Duration and Defrost Status $(\mathrm{sec} / \mathrm{hr} ; \mathrm{hrs} /$ day) & Four Refrigeration Display Cases \\
\hline
\end{tabular}


Annual energy consumption

Total Store's Natural Gas Consumption vs. Sale Area

\begin{tabular}{|c|c|c|c|c|c|c|c|}
\hline \multirow[t]{2}{*}{$\begin{array}{c}\text { Syste } \\
\text { m }\end{array}$} & \multirow{2}{*}{$\begin{array}{c}\begin{array}{c}\text { Sale } \\
\text { Area }\end{array} \\
f t^{2}\end{array}$} & \multicolumn{2}{|c|}{ Total Consumption } & \multicolumn{2}{|c|}{ Equivalent Energy } & \multicolumn{2}{|c|}{$\begin{array}{c}\text { Total Natural Gas } \\
\text { Cost } \\
\text { (CAN\$) }\end{array}$} \\
\hline & & $m^{3} / y$ & $m^{3} / f t^{2}$ & $\begin{array}{c}\mathrm{GJ} / \mathrm{y} \\
(\mathrm{kWh} / \mathrm{y})\end{array}$ & $\begin{array}{c}\mathrm{GJ} / f t^{2} / \mathrm{y} \\
\left(\mathrm{kWh} / f t^{2} / \mathrm{y}\right)\end{array}$ & $\$ / y$ & $\$ / f t^{2} / \mathrm{y}$ \\
\hline Syst-1 & 28,302 & 45,179 & 1.59 & $\begin{array}{c}1.6 \\
\left(4.4^{*} 10^{6}\right)\end{array}$ & $\begin{array}{c}5.6^{*} 10^{-5} \\
(155)\end{array}$ & 22,534 & 0.80 \\
\hline Syst-2 & 30,838 & 35,625 & 1.15 & $\begin{array}{c}1.27 \\
\left(3.5^{*} 10^{6}\right)\end{array}$ & $\begin{array}{l}4.12 * 10^{-5} \\
(113)\end{array}$ & 17,860 & 0.58 \\
\hline
\end{tabular}

Total Store Annual Electrical Energy Consumption and Costs (Including Demand Power Cost) vs. Sale Area (CAN\$)

\begin{tabular}{|c|c|c|c|c|c|c|c|}
\hline \multirow[t]{2}{*}{ System } & \multirow{2}{*}{$\begin{array}{c}\text { Sale } \\
\text { Area } \\
f t^{2}\end{array}$} & \multicolumn{3}{|c|}{$\begin{array}{c}\text { Total Store Electrical Energy } \\
\text { Consumption } \\
\text { (including compressors and heat } \\
\text { pumps) }\end{array}$} & \multicolumn{3}{|c|}{$\begin{array}{l}\text { Total Store Electrical Energy Cost } \\
\text { (Power : 11,97 \$/kW) }\end{array}$} \\
\hline & & $\mathbf{k W h} / \mathbf{y}$ & $\mathbf{k W h} / f t^{2} \cdot \mathbf{y}$ & $\begin{array}{l}\text { vs. } \\
\text { CON.1 } \\
(\%)\end{array}$ & $\$ / \mathbf{y}$ & $\mathbf{\$} / f t^{2} \cdot \mathbf{y}$ & $\begin{array}{l}\text { vs. CON.1 } \\
(\%)\end{array}$ \\
\hline Syst-1 & 28,302 & $2,770,873$ & 97.9 & +2.4 & $157, .704$ & 5.6 & -12.5 \\
\hline Syst-2 & 30,838 & $2,768,775$ & 89.8 & -5.7 & 163,411 & 5.3 & -17.2 \\
\hline CON.1 & 12,200 & $1,095,462 *$ & $95.5^{*}$ & - & $78440 *$ & $6.4^{*}$ & - \\
\hline
\end{tabular}

* Without Electrical Cooking 
Annual Compressor Electrical Energy Consumption and Costs (Including Power Demand Cost) - vs. Sale Area (CAN\$)

\begin{tabular}{|c|c|c|c|c|c|c|c|}
\hline \multirow[t]{2}{*}{$\begin{array}{c}\text { Syste } \\
\text { m }\end{array}$} & \multirow{2}{*}{$\begin{array}{c}\text { Sale } \\
\text { Area } \\
f t^{2}\end{array}$} & \multirow{2}{*}{$\begin{array}{c}\text { Compressors } \\
- \\
\end{array}$} & \multicolumn{3}{|c|}{$\begin{array}{l}\text { Total Energy Consumption } \\
\text { (Compressors only) }\end{array}$} & \multicolumn{2}{|c|}{$\begin{array}{c}\text { Total Electrical Energy } \\
\text { Cost } \\
\text { (Compressors only) } \\
\end{array}$} \\
\hline & & & $\mathbf{k W h} / \mathbf{y}$ & $\begin{array}{l}\text { \% of Total } \\
\text { Store } \\
\text { Cons. }\end{array}$ & $\mathbf{k W h} / f t^{2} \cdot \mathbf{y}$ & $\$ / \mathbf{y}$ & $\mathbf{\$} / f t^{2} \cdot \mathbf{y}$ \\
\hline \multirow[t]{3}{*}{ Syst-1 } & 28,302 & Low Temp. & 264,906 & 9.6 & 9.4 & 15,077 & 0.53 \\
\hline & & Medium T. & 637,299 & 23 & 22.5 & 36,262 & 1.28 \\
\hline & & $\begin{array}{c}\text { TOTAL } \\
\text { compressors }\end{array}$ & 902,205 & 32.5 & 31.9 & 51,339 & 1.81 \\
\hline \multirow[t]{5}{*}{ Syst-2 } & 30,838 & Low/Dual T. & 423,291 & 15.3 & 13.7 & 24,982 & 0.81 \\
\hline & & Medium T. & 206,298 & 7.5 & 6.69 & 12,172 & 0.39 \\
\hline & & $\begin{array}{c}\text { TOTAL } \\
\text { compressors }\end{array}$ & 629,589 & 22.7 & 20.4 & 37,154 & 1.2 \\
\hline & & Heat Pumps & 313,805 & 11.3 & 10.2 & 18,521 & 0.6 \\
\hline & & TOTAL & 943,394 & 34.0 & 30.6 & 55,675 & 1.8 \\
\hline CON. & 12,200 & $\begin{array}{c}\text { TOTAL } \\
\text { compressors }\end{array}$ & 355,721 & $30.6^{*}$ & 29.2 & 23,995 & 1.97 \\
\hline
\end{tabular}

* Excluding electrical cooking. 


\section{$\underline{\text { Denmark }}$}

Fakta market in Beder, Denmark (newest store in the Fakta chain as of July 2001)

Store details

Size $-490 \mathrm{~m}^{2}$ sales area $\left(720 \mathrm{~m}^{2}\right.$ total area $)$

Operating hours/day - 12 hours/day

Lighting load - $12.18 \mathrm{~kW}$ indoor; $1 \mathrm{~kW}$ outdoor

\section{Refrigeration system}

Type - This is a cascade system using propane as the refrigerant for the higher temperature loads $\left(-14 / 25^{\circ} \mathrm{C}\right)$ and $\mathrm{CO}_{2}$ as the refrigerant for the lower temperature loads $\left(-32 /-10^{\circ} \mathrm{C}\right)$. The propane cycle rejects heat through an air-cooled condenser at the roof of the supermarket while the $\mathrm{CO}_{2}$ condenses in a cascade heat exchanger that also serves as one of two evaporators for the propane cycle. $\mathrm{CO}_{2}$ is used directly (direct expansion) in the low-temperature (LT) cabinets and cold stores of the supermarket, while the propane circuit chills propylene glycol brine in its second evaporator. The glycol is pumped in a closed system to the high-temperature (HT) cabinets and cold stores.

Design capacity $-33 \mathrm{~kW}$ at $-14^{\circ} \mathrm{C}$ evaporating temperature, propane circuit (21 $\mathrm{kW}$ for $\mathrm{HT}$ cabinets, $12 \mathrm{~kW}$ for $\mathrm{CO}_{2}$ circuit condenser); $10 \mathrm{~kW}$ at $-32^{\circ} \mathrm{C}$ evaporating temperature, $\mathrm{CO}_{2}$ circuit Primary refrigerant type and charge $-10 \mathrm{~kg}$ propane; $6 \mathrm{~kg} \mathrm{CO}$ Secondary refrigerant type and charge - 1201 propylene glycol Estimated annual losses - propane circuit, $2 \%$ of charge; $\mathrm{CO}_{2}$ circuit, $15 \%$ of charge

\section{Propane system components}

\begin{tabular}{|l|l|}
\hline Description & Supplier \\
\hline 2 compressors & Bitzer, 4T-8.2P \\
\hline Air-cooled condenser & ECO FCE 071C63 \\
\hline Plate heat exchanger & R290/PG1: 21 kW, Swep, B25x70 \\
\hline Plate heat exchanger & R290/R744: $10 \mathrm{~kW}$, Swep V27x80 HP \\
\hline Plate heat exchanger & R290/R290: $2 \mathrm{~kW}$, Swep, B12x70 \\
\hline Plate heat exchanger & R290/PG: $3 \mathrm{~kW}$, Swep B27x50 \\
\hline Electronic expansion valve & Danfoss ETRE - 30 kW \\
\hline Electronic expansion valve & Siemens Staefa $-14 \mathrm{~kW}$ \\
\hline
\end{tabular}

$\mathrm{CO}_{2}$ system components

\begin{tabular}{|l|l|}
\hline Description & Supplier \\
\hline Compressor for $\mathrm{CO}_{2}$ & Bitzer, X2KC-3.2, BSE 55 \\
\hline Expansion valve & AKV (nozzle 2-4) \\
\hline Safety pressure switches & KP 5 \\
\hline Filter dryer & DU 303 \\
\hline
\end{tabular}


Display cases

\begin{tabular}{|c|c|c|c|c|}
\hline & Air on & \multicolumn{2}{|c|}{ Refrigeration load [W] } & Dimensions \\
\hline & {$\left[{ }^{\circ} \mathrm{C}\right]$} & $\begin{array}{c}\text { Medium } \\
\left(+2^{\circ} \mathrm{C}\right)\end{array}$ & $\begin{array}{c}\text { Low } \\
\left(-20^{\circ} \mathrm{C}\right)\end{array}$ & $\mathrm{LxBxH}\left[\mathrm{mm}^{3}\right]$ \\
\hline Storage (glass doors to shop) & $-2^{\circ} \mathrm{C}$ & 4500 & - & $5100 \times 3300 \times 2360$ \\
\hline Storage, frozen food (doors) & $-26^{\circ} \mathrm{C}$ & - & 4200 & $3600 \times 3300 \times 2450$ \\
\hline Storage, ice cream (doors) & $-28^{\circ} \mathrm{C}$ & & 2800 & $2100 \times 3300 \times 2450$ \\
\hline Vertical cabinet (no doors) & $-2^{\circ} \mathrm{C}$ & 14400 & - & $10 \mathrm{~m}$ in length \\
\hline Horizontal case & $-27^{\circ} \mathrm{C}$ & & 2200 & $3750 \times 1000 \times 960$ \\
\hline Horizontal case & $-27^{\circ} \mathrm{C}$ & & 800 & $1985 \times 1000 \times 960$ \\
\hline Horizontal case & $-2^{\circ} \mathrm{C}$ & 1400 & & $3750 \times 1000 \times 960$ \\
\hline Horizontal case & $-2^{\circ} \mathrm{C}$ & 700 & & $1985 \times 1000 \times 960$ \\
\hline Total & & 21000 & 10000 & \\
\hline
\end{tabular}

* Type of defrost method: $\quad$ Electric resistance

HVAC system

Type - ventilation only; $2.62 \mathrm{~kW}$ power input

System operating data

Saturated discharge and suction temperatures

\begin{tabular}{|l|l|}
\hline Propane system: & \\
Condensation Temperature: & $25^{\circ} \mathrm{C}($ avg. $) / 22^{\circ} \mathrm{C}(\min ) / 30^{\circ} \mathrm{C}(\max )$ \\
Evaporation temperature: & $-14^{\circ} \mathrm{C}($ avg.) \\
Capacity (design): & $33 \mathrm{~kW}$ \\
\hline CO2 system: & $-11^{\circ} \mathrm{C}$ (avg.) \\
Condensation Temperature: & $-32,5^{\circ} \mathrm{C}($ avg.) \\
Evaporation temperature: & $10 \mathrm{~kW}$ \\
Capacity (design): & \\
\hline Brine PG(40\%): & $-8^{\circ} \mathrm{C}$ \\
Outlet temperature: & $-2^{\circ} \mathrm{C}$ \\
Return temperature: & $21 \mathrm{~kW}$ \\
Capacity (design): & \\
\hline
\end{tabular}

System energy use and weather conditions

Total store energy consumption, July 2001

\begin{tabular}{|lcccc|}
\hline & $\mathrm{pcs}$ & $\mathrm{kW} / \mathrm{pcs}$ & Hours/day & $\mathrm{kWh} / \mathrm{July}$ \\
\hline Refrigeration plant & 1 & - & 24 & 8682 \\
\hline In store lighting & 210 & 0,058 & 12 & 4531 \\
\hline Out store lighting & 10 & 0,1 & 12 & 372 \\
\hline Ventilation store & 1 & 2,62 & 14 & 1137 \\
\hline Tellers & 3 & 0,4 & 12 & 446 \\
\hline Bottle machine & 1 & 1 & 1 & 31 \\
\hline Various & 1 & 2 & 12 & 372 \\
\hline Total & & & & 15571 \\
\hline
\end{tabular}


Refrigeration system energy consumption detail, July 2001

\begin{tabular}{|l|c|}
\hline Consumer & $\begin{array}{c}\text { Energy consumption } \\
{[\mathrm{kWh} \text { for July }]}\end{array}$ \\
\hline Propane compressor 1 & 3565 \\
\hline Propane compressor 2 & 1240 \\
\hline $\mathrm{CO}_{2}$ compressor & 605 \\
\hline Cases and cabinet: & 107 \\
\hline Lighting & 487 \\
\hline Ventilation & \\
\hline Storage rooms: & 391 \\
\hline Lighting & 744 \\
\hline Ventilation & 126 \\
\hline & 1116 \\
\hline Brine pump: & 84 \\
\hline Heaters (Edge): & 140 \\
\hline Defrost (cases, cabinet and storage) & 78 \\
\hline Ventilation condenser & 8682 \\
\hline Electronics & \\
\hline Total & \\
\hline
\end{tabular}

The average outdoor temperature during the July 2001 period was $17.9^{\circ} \mathrm{C}$. Store indoor temperature averaged $22.5^{\circ} \mathrm{C}$. Energy consumption of the refrigeration system in the Fakta Beder store compared to eight similar Fakta supermarkets with conventional R404A direct expansion refrigeration systems is illustrated in Figure A1. The time period plotted begins in July 2000 and ends in February 2002. 

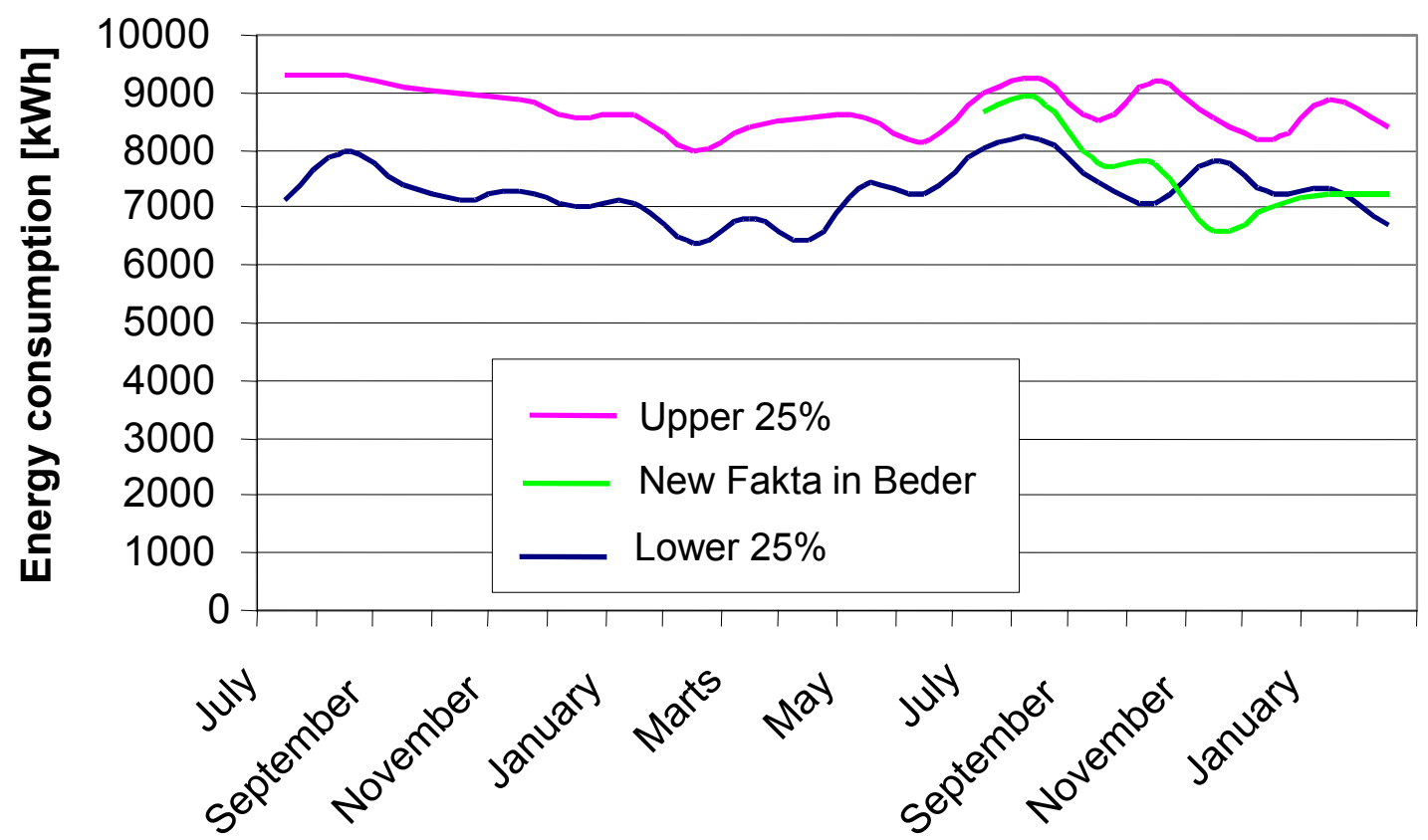

Figure A1 - Comparison of energy use of Fakta Beder store (with cascade refrigeration system) to that of eight other Fakta stores (with conventional R404A DX refrigeration systems); July 2000 through February 2002. 


\section{$\underline{\text { United States }}$}

\section{Test store - Distributed compressor refrigeration system \\ Size $-4830 \mathrm{~m}^{2}$ sales area \\ Operating hours - $168 \mathrm{hrs} /$ week}

\section{Refrigeration system}

The system consists of several small compressor cabinets distributed throughout the store and located close to the loads they serve. Heat rejection is done via a water/glycol loop that connects the compressor cabinets to roof-mounted cooling towers (dry type). Water source heat pumps are integrated into the condenser cooling loop and recover the refrigeration waste heat in winter to heat the store space.






\begin{tabular}{|c|c|c|c|c|c|}
\hline \multicolumn{3}{|c|}{$\begin{array}{r}\text { Cabinet F Low/Medium Temperature } \\
\text { Capacity: }-6.7^{\circ} \mathrm{C} \& 43^{\circ} \mathrm{C}\end{array}$} & \multicolumn{3}{|c|}{$\begin{array}{r}\text { Cabinet H Low/Medium Temperature } \\
\text { Capacity: }-15^{\circ} \mathrm{C} \& 43^{\circ} \mathrm{C}\end{array}$} \\
\hline \multirow[t]{2}{*}{$\mathrm{F}-1$} & ZF09K4 & \multirow{2}{*}{ K4 Capacity: $-8.3^{\circ} \mathrm{C} \& 43^{\circ} \mathrm{C}$} & $\mathrm{H}-1$ & ZS26K4E & 6.2 \\
\hline & & & $\mathrm{H}-2$ & ZS26K4E & 6.2 \\
\hline $\mathrm{F}-2$ & ZS30K4 & 9.2 & \multicolumn{3}{|c|}{ Capacity: $1.7^{\circ} \mathrm{C} \& 43^{\circ} \mathrm{C}$} \\
\hline $\mathrm{F}-3$ & ZS30K4 & 9.2 & $\mathrm{H}-3$ & ZS38K4E & 15.9 \\
\hline $\mathrm{F}-4$ & ZS30K4 & 9.2 & $\mathrm{H}-4$ & ZS38K4E & 15.9 \\
\hline F-5 & ZS38K4 & 11.3 & $\mathrm{H}-5$ & ZS45K4E & 19.1 \\
\hline \multicolumn{3}{|c|}{ Cabinet I Medium } & \multicolumn{3}{|c|}{ Cabinet J Low/Medium Temperature } \\
\hline & & Capacity: $-8.3^{\circ} \mathrm{C} \& 43^{\circ} \mathrm{C}$ & \multicolumn{3}{|r|}{ Capacity: $-6.7^{\circ} \mathrm{C} \& 43^{\circ} \mathrm{C}$} \\
\hline |-1 & ZS38K4E & 12.0 & $\mathrm{~J}-1$ & ZF11K4E & 3.6 \\
\hline $\mid-2$ & ZS38K4E & 12.0 & $\mathrm{~J}-2$ & ZF13K4E & 4.2 \\
\hline I-3 & ZS45K4E & 14.4 & $\mathrm{~J}-3$ & Zf13K4E & 4.2 \\
\hline I-4 & ZS45K4E & 14.4 & & & \\
\hline $1-5$ & ZS45K4E & 14.4 & & & Capacity: $-9.4^{\circ} \mathrm{C} \& 43^{\circ} \mathrm{C}$ \\
\hline & & & $\mathrm{J}-4$ & ZS38K4E & 10.8 \\
\hline & & & $\mathrm{J}-5$ & ZS38K4E & 10.8 \\
\hline & & & J-6 & ZS38K4E & 10.8 \\
\hline
\end{tabular}

Primary refrigerant type and charge - R-404A; estimated at about $410 \mathrm{~kg}$ total Secondary refrigerant type and charge - ethylene glycol on condenser fluid loop; total charge unknown

Estimated annual losses - primary refrigerant annual loss estimated at $5 \%$ of total charge

Display case line ups, storage and preparation room areas, and miscellaneous loads connected to compressor cabinets

\begin{tabular}{|c|c|c|}
\hline Circuit & $\begin{array}{l}\text { Case Length, No. of Doors, or } \\
\text { Walk-in Floor Area }\end{array}$ & $\begin{array}{l}\text { Design Refrigeration Load } \\
(\mathrm{kW})\end{array}$ \\
\hline \multicolumn{3}{|c|}{ Cabinet A Sat. Suction Temp $-32^{\circ} \mathrm{C}$} \\
\hline Walk-in Freezer & $94.1 \mathrm{~m}^{2}$ & 22.3 \\
\hline \multicolumn{3}{|c|}{ Cabinet B Sat. Suction Temp $-32^{\circ} \mathrm{C}$} \\
\hline Walk-in Freezer & $47 \mathrm{~m}^{2}$ & 11.1 \\
\hline \multicolumn{3}{|c|}{ Cabinet B Sat. Suction Temp $-26^{\circ} \mathrm{C}$} \\
\hline Reach-in Frozen Food & 23 Doors & 10.1 \\
\hline \multicolumn{3}{|c|}{ Cabinet $\mathrm{C}$ Sat. Suction Temp $-26^{\circ} \mathrm{C}$} \\
\hline Reach-in Frozen Food & 52 Doors & 19.8 \\
\hline Multi-Deck Frozen Food & $2.4 \mathrm{~m}$ & 3.5 \\
\hline \multicolumn{3}{|c|}{ Cabinet D Sat. Suction Temp $-32^{\circ} \mathrm{C}$} \\
\hline Multi-Deck Frozen Meat & $17 \mathrm{~m}$ & 16.7 \\
\hline Multi-Deck Frozen Fish & $8.5 \mathrm{~m}$ & 7.0 \\
\hline Walk-in Frozen Fish & $13.4 \mathrm{~m}^{2}$ & 3.5 \\
\hline \multicolumn{3}{|c|}{ Cabinet $\mathrm{E} \quad$ Sat. Suction Temp $-6.7^{\circ} \mathrm{C}$} \\
\hline Multi-Deck Dairy & $36.6 \mathrm{~m}$ & 47.1 \\
\hline Multi-Deck Cheese & $4.3 \mathrm{~m}$ & 5.5 \\
\hline
\end{tabular}




\begin{tabular}{|c|c|c|}
\hline Walk-in Dairy & $79.6 \mathrm{~m}^{2}$ & 18.2 \\
\hline \multicolumn{3}{|c|}{ Cabinet $\mathrm{F} \quad$ Sat. Suction Temp $-8.3^{\circ} \mathrm{C}$} \\
\hline Service Deli & $25.6 \mathrm{~m}$ & 7.6 \\
\hline Multi-Deck Cheese & $6.1 \mathrm{~m}$ & 8.4 \\
\hline Isle Deli & $4.9 \mathrm{~m}$ & 11.3 \\
\hline Walk-in Deli & $14.2 \mathrm{~m}^{2}$ & 4.5 \\
\hline Walk-in Raw & $4.5 \mathrm{~m}^{2}$ & 1.4 \\
\hline \multicolumn{3}{|c|}{ Cabinet $\mathrm{F}$ Sat. Suction Temp $-29^{\circ} \mathrm{C}$} \\
\hline Walk-in Deli Freezer & $7.5 \mathrm{~m}^{2}$ & 1.8 \\
\hline \multicolumn{3}{|c|}{ Cabinet $\mathrm{G}$ Sat. Suction Temp $8.3^{\circ} \mathrm{C}$} \\
\hline Single-Deck Meat & $7.3 \mathrm{~m}$ & 3.3 \\
\hline Multi-Deck Meat & $20.7 \mathrm{~m}$ & 26.9 \\
\hline Floral Display & $7.3 \mathrm{~m}$ & 9.1 \\
\hline Multi-Deck Deli & $8.5 \mathrm{~m}$ & 12.4 \\
\hline Single-Deck Fish & $4.9 \mathrm{~m}$ & 5.2 \\
\hline Walk-in Fish & $10.2 \mathrm{~m}^{2}$ & 3.2 \\
\hline \multicolumn{3}{|c|}{ Cabinet $\mathrm{H}$ Sat. Suction Temp $35^{\circ} \mathrm{F}$} \\
\hline Meat Prep Room & $6,144 \mathrm{ft}^{2}$ & 153,600 \\
\hline \multicolumn{3}{|c|}{ Cabinet $\mathrm{H}$ Sat. Suction Temp $-15^{\circ} \mathrm{C}$} \\
\hline Ice Maker & & 10.6 \\
\hline \multicolumn{3}{|c|}{ Cabinet I Sat. Suction Temp $-6.7^{\circ} \mathrm{C}$} \\
\hline Multi-Deck Produce & $35.4 \mathrm{~m}$ & 36.0 \\
\hline Table Fish & $4.6 \mathrm{~m}$ & 2.2 \\
\hline Walk-in Produce & $91.4 \mathrm{~m}^{2}$ & 19.5 \\
\hline \multicolumn{3}{|c|}{ Cabinet J Sat. Suction Temp $-9.4^{\circ} \mathrm{C}$} \\
\hline Walk-in Meat & $98.1 \mathrm{~m}^{2}$ & 23.2 \\
\hline Walk-in Bakery & $11.1 \mathrm{~m}^{2}$ & 5.8 \\
\hline \multicolumn{3}{|c|}{ Cabinet J Sat. Suction Temp $-29^{\circ} \mathrm{C}$} \\
\hline Walk-in Freezer Meat & $9.3 \mathrm{~m}^{2}$ & 2.2 \\
\hline Walk-in Freezer Bakery & $13.4 \mathrm{~m}^{2}$ & 3.2 \\
\hline Multi-Deck Bakery & $4.3 \mathrm{~m}$ & 4.6 \\
\hline
\end{tabular}

\section{Baseline store - Conventional multiplex direct expansion refrigeration system}

Size $-4830 \mathrm{~m}^{2}$ sales area

Operating hours $-168 \mathrm{hrs} /$ week

\section{Refrigeration system}

The system consists of three compressor racks - one for the low temperature load with seven compressors and two for the medium temperatures loads with six compressors each. All compressors are reciprocating type and the rack with highest suction temperature (Rack C) supplies mechanical subcooling to the other two racks. 


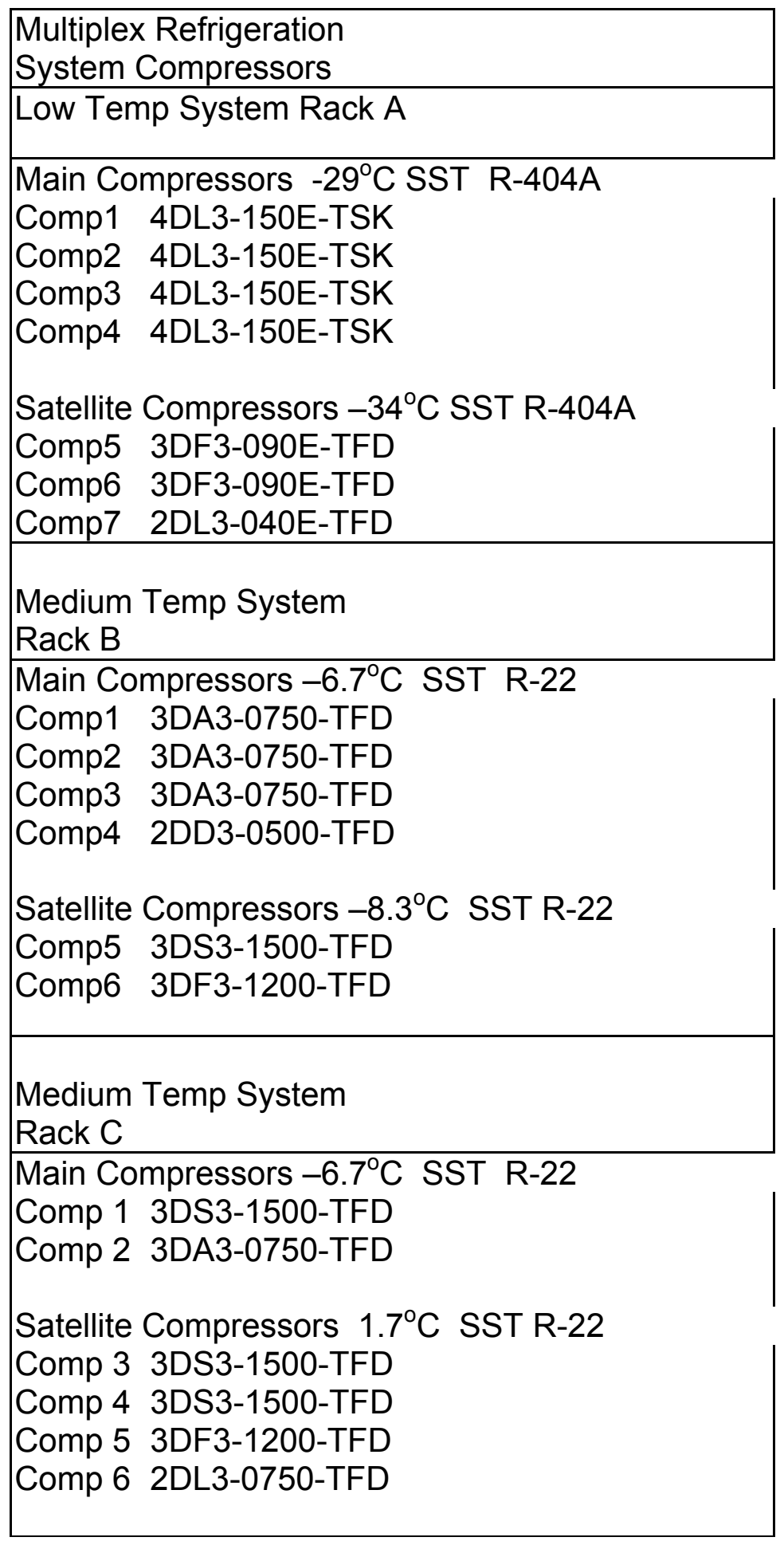


Display case line ups, storage and preparation room areas, and miscellaneous loads connected to compressor racks

\begin{tabular}{|c|c|c|}
\hline Circuit & $\begin{array}{l}\text { Case Length, No. of Doors, or } \\
\text { Walk-in Floor Area }\end{array}$ & $\begin{array}{l}\text { Design Refrigeration Load } \\
\text { (kW) }\end{array}$ \\
\hline \multicolumn{3}{|c|}{ Rack A Low Temperature - Sat. Suction Temp $-29^{\circ} \mathrm{C}$ Refrigerant - R404A } \\
\hline Reach-in Frozen Food & 76 Doors & 33.4 \\
\hline Multi-Deck Frozen Meat & $12.2 \mathrm{~m}$ & 17.7 \\
\hline Multi-Deck Frozen Fish & $5.5 \mathrm{~m}$ & 8.0 \\
\hline Multi-Deck Bakery & $3.7 \mathrm{~m}$ & 5.3 \\
\hline Walk-in Freezers & $85.9 \mathrm{~m}^{2}$ & 20.3 \\
\hline Ice Maker & & 10.6 \\
\hline \multicolumn{3}{|c|}{ Rack A Low Temperature - Sat. Suction Temp $-34^{\circ} \mathrm{C}$} \\
\hline Coffin Ice Cream & $31.6 \mathrm{~m}$ & 21.9 \\
\hline Coffin Shrimp & $4.9 \mathrm{~m}$ & 1.7 \\
\hline Walk-in Ice Cream & $16.7 \mathrm{~m}^{2}$ & 5.0 \\
\hline \multicolumn{3}{|c|}{ Rack B Medium Temperature - Sat. Suction Temp $-6.7^{\circ} \mathrm{C}$ Refrigerant - R22 } \\
\hline Reach-in Dairy & 46 Doors & 18.3 \\
\hline Single-Deck Produce & $17.1 \mathrm{~m}$ & 15.6 \\
\hline Multi-Deck Produce & $7.3 \mathrm{~m}$ & 9.4 \\
\hline Service Meat \& Deli & $19.5 \mathrm{~m}$ & 6.9 \\
\hline Multi-Deck Deli & $14.6 \mathrm{~m}$ & 20.5 \\
\hline Coffin Cheese \& Deli & $4.9 \mathrm{~m}$ & 7.3 \\
\hline Tables Fish & $6.1 \mathrm{~m}$ & 2.9 \\
\hline Cooler Floral & $13 \mathrm{~m}^{2}$ & 3.1 \\
\hline Floral Display & $2.4 \mathrm{~m}$ & 3.0 \\
\hline \multicolumn{3}{|c|}{ Rack B Medium Temperature - Sat. Suction Temp $-8.3^{\circ} \mathrm{C}$} \\
\hline Bakery Display & $4.6 \mathrm{~m}$ & 3.7 \\
\hline Multi-Deck Meat & $20.7 \mathrm{~m}$ & 26.9 \\
\hline Isle Cheese \& Deli & $17.1 \mathrm{~m}$ & 18.6 \\
\hline Isle Ready Meals & $15.8 \mathrm{~m}$ & 16.8 \\
\hline \multicolumn{3}{|c|}{ Rack C Medium Temperature - Sat. Suction Temp $-6.7^{\circ} \mathrm{C}$ Refrigerant - R22 } \\
\hline Walk-in Coolers & $204.0 \mathrm{~m}^{2}$ & 57.9 \\
\hline \multicolumn{3}{|c|}{ Rack C Medium Temperature - Sat. Suction Temp $1.7^{\circ} \mathrm{C}$} \\
\hline Meat Prep Room & $93.8 \mathrm{~m}^{2}$ & 41.4 \\
\hline Produce Prep Room & $48.3 \mathrm{~m}^{2}$ & 11.4 \\
\hline Mechanical Subcooling & & 106.0 \\
\hline
\end{tabular}

Primary refrigerant type and charge -

$\mathrm{R}-404 \mathrm{~A}$ in low temperature system; estimated at about $454 \mathrm{~kg}$ total

$\mathrm{R}-22$ in medium temperature system; estimated $908 \mathrm{~kg}$ total

Estimated annual losses -refrigerant annual loss estimated at $20 \%$ of total charge 
System operating data \& measured energy use

Energy Consumption Comparison between Multiplex and Distributed Refrigeration Systems - May 2001 through February 2002

\begin{tabular}{|c|c|c|c|c|}
\hline & \multicolumn{4}{|c|}{ Energy Consumption (kWh/day) } \\
\hline & Distributed & Multiplex & Difference & $\begin{array}{l}\% \\
\text { Difference }\end{array}$ \\
\hline $\begin{array}{l}\text { May-Aug } \\
\text { LT } \\
\text { Compressor } \\
\text { MT } \\
\text { Compressor } \\
\text { Heat Reject } \\
\text { Total }\end{array}$ & $\begin{array}{l}1306.4 \\
1594 \\
702.7 \\
3603.2\end{array}$ & $\mid \begin{array}{l}1290.2 \\
1201.2 \\
608.4 \\
3100.5\end{array}$ & $\begin{array}{l}16.2 \\
392.8 \\
94.3 \\
502.7\end{array}$ & $\mid \begin{array}{l}1.2 \\
24.6 \\
13.4 \\
14.0\end{array}$ \\
\hline \begin{tabular}{|l|} 
Nov - Feb \\
LT \\
Compressor \\
MT \\
Compressor \\
Heat Reject \\
Total \\
\end{tabular} & $\begin{array}{l}863.2 \\
951.3 \\
316.1 \\
2130.5 \\
\end{array}$ & $\begin{array}{l}957.9 \\
635.9 \\
364.4 \\
1958.2 \\
\end{array}$ & $\begin{array}{l}-94.7 \\
315.4 \\
-48.3 \\
172.3 \\
\end{array}$ & $\begin{array}{l}-11.0 \\
33.2 \\
-15.3 \\
8.1 \\
\end{array}$ \\
\hline
\end{tabular}

Average State Points, Refrigeration Loads, and efficiencies for the Multiplex and Distributed Refrigeration Systems - May 2001 through February 2002

\begin{tabular}{|l|l|l|l|l|}
\hline \multicolumn{3}{|l|}{ May - Aug } & Nov - Feb \\
\hline Low Temp & Distributed & Multiplex & Distributed & Multiplex \\
\hline SST $\left({ }^{\circ} \mathrm{C}\right)$ & -26.6 & -28.4 & -27.3 & -29.0 \\
SDT $\left({ }^{\circ} \mathrm{C}\right)$ & 32.2 & 28.2 & 16.1 & 21.7 \\
Return Temp $\left({ }^{\circ} \mathrm{C}\right)$ & -11.4 & -16.6 & -8.7 & -11.7 \\
Liquid Temp $\left({ }^{\circ} \mathrm{C}\right)$ & 26.2 & 14.3 & 13.8 & 10.2 \\
Ref Load $(\mathrm{kW})$ & 100.0 & 133.5 & 90.6 & 113.1 \\
Comp Power $(\mathrm{kW})$ & 54.4 & 53.8 & 36.0 & 39.9 \\
COP & 1.84 & 2.48 & 2.52 & 2.83 \\
\hline \multicolumn{5}{|l|}{} \\
\hline Med Temp & Distributed & Multiplex & Distributed & Multiplex \\
\hline SST $\left({ }^{\circ} \mathrm{C}\right)$ & -8.8 & -5.1 & -10.3 & -6.6 \\
SDT $\left({ }^{\circ} \mathrm{C}\right)$ & 33.6 & 28.5 & 22.3 & 19.4 \\
Return Temp $\left({ }^{\circ} \mathrm{C}\right)$ & 8.0 & 9.4 & 6.8 & 9.6 \\
Liquid Temp $\left({ }^{\circ} \mathrm{C}\right)$ & 29.4 & 20.1 & 19.5 & 14.6 \\
Ref Load $(\mathrm{kW})$ & 213.9 & 191.4 & 158.6 & 129.8 \\
Comp Power $(\mathrm{kW})$ & 66.4 & 50.1 & 39.6 & 26.5 \\
COP & 3.22 & 3.82 & 4.01 & 4.90 \\
\hline
\end{tabular}


TEWI Analysis for the Field Test Results - May 2001 through February 2002

\begin{tabular}{|c|c|c|c|c|c|c|}
\hline & \multirow{2}{*}{\multicolumn{2}{|c|}{$\begin{array}{l}\text { Refrigerant } \\
\text { Leakage } \\
(\mathrm{kg})\end{array}$}} & \multirow{3}{*}{$\begin{array}{l}\text { Energy } \\
(\mathrm{kWh})\end{array}$} & \multicolumn{3}{|c|}{ TEWI (kg CO2) } \\
\hline & & & & \multirow[t]{2}{*}{ Direct } & \multirow[t]{2}{*}{ Indirect } & \multirow[t]{2}{*}{ Total } \\
\hline & $\mathrm{R}-404 \mathrm{~A}$ & R-22 & & & & \\
\hline $\begin{array}{l}\text { May - August } \\
\text { Multiplex } \\
\text { Distributed } \\
\text { Difference }\end{array}$ & \begin{tabular}{|l|}
30.3 \\
7.7
\end{tabular} & 60.3 & $\begin{array}{l}381,300 \\
443,169\end{array}$ & $\begin{array}{l}202,055 \\
24,895\end{array}$ & \begin{tabular}{|l|}
247,845 \\
288,060
\end{tabular} & $\begin{array}{l}449,900 \\
312,954 \\
136,046\end{array}$ \\
\hline $\begin{array}{l}\text { Nov - Feb } \\
\text { Multiplex } \\
\text { Distributed } \\
\text { Difference } \\
\end{array}$ & $\begin{array}{l}30.3 \\
7.7\end{array}$ & 60.3 & \begin{tabular}{|l}
234,960 \\
255,600
\end{tabular} & $\begin{array}{l}202,055 \\
24,895\end{array}$ & $\begin{array}{l}152,724 \\
164,034\end{array}$ & $\begin{array}{l}354,779 \\
188,929 \\
165,850\end{array}$ \\
\hline
\end{tabular}

Field Test Results for the Water-Source Heat Pumps Space Heating Performance (November 2001 - February 2002)

\begin{tabular}{|l|l|l|l|l|}
\hline & $\begin{array}{l}\text { Average Heat } \\
\text { Recovered }(\mathrm{kW})\end{array}$ & $\begin{array}{l}\text { Average Space } \\
\text { Heat Load }(\mathrm{kW})\end{array}$ & $\begin{array}{l}\text { Heat Pump } \\
\text { Energy }(\mathrm{kWh})\end{array}$ & $\begin{array}{l}\text { Gas Displaced } \\
\left(\mathrm{m}^{3}\right)\end{array}$ \\
\hline November 01 & 72.7 & 95.6 & 17,236 & 8,076 \\
December 01 & 86.0 & 111.7 & 20,531 & 9,807 \\
January 02 & 88.5 & 115.7 & 21,004 & 10,080 \\
February 02 & 90.0 & 118.6 & 20,295 & 9,383 \\
Total & & & 79,066 & 37,346 \\
\hline
\end{tabular}

Amount of heat recovered estimated at $25.9 \%$ of total refrigeration system heat rejection during the period. The heat pumps could recover up to about $60 \%$ of the rejected heat. 